András Benedek / Ágnes Veszelszki (eds.)

\title{
In the Beginning \\ was the Image: \\ The Omnipresence \\ of Pictures
}

Time, Truth, Tradition

Visual Learning Edited by András Benedek and Ágnes Veszelszki

$\frac{\text { PETER LANG }}{\text { EDITION }}$ 
The authors outline the topic of visuality in the 21st century in a trans- and interdisciplinary theoretical frame from philosophy through communication theory, rhetoric and linguistics to pedagogy. As some scholars of visual communication state, there is a significant link between the downgrading of visual sense making and a dominantly linguistic view of cognition. According to the concept of linguistic turn, everything has its meaning because we attribute meaning to it through language. Our entire world is set in language, and language is the model of human activities. This volume questions the approach in the imagery debate.

András Benedek is Professor and Head at the Department of Technical Education, Budapest University of Technology and Economics. He has published several papers on human resource development issues.

Ágnes Veszelszki is Senior Assistant in Hungarian Linguistics at the Corvinus University of Budapest. Her research interests are focused on the impact of infocommunication technology on the (Hungarian) language. 
In the Beginning was the Image: The Omnipresence of Pictures 


\section{Visual Learning}

Edited by András Benedek and Ágnes Veszelszki

Volume 6 
András Benedek / Ágnes Veszelszki (eds.)

\author{
In the Beginning \\ was the Image: \\ The Omnipresence \\ of Pictures \\ Time, Truth, Tradition
}




\section{Bibliographic Information published by the Deutsche Nationalbibliothek}

The Deutsche Nationalbibliothek lists this publication in the Deutsche Nationalbibliografie; detailed bibliographic data is available in the internet at http://dnb.d-nb.de.

An electronic version of this book is freely available, thanks to the support of libraries working with Knowledge Unlatched. $\mathrm{KU}$ is a collaborative initiative designed to make high quality books Open Access for the public good. More information about the initiative and links to the Open Access version can be found at www. knowledgeunlatched.org.

Open Access: The online version of this publication is published on www.peterlang.com and www.econstor.eu under the international Creative Commons License CC-BY-NC-ND 4.0. Learn more on how you can use and share this work: https://creativecommons.org/licenses/by-nc-nd/4.0/.

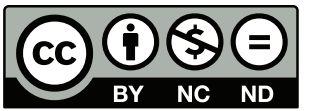

All versions of this work may contain content reproduced under license from third parties. Permission to reproduce this third-party content must be obtained from these third-parties directly.

The publication of this volume was sponsored by the Gergely László Foundation, Hungary.

ISSN 1435-845X

ISBN 978-3-631-67860-2 (Print)

E-ISBN 978-3-653-07007-1 (E-PDF)

E-ISBN 978-3-631-69871-6 (EPUB)

E-ISBN 978-3-631-69872-3 (MOBI)

DOI 10.3726/b10396

(C) Peter Lang GmbH

Internationaler Verlag der Wissenschaften

Frankfurt am Main 2016

Peter Lang Edition is an Imprint of Peter Lang GmbH.

Peter Lang - Frankfurt am Main · Bern · Bruxelles · New York ·

Oxford $\cdot$ Warszawa $\cdot$ Wien

This publication has been peer reviewed.

www.peterlang.com 


\section{Contents}

Ágnes Veszelszki

Preface.

Truth, Time and Visuality

Kristóf Nyíri

Towards a Theory of Common-Sense Realism

Sybille Krämer

Truth in Testimony: Or can a Documentary Film 'Bear Witness'? Some

Reflections on the Difference between Discursive and Existential Truth

Valeria Giardino

Space and Action to Reason: from Gesture to Mathematics

Daniel L. Golden

Visual Management of Time.

Javier E. Carreño

Husserl on the Right Timing of Depictions

VISUAL RHETORIC, ICONOGRAPHY

Petra Aczél

Rediscovering the Visual in Rhetorical Tradition:

Persuasion as Visionary in Suasory Discourse 69

Timothy Barney

The Rhetorical Lives of (Cold War) Maps

Orsolya Endrödy-Nagy

Paintings and Illuminated Manuscripts as Sources of the

History of Childhood: Conceptions of Childhood in the Renaissance 


\section{OnLine Visuality}

Krisztina Szabó

Digital and Visual Literacy: The Role of Visuality in

Contemporary Online Reading.

Gergely Havasmezöi

Images in the Hungarian Online News

Trischa Goodnow

The Selfie Moment: The Rhetorical Implications of

Digital Self Portraiture for Culture

James E. Katz and Elizabeth Thomas Crocker

Selfies as interpersonal communication

Ágnes Veszelszki

\#time, \#truth, \#tradition. An Image-text Relationship on Instagram:

photo and hashtag

Visuality in TeACHING AND LeARNing

Matthew Crippen

Dewey on Arts, Sciences and Greek Philosophy

András Benedek

SysBook as a Visual Learning Frame

János Horváth Cz.

Micro-content Generation Framework as a Learning Innovation

Notes on Contributors.

Index 


\section{Ágnes Veszelszki \\ Preface}

In the beginning was the image... The main title of the sixth volume in the Series Visual Learning (VL) was borrowed from William Horton's The Icon Book (and also appears in Shlain's book). The slightly altered Bible verse was cited in the workshop presentation Forgotten Theories of the Image delivered in June 2016 by Kristóf Nyíri, co-founder, with András Benedek, of the workshop and the series. In this presentation Nyíri argued that "there are not many famous authors whose works are, so to say, must-reads for their contemporaries, and there are not many sub-disciplines whose professionals naturally - for their own good and as an obligation - make reference to each other. VLL members do not constitute such a sub-discipline; but they might as well put their efforts in a somehow convergent theoretical direction." This aim is pursued by the events of the Visual Learning Lab (VLL), organised by the Budapest University of Technology and Economics for seven years now since 2009: the monthly seminar-like workshops and the annual international conference. A peer reviewed selection of such conference papers is published every year in the Series Visual Learning by the Peter Lang publishing house.

In honour of the traditions, the main title of the November 2015 conference was again a triple alliteration: Time, Truth, Tradition. The editors of the current volume selected 16 of the 30 papers presented in the conference. The papers can be divided into four major thematic groups: the theoretical questions of visuality; visual rhetoric; online visuality; and visuality in teaching and learning. Using a fashionable way to visualise keywords, the full content of the book can be compressed into the following word cloud (W1) which reveals the main points of contact:
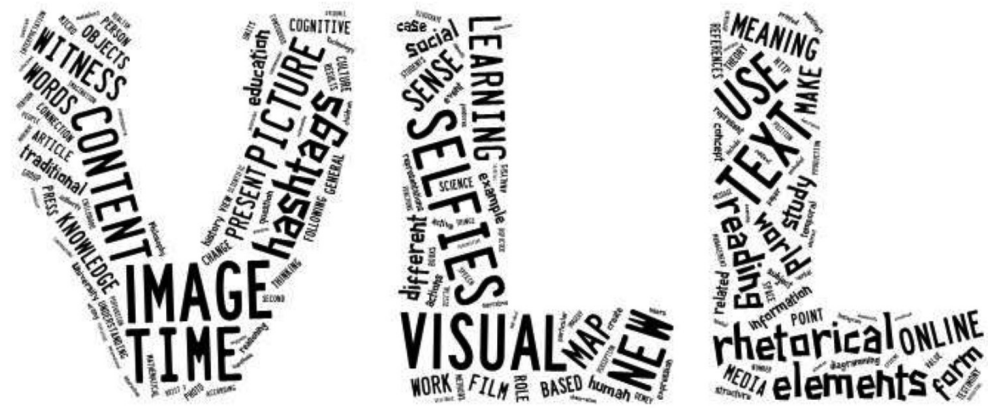
The keynote paper of the book is authored by Kristóf Nyíri, and titled: Towards a Theory of Common-Sense Realism. In his paper he aimed to "outline a specific philosophical strategy for the defence of common-sense realism and the rejection of relativism. The strategy is specific in that it is based on the assumption that the human mind is a visual one - indeed [...] fundamentally a kinesthetic or motor one. The primary contact we make with reality is not verbally mediated; rather, it is direct, kinesthetic, perceptual, visual". The paper distinguishes common sense, common-sense realism and scientific realism from relativism and from each other as well. Referring to, among others, Gombrich, Arnheim and Gibson, the author makes a case for (common-sense) realism in connection with visuality. In this regard, Nyíri concludes that "contemporary common sense does not have room, just as common sense never had room, for relativism. Common sense believes that it relies on the best available sources of knowledge. It understands that it might hold erroneous views, but trusts that progress will correct them."

The same aspect, Truth, is reflected in Sybille Krämer's paper Truth in Testimony: Or can a Documentary Film 'Bear Witness'? Some Reflections on the Difference between Discursive and Existential Truth. An Austrian with Bosnian roots, director Haris Bilajbegovic filmed a documentary about the cruelties committed by Serbian militiamen in a Bosnian village in 1992. The mass execution had only one survivor whose testimony provided the grounds for the Hague Tribunal to convict the perpetrators years later. The $2012 \mathrm{film}$, which also cites statements from the testimony, was presented as a documentary. This provides the setting for the author to examine the dilemma of eye-witnessing, making reference to, among others, Derrida and Søren Kierkegaard's concept of "Existential Truth": "The dilemma associated with eye-witnessing can be expressed this way: speaking the truth constitutes the foundation and function of witnessing, yet at the same time nothing is as fallible and prone to error as witness testimony." Going back to the film Svjedok - The Witness, he establishes that it "can be understood as not only a documentary film but also a form of 'testimony' because the medium of film instantiates a social relation between the survivor witness and the filmmaker".

Referring back to the Krämer text in the fourth volume of the VL series and her own paper, Valeria Giardino presents her "hypothesis about the existence of a human capacity labelled diagramming", and connects it to a philosophy of mind. Thanks to the capacity of diagramming, "humans are able to recruit a variety of cognitive systems - spatial perception and action systems - that are already available in other contexts, with the specific aim of reducing cognitive loads for memory and assisting problem solving". The diagramming hypothesis can be linked to the moderate approach to embodiment. The author's hypothesis is based 
on evidence brought from experimental psychology and philosophy of mathematics: gestures in mathematical explanation (as "gestures show that spatial and motor elements might help comprehension"), formulas in algebra and diagrams in topology. Giardino says that "spatial cognitive artefacts act as multi-recruiting systems".

Daniel L. Golden focused on the visual management of time, and examined what tools of visuality (sundials, clockworks, time lines, calendars and time tables) help to put the flow of time under control. Such tools are "built upon visual components in order to make the abstraction conceivable, communicable, and operable for the human mind", he says. The "main driving force behind the requirements on timing, tracking, and synchronizing human activities" was the set of events called taylorism, which is connected to industrialization and free competition, and resulted in the increasingly fashionable concepts of time management and time economy. Golden presents the most important concepts of time (including the dichotomies organic vs. mechanical time; public time vs. private time, linear vs. cyclical time), as well as the traditional and novel tools of visualisation.

In the following chapter, Javier E. Carreño examines, on the basis of the phenomenologist Edmund Husserl, how static images can "apparently 'without a time', strike us as having a 'right' timing". This issue is raised in the phenomenological analyses of image-consciousness, time-consciousness, and aesthetic consciousness. He says: "the awareness of the 'right timing' of an image is a temporal awareness that an image triggers by intensifying the awareness of the depicted subject in a particular time-phase", and "in the case of a 'perfect timing of images', the viewer will be drawn towards the 'image now' phase in its completeness to a degree that can even disengage further phantasy continuations".

Petra Aczél - for the sixth time in the Series Visual Learning - argues for the need to rediscover the visual in the rhetorical tradition. As a recent development in scientific discourse, the importance of visuality is now accepted in the fields of human cognition and communication, and "the prevalence of images has apparently won over the scepticism of science towards the non-verbal". By contrast, in rhetoric, which is considered as a mainly verbal field, the role of visuality has still not been rediscovered (except for the topic of "visual tropes"). Following a consistent logic, this time the paper focuses on the "persuasion as visionary in suasory discourse", with particular respect to "the function of wonder (thaumazein), the connection between the verbal and visual and between the visionary and the persuasive-charismatic". In this regard, the connection between rhetoric and visuality can be concluded this way: "rhetoric and the rhetorical style is persuasive because of its visionary - making audiences to see, to feel, to enact - potential that is rooted in the speaker's visual-sensual encounter with the world." 
Timothy Barney's paper adopts a rhetorical approach as well in examining the rhetorical lives of (Cold War) maps. The rhetorical life of a map, in his views, means that "a map has a particular lifespan in which it exists as a communicative practice, as it works through the intersections of public and private spaces, institutional and popular contexts, and artistic and scientific modes of collection, synthesis, and expression". According to this concept, maps are linked both to the immediate document-level context and to the historic context. Using the concepts of Denis Wood and John Fels, Barney calls this context (which involves dedications, inscriptions, epigraphs, prefaces, notes, illustrations, and advertisements for the map, reviews, production information) paramap. This way, "a map is never just a map, but a confluence of social forces that constrains a culture's sense of its relationship to, and in, the world". To support his theory, the author analyses an American map taken about the Gulag in the Cold War era.

In her paper Paintings and Illuminated Manuscripts as Sources of the History of Childhood: Conceptions of Childhood in the Renaissance, Orsolya Endrödy-Nagy gives insight into a larger qualitative research project. Her goal is to "describe how the conceptions of childhood changed in a specific period during the 15th and 16th centuries", with the help of Renaissance paintings and other visual documents (manuscripts, old-prints and wooden-block prints), using qualitative analysis methods of semiotics, iconography, visual anthropology and visual sociology.

With a big leap in time (but without departing from the topic of visuality) we arrive to our present days and our focus is shifted toward the online world. All the papers in this bigger unit are connected to digital communication: online reading and online media; selfie as a special type of image shared over the internet; and hashtags, that is the labels attached to images.

Krisztina Szabó analyses digital and visual literacy from the perspective of the role of visuality in contemporary online reading, and states that "visual elements are neither just illustrations, nor just explanatory additional elements, nor secondary qualities beside texts, but they have at least an equal or even dominating role over text in the online reading processes", in fact, "in some cases [...] the text is subordinated to the visual". Her aim with this examination is "to help create and develop online reading literacy surveys of PISA (Programme for International Student Assessment), by making the methodological framework more adequate".

Gergely Havasmezői's paper is, in a way, a continuation of the previous one, as he presents the findings of an empirical research conducted on images published in the Hungarian online press. He distinguishes between two media groups based on whether they are published online or offline: "traditional" media which have a print version, their online versions thus being of secondary importance, and 
"new" media, which exclusively have an online form. His hypothesis, that there are significantly more visual elements in the articles of the "new" media, gained confirmation. The other thesis "that significantly more visual elements have self-standing contentual value in the 'new' media and the images appear in roles that does not exist in the 'traditional' media at all', got confirmed too, though less strongly.

These papers are followed by another tightly connected pair of works, both dealing with the selfie phenomenon, and both making reference to Lev Manovich's Selfie-City project and Instagram studies. Trischa Goodnow's analysis, which also relates to the rhetoric session of the book, focuses on the rhetorical implications of digital self portraiture for contemporary culture and states that "selfies reflect cultural perceptions about narrative, time, and values". She highlights three main values which make the selfie culture even more powerful and perceivable: adventure, popularity and attractiveness. Goodnow describes the relationship between selfie and time that "this type of image communicates the 'presentist' nature of contemporary culture".

James E. Katz and Elizabeth Thomas Crocker interpret selfie as a form of interpersonal communication, and they "see selfies as often filling an important conversational role". "As symbolic representations of self" selfies "are signs that evoke or provoke variegated meanings, and thereby are communicating ideas that competent viewers can discern". The authors examined the selfie phenomenon on the basis of frequency of making self-portraits, sharing them publically or privately, staging/spontaneity dimensions and the motives of making selfies. They concluded that "the power of the facial image, containing as it does so much information and meaning, will doubtless remain an important feature of the way we interpret the world visually, emotionally, and psychologically. Truly, we live in a world of images."

Ágnes Veszelszki's paper deals with a new, image-bound, minimalistic type of text, the so-called hashtag, which can be attached as metainformation to (even selfie-like) pictures on social networking websites and microblogging services. She examines the relationship between image and text (e.g. Instagram photo and hashtag) on the examples \#time, \#truth, \#tradition. Hashtag as metadata has the ability to append linguistic signs to an image, to facilitate its classification, archiving, retrieval and indicate authorship. With their sorting and searching function hashtags "not only connect different content or thematic blocs, but also connect users having similar fields of interests". Hashtags are deictic, indexical and are also used to abbreviate messages and to add some kind of a stylistic touch to what is being said. In its broader sense, the hashtag may be taken as the marker of epistemological modality in relation to the text. 
The last large thematic unit is comprised by three papers expressly reflecting on the relationship between education and visuality. Matthew Crippen deals with the works of John Dewey who "understood aesthetic experience as a dramatic process". The author discusses "how visual experience is imbued with narrative and therefore temporal structure, and the importance of this to understanding and learning" "Dewey favoured concepts of experience articulated by Plato and Aristotle, albeit giving experience more value than his predecessors." These issues are discussed by Crippen in a modern knowledge approach, with particular focus on the classical tekhne vs. theoria distinction which suggested that tekhne is a "lesser form of knowledge than theoria, that is, theoretical or contemplative knowledge". Dewey thinks that science and knowledge can be taken as a form of art. And what are the pedagogical implications of all this? "[...] we change the world and produce outcomes that change us. Thereby we learn."

Almost as a continuation of this train of thought, András Benedek argues for the active involvement of students and the importance of visuality in learning, and presents the software SysBook. The online framework was developed by a research group of the Budapest University of Technology and Economics. "Higher education has always been a unique laboratory for education-related innovations, concentrating significant research and development potentials with excellent subjects for experiments aiming at modernising education, i.e. students." In the light of the findings of Benedek et al., the requirements of knowledge- and ICT-based society is best reflected by curricula in which "verbal and visual elements are presented in a one-to-one ratio, and where knowledge elements are organized into a network, would be scale-independent and structured as a graph". The main criteria for such new type of (higher education) curricula can be expressed in six points: open online content; continuous synchronisation; automatic updating; content sharing and data security; unlimited memory (cloud services); a new creative learning environment.

The micro-content - Micro-content Generation Framework as a Learning Innovation presented by János Horváth Cz. - also forms part of this system. In essence, micro-content means that information is well structured, the units have limited volume, "while the validity of the information contained therein is guaranteed by the involvement of named authors, feedback by the community and proofreading provided by teachers". The author briefly overviews the history of micro-forms from postcards to text messages, Twitter and Snapchat messages, and also makes reference to SysBook. On the basis of what we know about the information collection habits of current higher education students, it could prove an efficient means 
of knowledge transfer to split content into smaller, more manageable chunks, and to let students create such information units for themselves.

The tradition of the Visual Learning Lab continues: our international conference will be held in 2017 as well, this time focusing on the three concepts of virtual - visual - veridical. It is also part of the tradition that the editors have checked all online references in the book before publication, so the date of last availability is not indicated after the URLs (but a note is made where the content is no longer available).

From 2016 Kristóf Nyíri will be replaced by Ágnes Veszelszki in the editorial of the series, but to maintain continuity, they will work together with Prof. András Benedek in the future. In order to ensure the solid theoretical foundations of the VLL workshops and the international conferences, Prof. Nyíri continues to take an active part in the implementation of these events. The editors are highly grateful and indebted to Kristóf Nyíri for his role in founding the research group, launching and editing the series, and for his outstandingly accurate work.

\section{References}

Horton, William (1994): The Icon Book. Visual Symbols for Computer Systems and Documentation. John Wiley \& Sons. 1.

Shlain, Leonard (1998): The Alphabet vs. the Goddess. The Conflict Between Word and Image. New York: Penguin Arkana. 432.

$\mathrm{W} 1=$ tagxedo.com

June 2016 



\section{Truth, Time AND Visuality}





\section{Kristóf Nyíri \\ Towards a Theory of Common-Sense Realism}

\section{The Visual Mind}

My aim in the present paper is to outline a specific philosophical strategy for the defense of common-sense realism and the rejection of relativism. The strategy is specific in that it is based on the assumption that the human mind is a visual one - indeed, as I will stress, fundamentally a kinesthetic or motor one. The primary contact we make with reality is not verbally mediated; rather, it is direct, kinesthetic, perceptual, visual.

Now my impression is that the visual approach is still entirely foreign to mainstream philosophy. So let me here begin, so to speak, at an introductory level. Let me perform, in your virtual presence, an experiment. The task is to count the number of ground-floor level windows in the house I live in. Normally, I could just walk around the house, and count the windows. But if I happen to be away, giving a conference talk, I cannot do that. What I can do is to close my eyes, imagine going round the house, and mentally count the windows. Having concluded the experiment, I come up with the number 10. Perhaps I have made a mistake. If I have, I can, once at home, correct myself by actually walking around and counting. Others are welcome to come to my place and repeat the counting. The result will, perhaps after some initial misunderstandings and explanations, turn out to be the same in every case, and in any conceptual framework. There will be nothing relative about it.

Would you be able to perform a similar experiment? Does everyone have vivid mental images? My understanding is that quite a few people claim not to experience such. And of course this is, famously, what Galton learnt in the 1880s, when sending out a questionnaire asking what kind of visual memories the addressee had of his or her breakfast table of that morning. Did they remember the layout of the items on the table? Did they remember colours? It was, mostly, well-educated adult males, having spent a lifetime with reading and writing, who replied that they had no visual recollections whatsoever, no visual mental images. Galton was baffled, and tried to find a solution to the problem: how do then these people manage to think at all? His solution: 
[...] the missing faculty seems to be replaced so serviceably by other modes of conception, chiefly, I believe, connected with the incipient motor sense, not of the eyeballs only but of the muscles generally, that men who declare themselves entirely deficient in the power of seeing mental pictures can nevertheless give life-like descriptions of what they have seen and can otherwise express themselves as if they were gifted with a vivid visual imagination (Galton 1907 [1883]: 61).

Not only in the case of memory images, but more generally, too, there is the motor dimension beneath the visual one. Facial expressions and gestures precede words both in the evolution of mankind and the development of the individual. This is an ancient insight, formulated by Plato already, insisted on also by Thomas Reid, the emblematic figure of common-sense philosophy. Reid was impressed by what he saw as "the natural signs of human thoughts, purposes, and desires [...] the natural language of mankind. An infant," Reid wrote, "may be put into a fright by an angry countenance, and soothed again by smiles" (Reid 1769: 89). This became a great subject for Darwin, too. A topic he was particularly fascinated by was the expression of attitudes such as affirmation and negation. To quote just two brief passages: "[a] man [...] who vehemently rejects a proposition, will almost certainly shut his eyes or turn away his face [...] in refusing food, especially if it be pressed on them, children frequently move their heads several times from side to side, as we do in shaking our heads in negation" (Darwin 1872: 32, 273). Some years later Mallery, in his Sign Language Among North American Indians, described the gesture of "negation [...] expressed by the right hand raised toward the shoulder, with the palm opposed to the person to whom response is made. This is the rejection of the idea presented" (Mallery 1881: 290). And let me here add a one-sentence third quote, written a century later by the prominent scientific realist Wilfrid Sellars, in a late paper of his where he as it were stepped back from the linguistic bias so characteristic of his major works: "The concept of rejection is more basic than the concept of negation" (Sellars 1981: 342).

Gestures do more than just express attitudes. The art theorist and Gestalt psychologist Rudolf Arnheim in his Visual Thinking speaks of "descriptive" gestures,

[...] those forerunners of line drawing. [...] the perceptual qualities of shape and motion are present in the very acts of thinking depicted by the gestures and are in fact the medium in which the thinking itself takes place. These perceptual qualities are not necessarily visual or only visual. In gestures, the kinesthetic experiences of pushing, pulling, advancing, obstructing, are likely to play an important part (Arnheim 1969: 117 f.). 
Arnheim's views on visual imagery and the motor have been strongly influenced by the prominent turn-of-the-century American psychologist Titchener. According to the latter, " $[\mathrm{m}]$ eaning is, originally, kinaesthesis; the organism faces the situation by some bodily attitude" (Titchener 1909: 176). Words build on imagery, but imagery, Titchener stressed, builds on kinaesthesis. Titchener's position was taken up and radicalized by Margaret Washburn. As she put it: "the whole of the inner life is correlated with and dependent upon bodily movement" (Washburn 1916: xiii).

To round out and sum up: Verbal language emerges from the natural language of facial expressions and gestures, which are movement and image at the same time. Our core vocabulary gains meaning from the visual and motor images it is based on (our extended vocabulary consists of metaphors, but to understand a live metaphor ${ }^{1}$ it is necessary to grasp the images it evokes). The human mind is primarily visual and motor. It is not through the mediation of words we make contact with reality, but through direct perception, with visual perception playing the definitive role.

\section{Realism vs. Relativism}

The sentence I concluded the previous section with amounts to a partial rudimentary - description of, and argument for, my position: common-sense realism. Now realism - as also anti-realism, thus also relativism - seems to come in innumerable varieties. Let me here print an oft-visited diagram (cf. Figure 1) from the internet (W1), and let me make some comments. First, common-sense realism is mistakenly said to be "naive"; it is a sophisticated philosophical position; the views of the common man in the street do not yet amount to a philosophy of common sense.

Secondly, I suggest that common-sense realism is the only realism worthy of the name, all other "realisms" are phoney compromises. ${ }^{2}$ Thirdly, I have to point out that non-relativists of course have a hard time understanding the fine distinctions relativists make between varieties of their creed; they find it difficult not to

1 On image and metaphor see Nyíri 2014: 30, 89, 93 f., 99 f.

2 I feel it particularly important to say this when it comes to today's so fashionable "structural realism," see my argument in the chapter Visualization and the Horizons of Scientific Realism (in Nyíri 2014, see there esp.p. 33). In the diagram above, ESR stands for "epistemic structural realism," OSR for "ontological structural realism" (and NOA for "natural ontological attitude"). 
see relativism and social constructivism as belonging to the same continuum; and they believe any relativism, if it goes beyond the obvious, is false.

Figure 1: Diagram: Philosophy of Science

\section{philosophy of science}

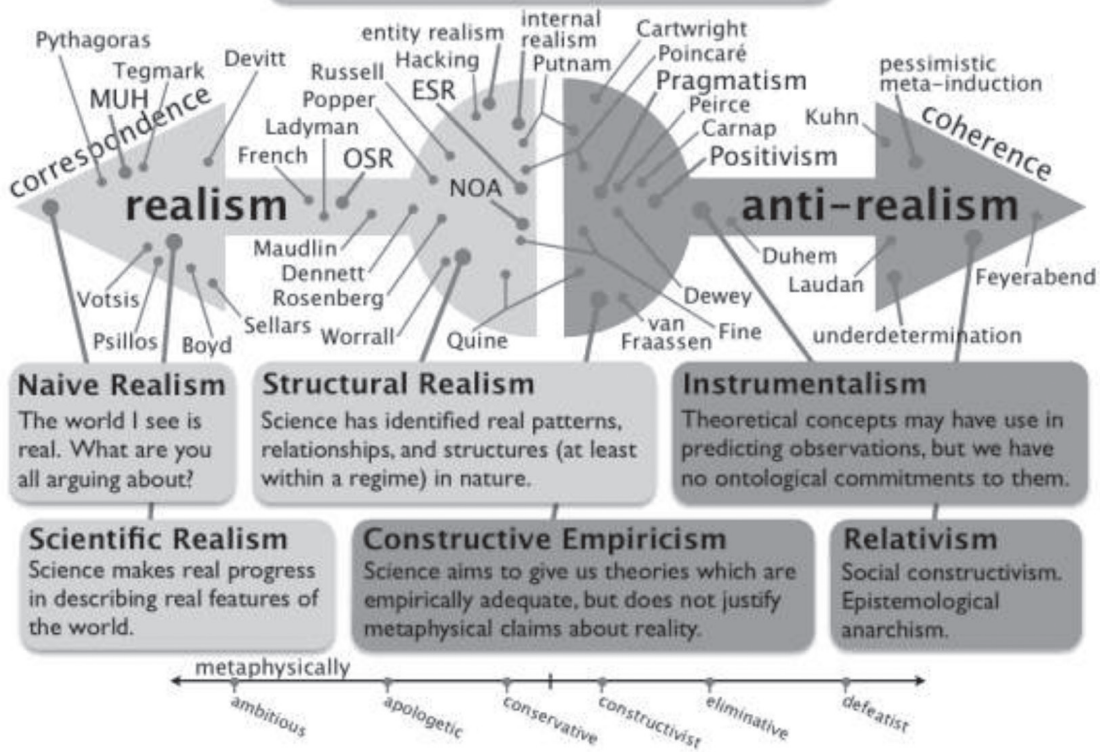

(source: W1)

A relativism clearly going beyond the obvious is "epistemic replacement relativism". In a recent defence of this approach, taking issue with Paul Boghossian, Martin Kusch wrote:

[...] Galileo recognized that facts about motion are relative facts. [...] Galileo showed that $[\ldots]$ utterances of the form ' $x$ moves' are untrue - they are either false or incomplete. Moreover, Galileo also pointed out that the closest truths in the vicinity of these untruths are relational truths of the form $x$ moves relative to frame of reference $F$. This makes it natural to suggest that Galileo was asking us to change the way we speak: replace the nonrelativized sentences with relativized ones, and assert only the relational propositions. [...] Galileo's relativism is the paradigm instance of the template of "replacement relativism" (Kusch 2010: 165). 
In his analysis, Kusch suggests the formula: "our epistemic system [...] is one of many equally valid epistemic systems" (Kusch 2010: 170). And he makes it clear that this is a formula that actually expresses his own position.

We have here a clear example of what one might call the linguistic bias in philosophy - note that people basically do not speak about movement, they see it and experience it. And when - rarely - they do experience relative movement, they as a rule, sooner or later, discover that they were suffering from an illusion. Enlightened common sense today understands that the Earth's immobility is such an illusion. But I wonder if one should convince enlightened common sense to accept relativism. In fact, I am sure one should not, because mankind's survival chances would thereby probably diminish. This is an age-old argument, but let me refer here to three more or less recent, important works once again formulating it.

First, to The Rediscovery of Common Sense Philosophy by Boulter, stressing that "natural selection favours those organisms whose perceptual systems generate visual perceptions which happen to correspond structurally more closely to that of the environment itself" (Boulter 2007: 114). Secondly, to Lynd Forguson's Common Sense, putting forward the "guiding idea" that "the individual members of our species would not get along as successfully as they do on this earth if their common-sense beliefs about the world [...] were not for the most part true" (Forguson 1989: iv). And thirdly, there is the devastating paper by Susan Haack, Reflections on Relativism, beginning with the observation: "Relativism' refers, not to a single thesis, but to a whole family. Each resembles the others in claiming that something is relative to something else; each differs from the others in what it claims is relative to what" (Haack 1998: 149). Haack takes the side of common-sense realism, with a subtle version of her own she calls "innocent realism," holding that "[p] erception is interpretative; but it is also direct" (Haack 1998: 161).

\section{Scientific vs. Common-Sense Realism}

What relations do obtain between common sense, common-sense realism, and scientific realism? The world of common sense is that of everyday time and space, of persons, objects, of observable entities, perhaps also of God, but on this latter point views begin to differ: William James believed the idea of God to be part of the common-sense world-view, G. E. Moore did not. Also, Moore held that common-sense truths were timeless, not open to revision by the progress of science. Moore's friend Wittgenstein, by contrast, tended to suggest 
that the task of philosophy was actually to enable common sense to integrate the ever-evolving discoveries of the natural sciences. I understand Wittgenstein as striving to make the seemingly contradictory views of the scientist compatible with "the coarse views of the man in the street" (see Nyíri 2015 and Nyíri [forthcoming]).

While the common-sense world is that of observable objects, modern science is positing unobservable entities in order to explain the observable world. Scientific realism holds that the unobservable entities posited by science are real. By implication, some or all of the entities of the common-sense world might turn out to be mere appearances. In an encompassing and profound analysis Sellars comes very close to conclude that the scientific image of the world will ultimately supplant the common-sense (the "manifest") one (Sellars 1963: 19, 27, 31 f., 36-39). By contrast, Michael Devitt in his brilliant book Realism and Truth argues that "scientific realism does not undermine common-sense realism" (Devitt 1997: 5 and 81 f.). He believes that common-sense realism does not need to defend itself by having recourse to operationalism or instrumentalism - to positions maintaining that "unobservables are simply 'useful fictions"'. These positions, in Devitt's view, require observability to have "an epistemic significance which it cannot have" (Devitt 1997: 127). Now I can agree neither with the main drift of the argument Sellars puts forward, nor with the particular point Devitt makes about instrumentalism. Enlightened common sense should not, and cannot, give up its primacy over science. And I suggest that we are indeed justified in taking some scientific theories to be purely instrumental; however, here our guiding criterion should be not observability, but rather imaginability. We cannot imagine what we cannot visualize. We cannot visualize say quantum theory, ${ }^{3}$ or time as the fourth dimension of space. The limits of scientific realism should be drawn at the point where the possibility of visualization ends. ${ }^{4}$

3 Devitt concedes that quantum theory is perhaps "not to be trusted at this stage as a guide to reality" (Devitt 1997: 132), but he does not formulate a general framework within which such a concession would naturally emerge.

4 This is the position I argue for in my paper Visualization and the Horizons of Scientific Realism (Nyíri 2014: 21, 23 f., 30-33). 


\section{Seeing Is Knowing: Realism Defended}

Both "seeing" and "knowing" are words with a wide variety of meanings - the above subtitle is not meant as a well-defined proposition, it is just meant to convey the idea that by looking at the world we are gaining real knowledge of it. ${ }^{5}$

\subsection{The Visible World}

Our mind is attuned to seeing, because there is a world with visible properties. This common-sense assumption has been analyzed, and corroborated, by an extensive and ramified body of literature. Here I have to restrict myself to just four carefully chosen - references. The first one is to psychologist J. J. Gibson, who in a number of influential papers and books, from the 1950s on, formulated a new - he termed it "ecological" - theory of vision. In his essay New Reasons for Realism he explains that " $[\mathrm{t}]$ he structure of an array of ambient light from the earth" displays "invariants [...] specific to the substances of which objects are composed, to the edges of objects, and to the layout of their surfaces," adding some pages later: "The doctrine of secondary qualities comes from a misunderstanding" (Gibson 1967: 164, 170). My second reference is to Arnheim once more, in particular to his formula "The mind cannot give shape to the shapeless" (Arnheim 1969: 90), conveying a basic Gestalt message. Thirdly, I refer to the important 1995 paper on common sense by Barry Smith. Elaborating on Gibson's theory, Smith offers a sustained argument in favour of the idea that the colours, tones, shapes, etc., that determine our perceptions and actions are to be "conceived as qualities of external things" (Smith 1995: 647). And lastly, I come back to Boulter, whose "transcendental argument for common sense in the domain of sense perception" again builds on Gibson. As Boulter concludes: "An external, pre-structured world is the source of the structure found in optic arrays. [...] Without a pre-structured world there is no visual perception" (Boulter 2007: 107,111). Let us draw the threads together. We are justified to regard edges, surfaces, shapes and colours to be objective visible properties of an external world.

5 A fascinating discussion of the topic "seeing" vs. "knowing" is given by Gombrich (1960, cf. there esp. pp. 12-14, 247 and 277 f.); on p. 277 and on p. 357 in the corresponding note with reference also to Bernard Berenson's notorious book (Berenson 1953). 


\subsection{The Visual Road to Realism}

A royal road to acquire a grasp of the essential argument for visual realism and against visual relativism is to follow the journey of Gombrich from the first edition of Art and Illusion (1960) to his final and devastating critique of Goodman's irrealism, in a talk he gave in 1978 (Gombrich 1981 [1978]). I have provided an overview of that journey in an earlier essay of mine, writing:

1972 saw Gombrich's first direct attack on Goodman, the former's main contentions here being that "Goodman appears to think that the eye must be strictly stationary" whereas "no stationary view can give us complete information," and [on the other hand] that the pictorial technique of perspectival representation reflects something essentially natural and objective - it does not need to be learned to be decoded. The second, devastating, attack came six years later, with Gombrich's paper Image and Code: Scope and Limits of Conventionalism in Pictorial Representation, vindicating the common-sense idea of pictures as natural signs, and explicating the controversial concept of resemblance by that of equivalence of response. As Gombrich here momentously puts it: "the images of Nature, at any rate, are not conventional signs, like the words of human language, but show a real visual resemblance, not only to our eyes or our culture but also birds or beasts" (Nyíri 2014 [2009]: 55 f.).

A longer journey is the one beginning with the first generation of Gestalt psychologists. I will just quote Wertheimer and Koffka. In 1923 Wertheimer wrote: "Our nervous system developed under the conditions of the biological environment; the Gestalt tendencies which were formed in that process do not by a miracle correspond to the regular conditions of the environment". ${ }^{6}$ A related observation by Koffka: "in reality our world is [...] not [...] a burlesque nightmare; as a rule, things are what they look like, or otherwise expressed, their looks tell us what to do with them, although as [...] optical illusion[s ...] show [...], perception may be deceptive" (Koffka 1955 [1935]: 76).

Of the second generation, Arnheim was a leading member. He adhered to the Gestalt school's founding view that experiencing images necessarily involves experiencing the patterns of forces they embody and convey. This applied to the images provided by our physical environment, but also to mental images, as well as to artificial images such as drawings, paintings, photographs and of course films and videos. Discussing memory images, Arnheim called attention to the "[f]orces inherent in the shape itself"; analyzing children's and adult amateurs' drawings, he

6 My translation. The original German runs: "Das Nervensystem hat sich unter den Bedingungen der biologischen Umwelt ausgebildet; die Gestalttendenzen, die sich dabei ausgebildet haben, sind nicht wunderbarerweise den regulären Bedingungen der Umgebung entsprechend..." (Wertheimer 1923: 336 f.). 
wrote of the "configurations of forces discerned in the draftsman's world and interpreted in his pictures" and the "constellation of forces that underlies the theme of the picture" (Arnheim 1969: 81, 259, 262).

\section{Conclusion}

In the wake of Arnheim, let me here make two comments which will bring me to the end of my paper. First, if the images provided by the world around us act like physical forces, then clearly they provide us with direct contact to reality. Secondly, reality can be depicted in various styles (Arnheim lays great stress on the realism of children's non-naturalistic drawings), contemporary enlightened common sense however does indeed set priorities between those styles, according to the practical task at hand. Children might depict reality in peculiar ways, but we have no reason to suppose that the visual world seems different to them from the way it seems to us. To quote Devitt: "Why does the world seem the way it does? The obvious answer is that the world seems that way because it is that way," a correspondence easily explicable "along Darwinian lines" (Devitt 1997: 74, 78). To some animal species the world of course might even seem different. However, as Boulter points out: “The fact that an organism's perceptual systems do not pick up or respond to all of reality does not imply that what they do pick up are not objective features of an extralinguistic reality" (Boulter 2007: 103).

To sum up: By integrating new scientific results, common sense is historically evolving. Still, contemporary enlightened common sense, guided by the philosophy of common-sense realism, has a conservative view of scientific discoveries: it does not accept the view that scientific change implies radical changes in ontology. Hence contemporary common sense does not have room, just as common sense never had room, for relativism. Common sense believes that it relies on the best available sources of knowledge. It understands that it might hold erroneous views, but trusts that progress will correct them. Epistemic systems different from its own it cannot but consider simply wrong.

\section{References}

Arnheim, Rudolf (1969): Visual Thinking. Berkeley: University of California Press. Berenson, Bernard (1953): Seeing and Knowing. London: Chapman and Hall. Boulter, Stephen (2007): The Rediscovery of Common Sense Philosophy. Houndmills, Basingstoke, Hampshire: Palgrave Macmillan.

Darwin, Charles (1872): The Expression of the Emotions in Man and Animals. London: John Murray. 
Devitt, Michael (1997): Realism and Truth. 2nd ed. with a new afterword. Princeton, NJ: Princeton University Press.

Forguson, Lynd (1989): Common Sense. London: Routledge.

Galton, Francis (1907 [1883]): Inquiries into Human Faculty and Its Development. London: J. M. Dent \& Co.

Gibson, James J. (1967): New Reasons for Realism. Synthese 17: 162-172.

Gombrich, Ernst H. (1960): Art and Illusion: A Study in the Psychology of Pictorial Representation. London: Phaidon Press.

Gombrich, Ernst H. (1981[1978]): Image and Code: Scope and Limits of Conventionalism in Pictorial Representation. In: Steiner, Wendy (ed.): Image and Code. Ann Arbor: University of Michigan Press. 11-42.

Haack, Susan (1998): Reflections on Relativism: From Momentous Tautology to Seductive Contradiction. In: Haack, Susan: Manifesto of a Passionate Moderate: Unfashionable Essays. Chicago: The University of Chicago Press. 149-166.

Koffka, Kurt (1955 [1935]): Principles of Gestalt Psychology. London: Routledge and Kegan Paul.

Kusch, Martin (2010): Epistemic Replacement Relativism Defended. In: Suárez, Mauricio - Dorato, Mauro - Rédei, Miklós (eds.): EPSA Epistemology and Methodology of Science: Launch of the European Philosophy of Science Association. Dordrecht: Springer.

Mallery, Garrick (1881): Sign Language Among North American Indians Compared with that Among Other Peoples and Deaf-Mutes. In: Powell, J.W. (Director): Smithsonian Institution - Bureau of Ethnology. Washington: Government Printing Office. 263-552.

Nyíri, Kristóf (2014 [2009]): Gombrich on Image and Time. In: Nyíri, Kristóf: Meaning and Motoricity: Essays on Image and Time. Frankfurt/M.: Peter Lang. 53-71.

Nyíri, Kristóf (2014): Meaning and Motoricity: Essays on Image and Time. Frankfurt/M.: Peter Lang Edition.

Nyíri, Kristóf (2015): Wittgenstein and Common-Sense Philosophy. In: Benedek, András - Nyíri, Kristóf (eds.): Beyond Words: Pictures, Parables, Paradoxes. Frankfurt/M.: Peter Lang Edition. 231-243.

Nyíri, Kristóf (forthcoming): Wittgenstein as a Common-Sense Realist. Conceptus. Issue 101.

Reid, Thomas (1769): Inquiry into the Human Mind, On the Principles of Common Sense. Third edition. London: Cadell.

Sellars, Wilfrid (1963): Philosophy and the Scientific Image of Man. In: Sellars, Wilfrid: Science, Perception and Reality. London: Routledge. 1-40. 
Sellars, Wilfrid (1981): Mental Events. Philosophical Studies 39: 325-345.

Smith, Barry (1995): Formal Ontology, Common Sense and Cognitive Science. Int. J. Human-Computer Studies 43: 641-667.

Titchener, Edward Bradford (1909): Lectures on the Experimental Psychology of the Thought-Processes. New York: Macmillan.

Washburn, Margaret Floy (1916): Movement and Mental Imagery: Outlines of a Motor Theory of the Complexer Mental Processes. Boston and New York: Houghton Mifflin.

Wertheimer, Max (1923): Untersuchungen zur Lehre von der Gestalt. Teil II. Psychologische Forschung 4: 301-350.

W1 = (CC-BY 4.0) 2014-2016 Ryan Reece philosophy-in-figures.tumblr.com. 

Sybille Krämer

\section{Truth in Testimony: Or can a Documentary Film 'Bear Witness'? Some Reflections on the Difference between Discursive and Existential Truth}

\section{Svjedok - The Witness (2012), a Film by Haris Bilajbegovic}

31 May 1992: A Bosnian village in the Sanski Most region of Bosnia-Herzegovina is raided by Serbian militiamen. The male inhabitants are then rounded up and forcibly led to a bridge. Four of the men have already been shot along the way; the others must jump individually from the bridge into the water. While swimming in the water they are then killed one at a time by volleys of gunfire. Only one man, Rajif Begic, survives this campaign of execution by removing his T-shirt after jumping in the water and allowing it to float downstream. While the T-shirt is riddled with bullets, he is able to save himself by concealing himself in bushes. Ten years after this event, Begic testifies before a tribunal in The Haag that is pursuing criminals in the Serbian army under the command of Goran Hadzic and Ratko Mladic. Begic's statements lead to the conviction of the principal offenders who directly participated in the bridge murders. The survivor of a war crime becomes its only and most relevant witness.

An Austrian with Bosnian roots, Haris Bilajbegovic, filmed a documentary about this event, in which he himself lost an uncle, and his Bosnian grandfather thus lost a son. His film Svjedok - The Witness premiered in 2012. The film was nominated for the German Human Rights Film Award, is available on DVD, and can be seen on Youtube. It was broadcast on Austrian television on the 20th anniversary of the Srebrenica massacre on July 25th, and was broadcasted again on July 30th, 2015. Rajif Begic's story constitutes the chronological axis of the film, and he is mostly filmed in close-up, like in interviews with Holocaust survivors. Within the film Raijf Begic also performs a plurality of witness functions at the same time: The film incorporates archival recordings of his testimony before the international criminal court, in which he serves as a legal witness. In the close-ups of his face and hands filmed in the studio, he reports on the event as a contemporary witness. He also walks through the original locations where the event took place and thus acts as a witness of "oral history". As a survivor, he also finds himself 
in the position of a moral and political witness who attempts to give a voice to those who were silenced by death.

Furthermore Begic's descriptions are followed by a reenactment of scenes of the event, ${ }^{1}$ which are staged like a feature film; the roles of the victims and the perpetrators are played by the inhabitants of the raided village themselves, and these scenes are filmed at the original locations where the event took place. Lastly, these scenes are intercut with shots of skeletonized remains that were excavated from the area around the bridge and later evaluated as DNA traces that match the victims of the massacre; their deaths are thus "proven" through evidence.

The film claims to depict a real event, as what it represents is factual rather than fictional.

But is it even possible for a film to raise a truth claim? What we see is an artificial world of moving images: actors performed the events reported by the witness in the film. These scenes were also staged, edited, combined, and assembled by the filmmaker. As a produced artwork, the film belongs definitely to the realm of the fictional. What entitles us to think that the events presented in the film are established facts that we truly know and not only believe after watching the film?

\section{On Truth}

Since Gottfried Wilhelm Leibniz, the concept of "truth" is seen as the truth not of things but rather of propositional sentences (Leibniz 1966: 15-21). Truth is associated with language. The pragmatic philosophy of language of the twentieth century made this insight even more radical: truth is assigned not simply to sentences but rather to statements produced in communicative, dialogical situations. A question of truth only emerges when the truth claim of a statement is doubted by someone else, and grounds for justification must or at least can then be given. I will call this the discursive or propositional truth, which has two characteristics:

(i) In the case of a truth statement, it must be possible to separate its genesis and validity. In other words, the grounds for justification must be independent of the individual history of the person who justifies the statement as well as the specific situation in which something was recognized and discovered. Truth is something that not only matters from the subjective perspective of a speaker but is also objectively valid from a third-person perspective.

(ii) If objective truth is connected to the medium of language, then it is "located" in a speech act in which one person claims something to another. Visual

1 For a discussion of artistic reenactment practices see Lütticken ed. 2005. 
images or films are characteristically different from languages - for example, images cannot negate something. According to this discursive concept of truth, images cannot be carriers of truth.

\section{The Dilemma of Witnessing}

When viewed from the perspective of the discursive concept of truth, the act of bearing witness leads to a dilemma. Witnessing is necessary when there is uncertainty about the course of events: someone who was physically present at the event reports his or her perception of the situation, and he or she does this in the presence of addressees, who have no access to the past event themselves. The subjective experience of the situation is expressed in an intersubjectively understandable language so that the jury judges or accepts the testimony of the witness to be true. Witnesses witness by saying something. This constitutes the core of our understanding of witnessing.

However, the verbalization of an experience opens up the possibility of errors and lies. Practices like oaths and vows in legal contexts - even though they are disappearing - point to this problem. At the same time, we know that nothing is as susceptible to error as a witness report (Ross-Read-Toglia ed. 1994). It is empirically certain that half of all eyewitnesses are wrong. Every testimony thus has the potential to be false, and this possibility becomes even more precarious when a witness is the sole witness. The dilemma associated with eyewitnessing can be expressed this way: speaking the truth constitutes the foundation and function of witnessing, yet at the same time nothing is as fallible and prone to error as witness testimony.

It is no wonder that the claim to truth of testimony is fundamentally questioned in philosophy - and from entirely differently positions (for an overview: Gelfert 2014: 95-124; Fricker 1995). In the context of an individualistic conception of knowledge, according to which everyone must be able to justify what he or she knows through his own cognitive resources, no knowledge can be transmitted through the words of others. Testimony is only epistemically valid when its receivers are able to verify the claims of the witness with their own epistemic abilities, such as memory, perception, and reasoning. Its consequence is a philosophical skepticism with regard to testimony: witness statements do not create objective knowledge unless the transmitted information can be traced back to other forms of evidentiary and corroborating knowledge in the third-person perspective. It is only in this case that there is a separation possible between origin and validity.

Jacques Derrida also questions the claim to truth of testimony, as it creates not a fact but rather a fiction (Derrida 2000: 147-182; Derrida 2003). Witnessing thus 
requires an act of belief on the part of the listener. "I testify" means "you must believe me" (Derrida 2000: 159). Derrida separates testimony from the realm of knowledge and moves it into the domain of belief; the relation to truth of witness testimony is thereby eliminated.

Traditional skepticism with regard to testimony and the poststructuralist fictionalization of testimony thus converge in the problematization of the truth content of witnessing. Testimony does not create evidence, and it is not proof otherwise it would no longer be testimony. It is impossible to separate what the witness communicates from his or her own personal perception and experience. The irreversibility of the past event combined with the first-person perspective of the witness's perception of the event makes it impossible for witness knowledge to be independently verified and justified. This is the epistemic dilemma of testimony.

But is this combination of speech act, evidence, proof, justification, and truth the only possible form of truth that can play a role in witnessing?

I want to argue that there is another significant form of truth involved in witnessing, which is not attributed to verbal statements but rather to people. Moreover, the specific quality of this form of truth is that it cannot be stated, but rather "only" shown and thus made visible. But how is this other form of truth to be understood (Krämer 2016a)?

\section{Existential Truth: Søren Kierkegaard}

Kierkegaard develops two concepts of truth, which are derived from the difference between "knowing a truth" and "being a truth" (Kierkegaard 2012: 215). In so far as truth is linked to knowledge it can be formulated in language; methodically acquired and justified; intersubjectively transmitted, taught, and learned; and embodied in text and speech. However, the kind of truth that Kierkegaard sees embodied by Jesus in his religious role as Christ is entirely different. This form of truth has a performative dimension, as it cannot be taught but rather only lived; its existence is thus shown and then (re)enacted by other people in their own lives (Kierkegaard 2012: 214).

This is a truth that is inseparable from the path by which it is acquired. With questions of knowledge - according to Kierkegaard - the discovery of a new finding is supposed to be time-consuming; once it is part of the knowledge system, it is no longer necessary for others to follow the path of its discovery. Truth that consists in being rather than knowledge is different, however, as its origin and validity cannot be separated and it is not predicated on propositions but rather on people. I will call this "existential truth". 
For Kierkegaard, the aim of "witnessing" is this existential truth. In religious testimony, for example, Christ does not speak the truth but rather shows it (Kierkegaard 2012: 213). This testimony requires its listeners to believe.

Kierkegaard thus does not open up Derrida's opposition between knowledge, which is capable of truth, and belief, which is not. The sphere of belief itself characteristically involves an "either/or" decision that cannot be resolved by thought, reason, method, and knowledge; rather, it is a situation that requires a "leap." For Kierkegaard, the origin of ethics lies precisely in this absolutely understood "either/or" (Kierkegaard 1998: 727). Yet, if believers lack a guiding method, then how is this either/or to be decided? What is the determining factor in the choice between different possibilities?

Kierkegaard's answer is "authority" (Kierkegaard 2012: 302). Authority is the attribute of a person who speaks and acts in the name of an entity that transcends the individual. In its weak form it is the authority conferred by an office or the authority of parents with respect to their children. In its strong, paradigmatic form it is the religious authority of the apostles, which is based on being the emissaries of a message that they themselves did not create: they speak and act not on their own behalf but rather in the name of an entity who has authorized them (Kierkegaard 2012: 301-315).

\section{The Second Person Model of Witnessing}

It is surely irritating that this kind of truth is not propositional, that it only manifests in real life, that it requires a leap into uncertainty, and that its only guarantee is belief in an authority. Yet this conceptual constellation intersects at an interesting point with the contemporary postanalytic debate over testimony - albeit without reference to Kierkegaard and with the crucial difference that concepts like testimony, authority, trust, and belief can actually generate a form of knowledge. This is the second person model (McMyler 2011:91-112).

Remember that knowledge from the third-person perspective means that a speaker can give reasons for his assertion, which listeners can understand and recognize. If this is the case, then the knowledge that arises is based on evidence. However, the second person model assumes that there are legitimate forms of knowledge that are not based on evidence and thus grounded in the third-person perspective. The second person model deploys a social theory of knowledge: as a result, evidence is replaced by concepts of social interaction, such as "trust" and "authority". Thomas Reid already demonstrated that knowledge is a "social operation of the mind" (Reid 2002: 68). Individuals are not epistemically autonomous, but rather mind and knowledge emerge through cooperative social 
activities. ${ }^{2}$ The social theory of knowledge generation emphasizes that "telling" - the transmission of content via speech, image, and writing - can still be accepted as knowledge without independent verification and justification. This "telling" takes many forms: it begins when we ask strangers for the time, when we hear news on television, when we divide numbers without understanding why the division algorithm works, and when we obtain information through Wikipedia or printed encyclopedias. It also occurs when bearing witness to perceptions to addressees who were not present at the perceived event. Telling is not arguing (Moran 2005: 1-29): it does not provide reasons for what is told, and the audience is not able to judge the truth content of what is told on their own. This is precisely the situation of our epistemic dependence on the knowledge of others (McMyler 2011: 142). It does not negate the creation of knowledge from testimony, but rather it defers its justification. The speech act of the witness is not an assertion, but rather an assurance (Moran 2005: 7). The witness gives the audience a guarantee that he will assume responsibility for his statement if problems and doubts should arise. As with every guarantee, it thus concerns future behavior. The authority of the witness consists precisely in issuing a guarantee for his own statement. And the audience recognizes this authority if and only if it accepts this guarantee, trusts the witness, believes in him, and accepts the truth of his testimony (McMyler 2011: 113-140).

Kierkegaard's belief in the religious authority of the apostles as the emissaries of God thus became trust in the epistemic authority of the witness as the emissary of an experience that the listeners do not share. In the case of witnessing, however, there is one crucial condition that enables the social configuration of assurance, authority, trust, telling, and believing and creates new knowledge: the witness must not only speak, but also address his listeners directly. The realization of authority and trust as complementary sides of a reciprocal social relationship in the form of the second person model is thus based on the direct speech associated with the telling of testimony.

\section{A Documentary Film as Testimony?}

This brings me back to the film Svjedok - The Witness.

A documentary film claims that what it shows is not invented but rather found. For Dirk Eitzen, the crucial criterion for distinguishing between documentary and fictional films is the question "could it be a lie". ${ }^{3}$ At the same time, Eitzen also

2 For the foundational function of cooperation and agreement see: Kusch 2002.

3 "A documentary is any motion picture that is susceptible to the question 'Might it be lying?”' (Eitzen 1998: 13). 
emphasizes that the genre boundary between documentary and fictional films is ambiguous, as it depends on whether recipients interpret a film as real or fictional. Accepting a film as a documentary means that the public trusts the film and the filmmaker.

The phenomenon of witnessing is linked to documentary films through the uncertainty concerning the reality content of a spoken or filmic statement and the trust that is either given or refused to a witness or a film. I argue that the film Svjedok - The Witness introduces a third possibility with respect to the "mere" documentary film, on the one hand, and the "mere" witness statement given in the physical presence of receivers, on the other hand, in so far as it is not simply a documentary film but it also provides testimony. The hypothesis, therefore, is that the film Svjedok - The Witness not only filmically represents the act of bearing witness but is itself also a testimonial (Krämer 2016b).

But how can a film that - from a media-technical perspective - is undoubtedly staged by the filmmaker and addressed to an anonymous public, who must forego the co-presence between the witness and the audience that is constitutive of witnessing, nevertheless bear witness?

Keep in mind that eyewitnesses do not simply act as causal tracers of an event if that were the case, they would function as evidentiary proof; rather, eyewitnesses act symbolically by means of linguistic representations, and it is precisely this speech act - the discursification of their experience - that opens up the possibility for error or even intentional lies, while at the same time allowing them to assume responsibility for and offer a guarantee of the truth content of their speech. The truth content of testimony is always only "promised" and "assured," but never made evident as proof.

The witnessing film functions in a similar way, as the staged and composed sequences of images cannot be proof of truth, but they can raise a claim to reality insofar as it is self-referentially marked in the film that the world it symbolically generates and presents is just like the real world. Viewers should not perceive the film as real in the sense of a photograph, which is impressed as a trace on a sensitive surface by a constellation of light and a chemical reaction at a specific moment in time. Rather, the film should be seen as if it is the reproduction of a historical event. This "as if" highlights a gap that cannot be skipped over and a persistent uncertainty on the part of viewers. This is precisely the "usual" situation of an audience faced with witness statements: the speech of witnesses is supposed to be perceived as if it were true, yet without the certainty that it is.

Remember that the second person model overcomes this veracity gap in that testimony does not function as proof, but nevertheless transmits knowledge by 
virtue of the personal address of the witness, which transforms his statement into the promise of a guarantee. Yet this is precisely foreclosed by the mass-media construction of the film and the anonymization of the public.

Could there be a filmic equivalent of the cooperative social relationship between a witness and his audience? One answer comes to mind: couldn't the filmmaker, as the author of the film and the representative of the witness, stand surety for the promise of truth connected with his film? This would be a classic case of "secondary witnessing" - a concept developed in connection with survivor testimonies, particularly in relation to the Holocaust.

\section{Secondary Witnessing?}

The often-cited last line of Paul Celan's poem Ashes-Glory claims that "no one bears witness for the witness," yet the empathic and often videographic "work" with survivors of the Holocaust is based on the guiding principle of secondary witnessing (this concept goes back to de Pres 1976 and Langer 1991; Laub 1992: 75-92). According to the proponents of this idea, the experience of violence traumatizes its victims so intensely that they can only be brought to articulate their experience through active, empathic listening. The person who appeals to the witness thus becomes a co-producer of the testimony, ${ }^{4}$ which gives rise to a kind of "representative witnessing" (Weine 2006: 11).

But this approach to survivors poses a problem. However much the self-understanding of the interviewer as co-creator is necessary in clinical and therapeutic contexts (see Weine 2006), the self-empowerment of the "representative witness" or secondary witness remains problematic. Is the "earwitness" supposed to be "the redeemer of the eyewitness" (Schneider 2007: 65)? Concepts like "representative witnessing" tend to negate the difference between those who were exposed to traumatizingly violent situations and those who were not. The sublime structure of witnessing, which is based on the gap between the witness, who is physically and psychologically involved in an event, and the addressee, for whom the past event embodies an inaccessible past, thus collapses in a way that to some extent levels the unattainable position of the witness.

"Secondary witnessing" cannot compensate for, much less suspend, Paul Celan's "no one bears witness for the witness".

Questioning the relationship between the filmmaker and the interviewed and filmed survivor witness nevertheless points in a compatible direction.

4 "[T] estimony must be co-created by a survivor and an authoritative listener [...]" and "the listener actually knew more than the survivor" (Weine 2006: 33). 
I argue that Svjedok - The Witness can be understood as not only a documentary film but also a form of "testimony" because the medium of film instantiates a social relation between the survivor witness and the filmmaker. This is not the contract-oriented relation between an actor and a producer or the secondary witnessing of the filmmaker with respect to a victim and a survivor. Rather, the way the filmmaker made the film demonstrates his trust in the witness's description of the events. The film is thus a testimony not to the catastrophic event that it superficially depicts - the witness report of a war crime - but rather to the profound friendship and personal connection between the witness and the filmmaker. The style of the film embodies a form of sociality that - communitarianly extended (Froger 2014: 73) - can also make the viewers part of the community created by the film; a community whose bond is the political-ethnic solidarity created by the survivor testimony in the film.

\section{Summary}

Is it sufficient to say that the film Svjedok - beyond what it implies about the documentation of an event - consists in the creation of a social relation between the filmmaker and the witness, and that this social relation also "invites" viewers to establish this kind of connection?

The creation of communitarian connections through the viewing of documentary films goes back to Marion Froger. She refers to the cultural-anthropological phenomenon of the gift: with some documentary films, the "informational value of the image" recedes behind the film's function to create a "communitarian connection" between the filmed person, the filmmaker, and the film viewer (Froger 2014: 76).

Gifts make relationships. ${ }^{5}$ In terms of social anthropology, the gift is an act that creates a form of community that is not based on the validity of conventions, rules, and laws. Rather, it creates social relations that differ from the functional relations regulated by law, politics, and the economy and that produce instead a sense of mutual closeness, which is typical of spatial, neighborly, familiar, and ethnic communities. Friendship paradigmatically embodies such an "unregulated" sociality.

The executions that took place on the bridge, which took the lives of Raijf Begic's brothers and Haris Bilajbegovic's uncle, accidentally brought them into a fateful connection. Through the film this accidental connection becomes an intentional collaborative project, in which they both follow the impulse to give a

5 On the relationship between giving and testimony see Derrida 1994. 
voice to the Bosnian war dead. The film thus creates a second-person relationship that can be described in terms of "giving": Haris Bilajbegovic gives the surviving witness a filmic space of public attention for his story, and he bestows almost blind faith in what the survivor reports by staging the reconstructed scenes in a "live" mode that conveys a sense of the real presence of true events. He also contributes to its documentary authenticity by simultaneously embedding evidence and archived recordings into the story.

Conversely, Raijf Begic's story gives an answer that the filmmaker had long sought in order to be able to reconstruct the event on the bridge, which also affected his family. The survivor thus entrusts himself to the filmmaker as a person who is intimately familiar with the means of representation: he exposes himself through this disclosure and reveals himself to the anonymous public. It also takes courage to admit to being an eyewitness twenty years after the crime and to contribute to the conviction of the perpetrators in The Haag.

The filmmaker and the witness are both giving; they are also both receiving.

The production of the film thus establishes a network of consent for those who took part, which also includes the inhabitants of the Bosnian village who performed in the staged scenes and whose roles were divided into those of victims and perpetrators. Making the film and participating in the film is an act of connection, perhaps even an act of friendship, but in any case an act of social cooperation, political articulation, and ethnic identification. What is verified is not simply a testimony, but rather a social relation that emerges in and through the film.

\section{References}

Derrida, Jacques (2000): A Self-Unsealing Poetic Text. Zur Poetik und Politik der Zeugenschaft. Translated by K. H. Nielsen. In: Baumann, Peter (ed.): Zur Lyrik Paul Celans. München: Fink. 147-182.

Derrida, Jacques (2003): Bleibe. Maurice Blanchot. Wien: Passagen.

Derrida, Jacques (1994): Zeugnis, Gabe. In: Weber, Elisabeth (ed.): Jüdisches Denken in Frankreich. Frankfurt a. M.: Suhrkamp.

Eitzen, Dirk (1998): Wann ist ein Dokumentarfilm? montage/AV 7/2: 13-44.

Fricker, Elizabeth (1995): Telling and Trusting: Reductionism and Anti-Reductionism in the Epistemology of Testimony. Mind 104 (441): 393-411.

Froger, Marion (2014): Die Gabe und das Bild der Gabe. Dokumentarische Ästhetik und Gemeinschaft. Zeitschrift für Medienwissenschaft 11: 65-78.

Gelfert, Axel (2014): A Critical Introduction to Testimony. London etc.: Bloomsbury. 
Kierkegaard, Sören (2012): Einübung im Christentum. Zwei kurze ethisch-religiöse Abhandlungen. Das Buch Adler. Edited by Walter Rest. Second edition. München: Deutscher Taschenbuch Verlag.

Kierkegaard, Sören (1998): Entweder - Oder. Part I and II. München: Deutscher Taschenbuch Verlag.

Krämer, Sybille (2016a): Spur, Zeuge, Wahrheit. Zeugenschaft im Spannungsverhältnis zwischen diskursiver und existenzialer Wahrheit. In: Däumer, Matthias Kalisky, Aurelia - Schlie, Heike (eds.): Über Zeugen: Szenarien von Zeugenschaft und ihre Akteure. München: Fink.

Krämer, Sybille (2016b [forthcoming]): Svjedok - Der Zeuge (2012), oder: Kann ein Film ein Zeugnis sein? In: Krämer, Sybille - Schmidt, Sibylle (eds.): Zeugen in der Kunst. München: Fink.

Kusch, Martin (2002): Knowledge by Agreement. Oxford: Oxford University Press. Langer, Lawrence L. (1991): Holocaust Testimonys. The Ruins of Memory. New York: Yale University Press.

Laub, Dori (1992): An Event without a Witness: Truth, Testimony and Survival. In: Felman, Shoshana - Laub, Dori (eds.): Testimony: Crisis of Witnessing in Literature. Psychoanalysis and History. New York-London: Routledge. 75-92.

Leibniz, Gottfried Wilhelm (1966): Dialog über die Verknüpfung zwischen Dingen und Worten. In: Leibniz, G. W.: Hauptschriften zur Grundlegung der Philosophie. Vol. I. Hamburg: Meiner. 15-21.

Lütticken, Sven et al. (eds.) (2005): Life, Once More: Forms of Reenactment in Contemporary Art. Rotterdam: Witte de With.

McMyler, Benjamin (2011): Testimony, Trust \& Authority. Oxford: UP.

Moran, Richard (2005): Getting Told and Being Believed. Philosophers Imprint 5: 1-29.

Pres, Terrence de (1976): The Survivor. The Anatomy of Life in the Death Camps. New York: Oxford University Press.

Reid, Thomas (2002): Essays on the Intellectual Powers of Man. University Park: Penn State UP.

Ross, David F. - Read, Don J. - Toglia, Michael P. (eds.) (1994): Adult Eyewitness Testimony: Current Trends and Developments. Cambridge: Cambridge UP.

Schneider, Christian (2007): Trauma und Zeugenschaft. Mittelweg 36/3: 59-74.

Weine, Stevan (2006): Testimony After Catastrophe. Narrating the Traumas of Political Violence. Evaston, Ill.: Northwestern University Press. 



\section{Valeria Giardino Space and Action to Reason:
from Gesture to Mathematics}

\section{The Target: Tools for Thought}

In our cultural evolution, humans have created several instruments, not only with the intention of surpassing their physical limits - think of a hammer or a pair of glasses - but also with the aim of enhancing their memory and inferential powers; consider for example a map or the abacus. In the present paper I will focus on tools for thought. How do they work? Or, to clarify, how do we work with them?

In her article in the fourth volume of the Series Visual Learning, Krämer (2014) has pointed out that the human sciences have generally focused on a crucial dichotomy between word and image. However, tools for thought do not seem to fit this binary ordering: tables, graphs, diagrams or maps, arise as a "conjunction of language and image," which is very powerful since it makes "saying" and "showing" work together, thus reaching beyond the word/image binary opposition. Such a conjunction establishes an "operative iconicity": cognitive artefacts are not only intended as representations (a map represents a city and a Venn diagram represents certain logical relations) but they are also inviting their user to rely on them as instruments to generate and further explore the represented objects of knowledge (we navigate the city through a map and we extract new logical relations by reconfiguring a Venn diagram).

Writing as well can be considered a cognitive artefact. ${ }^{1}$ Goody (2000) took the experience of the protagonist of Defoe's Robinson Crusoe as paradigmatic: it is only where he finds pen, ink and paper that he finally begins "keeping things very exact," most of all by telling the time. In Goody's view, writing has been a crucial improvement in our cultural evolution, since it has influenced not only the content of our exchanges but their very structure. The drawing of the line has been a graphic accomplishment that has changed forever the way we formulate our thoughts (think for example of the line constituted by the carvings in a stone to track days passing by). Writing and the drawing of conceptual lines are

1 In the following, I will use cognitive artifact as synonym for tool for thought. However, it is true that there might be cases of tools for thought that are not strictly speaking artifacts, for example gestures. 
phenomena that cannot be considered from within the word/image dichotomy. Despite this, operative iconicity brings about a form of "cognitive technology" that becomes available for sharing and structuring the content of our thoughts. As Goody suggests, we could think for example of the mathematical table - certainly a product of writing but more interestingly of the drawing of the graphical line - as a tool for thought whose functioning can be taught to and learned also by people who can neither read nor write. The table here is "a technology for the intellect"; in Krämer's words: it belongs to the class of the "diagrammatic," overcoming the word/image dichotomy.

In the present paper, I will assume that "operative iconicity" is indeed the characteristic feature of numerous tools for thought and my aim will be to explain the conditions for it. In Section 2, I will introduce my hypothesis about the existence of a human capacity labelled diagramming. In Section 3, I will discuss diagramming in relation to the philosophy of mind. In Section 4, I will present some pieces of evidence coming from experimental psychology and philosophy of mathematics supporting the diagramming hypothesis. Finally, in Section 5 I will briefly discuss some open questions.

\section{The Hypothesis: Diagramming}

In an article in the fourth volume of this series, I introduced my hypothesis about the existence of a capacity that I have labelled diagramming (Giardino 2014). Thanks to this capacity, humans are able to recruit a variety of cognitive systems spatial perception and action systems - that are already available in other contexts, with the specific aim of reducing cognitive loads for memory and assisting problem solving. The human species is endowed with natural capacities for treating spatial information and planning/regulating action in the external world, which have an undisputable survival value. In my view, by connecting the systems responsible for spatial perception and action - and possibly other systems - humans have invented a class of (cognitive) artefacts capable of assisting them in solving new problems originated in the course of their cultural evolution - the nature of which would have made it impossible to address them using one of those systems alone. In particular, according to my hypothesis: (i) the production and the analysis of spatial cognitive artefacts recruit action systems; (ii) in some cases, recruiting action systems makes problem solving easier (problems are solved more efficiently, more quickly, and with less cognitive efforts); (iii) spatial cognitive artefacts trigger this recruiting and therefore they act as multi-recruiting systems.

In line with Krämer, I argue that to give an account of the functioning of cognitive tools it is necessary to go beyond the dichotomy word/image. In fact, spatial 
cognitive artefacts are not simply visual tools but dynamic devices, allowing for new inferences by being acted upon; tools for thought are the medium where space perception and orientation, action planning and regulation and other cognitive systems (e.g. visual and conceptual) operate in coordination in view of a cognitive task. For this reason, they can gain us a unique insight on the functioning of the human mind and on its motives and capacities for cultural innovation.

Imagine performing an action on a geometric figure, such as translating or rotating it. This will bring together various cognitive systems by triggering each of them: in that same action, the conceptual system will recognize the conformity to some invariance; the visuo-spatial system a transformation in time; and the action system a movement or a movement plan (Giardino 2014). The connection among these different perspectives will allow for the performance of the appropriate inference. Thanks to diagramming, the physical properties of a particular representation are interpreted as referring to other elements - abstract as well which are not directly present in the space of the representation: by manipulating physical properties, it will be in some cases possible to learn something new about the objects or the events which they refer to. The products of the diagramming capacity are "iconic," that is, conceived to structure the space of the problem. By using the term "iconic," the reference is to the notion of "icon" as introduced by Peirce. As Peirce suggests, a "diagram-icon" is a tool that allows making inferences because it has been constructed with an intention and is dynamic: the diagramicon leads its interpretant to a state of activity that, mingled to curiosity, brings one to experimentation (Peirce [c. 1906]). It is an "operative iconicity," to use Krämer's term again.

\section{The Background: Moderate Embodiment}

In the recent philosophical literature, various hypotheses about the nature of our mind have been put forward that are possibly in line with the diagramming hypothesis. For example, Varela et al. (1991) have proposed that the mind is embodied, and Clark and Chalmers (1998) that it is extended. Despite being very inspiring, the metaphors of the mind as embodied or extended do not seem unfortunately to be enough when it comes to clarifying, in practice, how humans were able to create and are able to rely on 'scaffolding' structures in order to enhance their reasoning and inferential capacities. I do not take here any particular metaphysical stance about the location of the mind in the environment; more modestly, I claim that cognitive processes do not happen exclusively in the brain but extend themselves beyond the skin and skull of an individual, and therefore cognition happens to be distributed between internal and external structures, for 
example, in space (see for reference Hutchins 2001). It still remains to evaluate the possible role of the body: how much the experience of having a particular body would matter for the performance of a variety of cognitive tasks?

On this topic, Goldman (2012) has interestingly proposed to assume a moderate approach to embodied cognitive science. According to Goldman, empirical studies show that human cognition can in fact be considered for the most part as embodied because information obtained from proprioception and kinesthetics (which refer in the first place to the perception of the position and of the movements of the different parts of the body), happens to be often reused for other, more abstract tasks. The empirical part of Goldman's claim is that there exist so-called bodily representational codes, that is, a subset of mental codes that are primarily or fundamentally applied in forming interoceptive or directive representations of one's own bodily states and activities (see for reference Goldman-Vignemont 2009). The philosophical part of Goldman's claim is that the brain reuses or redeploys cognitive processes having different original use to solve new tasks in new contexts; when it comes to bodily representational codes, these appear to be extremely pervasive: selected cognitive tasks might be executed via embodied processes, and there is no need to ascend to more global claims.

Goldman's proposal leads to a "moderate" conception of embodiment-oriented cognitive science precisely because it specifies the role of the body in cognition, first by defining what bodily representational codes are and then by explaining how they happen to have an influence on some cognitive processes. This framework is crucial to consider diagramming as allowing us to perform actions on material spatial artefacts, leading to cognitive advantages in some particular tasks. Such a view runs counter to standard theories in cognitive science, which have claimed that core knowledge representations in cognition are amodal data structures that get processed independently of the brain's modal systems for perception, action and introspection.

\section{Some Evidence from Mathematics}

\subsection{Gestures in Explanation}

What if mathematics in particular is (moderately) embodied? As a first piece of evidence in favour of the existence of the diagramming capacity, consider gesture in mathematics. According to standard approaches, mathematics is an abstract science, dealing with abstract objects described by signs not sharing any properties with the ordinary objects we interact with every day. However, some recent studies have questioned the existence of a sharp distinction between abstract knowledge 
on the one hand and the concrete world on the other. According to Lakoff and Núñez (2000), abstract mathematical concepts are rooted in embodied activities, such as for example our ways of thinking about the world, and how we describe it, that is, our perception. In line with previous studies on language (see for reference Lakoff-Johnson 1980), the authors propose that abstract scientific concepts, as well as ordinary ones, can be reformulated in terms of metaphors, which are not mere linguistic phenomena, but crucial elements of thought. Indeed, the typical mathematical jargon contains many terms that allude to our relationship with the real world: natural numbers "grow" indefinitely, points "lay" on a line, functions "move" to zero. The basis of these metaphors is bodily experience: mathematics is embodied because we understand and explain it by making appeal to embodied cognitive mechanisms, of which conceptual metaphor is the main one.

Recently, Sinclair and Gol Tabaghi (2010) have interviewed six mathematicians and asked them to explain the meaning of the mathematical concept of "eigenvector". The interviews were filmed, with the aim of evaluating the mathematicians' embodied reasoning. The videos show that the mathematicians make use of a variety of representations - speech, gestures, diagrams, and so on - moving from one to the other without difficulties, thus blurring the alleged boarders between the mathematical and the physical world. They all well know the formal 'manual' definition of eigenvector, single, atemporal and static; nonetheless, without exception, they offer a description of eigenvectors that alludes to a very different interpretation, including also temporal and kinaesthetic elements, as shown both in the terms and in the gestures they use. Metaphors are common: some of the mathematicians focus on the transformations of the vectors, by saying and showing in their gestures how they "shrink" or "turn"; others describe the vectors' personality, by claiming that they "go in the same direction," they "align," and so on. In other words, none of the mathematicians speaks of eigenvectors only in terms of algebraic equalities. Moreover, some metaphors are perceptual (for example, one mathematician thinks of the quadratic function as a "goblet") but most of them have a movement component. Furthermore, the high variability in their gestures seems to depend on their respective education and competence, i.e. on their relevant background knowledge. Gestures, compared to language, are in some sense the 'degree zero' of diagramming: they give more possibilities than simple speech to express continuity, time and movement, thus confirming the intuition of the French mathematician Châtelet (1993), who saw in a mathematical diagram the "crystallization" of a gesture. 


\subsection{Formulas in Algebra}

A second piece of evidence in favour of the existence of diagramming comes from recent experimental work on mathematical notations. Landy and Goldstone (2007) have considered how physical layout affects the segmentation of simple equations. A difficult and yet routine part of mathematical reasoning is to segment a notational form, that is, to parse it into its formal components. For example, in a formula, in the absence of parentheses, multiplication comes before addition, and therefore the equation must be parsed accordingly. Following the standard approaches to mathematical reasoning, the cognitive parser executes segmentation by applying formal rules to individual notational symbols; the assumption is that abstract symbol sequences are trivially extracted from physical notations. To run counter to this assumption, the authors added several visual cues such as spacing, lines or circles to the formulas of an equation and then showed them to their subjects. The hypothesis was that such cues would trigger the application of perceptual grouping mechanisms and as a consequence the capacity for symbolic reasoning. The results showed indeed that the subjects' judgments about the validity of the equations were more likely to be correct if visual groupings were in line with valid operator precedence (multiplication must be executed before addiction in the absence of parentheses). This would give evidence to the authors' hypothesis that people use typically available non-formal information to make grouping judgments, and only subsequently integrate this information with formal rules, which is in line with diagramming.

\subsection{Diagrams in Topology}

A third piece of evidence in favour of diagramming comes from my research about visual tools in topology. Several philosophers have discussed the use of diagrams in mathematics (Giardino [forthcoming]): mathematicians often rely on the space of the representations they use in some cases by performing some actions on them. Space is crucial for reasoning: as it is well known, in the 1980s Johnson-Liard (1983) proposed a theory of human reasoning that was based on mental models, that is, human reasoning would be a mental simulation process in which models of the premises are constructed, inspected, and validated. However, according to the diagramming hypothesis, spatial cognitive artefacts are multi-recruiting systems, and therefore also the actions performed are crucial for reasoning. Kirsh and Maglio (1994) have famously proposed to distinguish between pragmatic and epistemic actions: actions of the first kind aim to bring the agent closer to his or her physical goal, while actions of the second kind "use [the] world to improve cognition," i.e., they are "physical actions that make 
mental computation easier" (Kirsh-Maglio 1994: 513). An epistemic action is performed outside on the physical objects that are available, and it is precisely the performance of this action that enhances our inferential capacities. The concept of epistemic action can be extended to the use of signs in mathematics. As De Cruz and De Smedt have recently proposed, mathematical symbols "enable us to perform mathematical operations that we would not be able to do in the mind alone, they are epistemic actions" (De Cruz-De Smedt 2013: 4). Of course, such a view is not epistemologically innocuous, since it assumes that mathematical signs are intimately linked to the concepts they represent and vice versa.

Recently, together with Silvia De Toffoli, we have considered the case of a practice of mathematics where concrete manipulations and transformations are performed on the space of the representations: the practice of proof in topology, in particular in knot theory and low dimensional topology (De Toffoli-Giardino 2014; 2015). ${ }^{2}$ In our interpretation, knot diagrams are dynamic tools: in perceiving a diagram; one has to see the possible moves that can be applied to them. For this reason, experts have developed a specific form of enhanced manipulative imagination, which allows them to draw inferences from knot diagrams by imagining, and in some cases actually performing, epistemic actions on them. We argued that the meaning of a knot diagram is not pre-defined before the definition of its context of use: it is only when the mathematicians fix the mathematical space in which the particular diagram is embedded and as a consequence choose which manipulations are allowed that the knot diagram becomes meaningful. This indeterminacy of meaning is precisely the feature that makes knot diagrams a space for experimentation, where different actions and consequently different possible interpretations can be tested. For this reason, knot diagrams are a good notation, because they represent mathematical concepts but at the same time have inferential power: a notation is "good" when it not only facilitates calculation but also prompts new ideas and induces new developments. Also the actual practice of proving in low-dimensional topology involves a kind of reasoning that cannot be reduced to formal statements without a loss of intuition: the representations that are commonly used in low-dimensional topology are heterogeneous, i.e. neither entirely propositional nor entirely visual (the word/image dichotomy does not apply).

2 More recently and along the same line of thought, we have analysed the proof of "Alexander's Theorem," which allows connecting knots to topological braids (De Toffoli-Giardino 2016). 
Manipulative imagination is shared by experts: it is the kind of reasoning that one has to master to become a practitioner. Moreover, the manipulations allowed on the representations as well as the representations themselves are epistemologically relevant, since they are integral parts both of the reasoning and of the justification provided: the representations give a material form to the transformations (and in this sense they embody them), thus allowing experts performing epistemic actions (and in particular drawing inferences) on them. These actions are controlled by the shared practice: the set of legitimate transformations is limited and determined by the context. Differently from gestures, diagrams are not idiosyncratic but part of a solid and stable practice.

\section{Open Problems}

To sum up, according to the diagramming hypothesis, spatial cognitive artefacts act as multi-recruiting systems. Despite not being material, gestures show that spatial and motor elements might help comprehension. Moreover, it has been shown that the way the notation is perceived influences comprehension and that experts in topology are able to envision (physical) transformations on the diagrams having conceptual consequences.

If diagramming really exists, then two questions can be formulated in relation to the general topic of this collection. The first question is for people working in education: would it be better to replace the reference to visual learning with that of (moderately) embodied learning? The second question is for the developers: what happens (or maybe what has already happened) when diagramming meets the new technologies? For example, should touch screen technologies be designed in accordance to a more serious reflection about the role of space and action in reasoning? This is matter (I hope) of further research.

\section{References}

Châtelet, Gilles (1993): Les Enjeux du mobile: Mathématique, physique, philosophie. Paris: Collection Des Travaux, Edition du Seuil.

Clark, Andy - Chalmers, David John (1998): The Extended Mind. Analysis 58/1: $10-23$.

De Cruz, Helen - De Smedt, Johan (2013): Mathematical symbols as epistemic actions. Synthese 190: 3-19.

De Toffoli, Silvia - Giardino, Valeria (2014): Forms and Roles of Diagrams in Knot Theory. Erkenntnis 79/4: 829-842. 
De Toffoli, Silvia - Giardino, Valeria (2015): An Inquiry into the Practice of Proving in Low-Dimensional Topology. Boston Studies in the Philosophy and History of Science 308: 315-336.

De Toffoli, Silvia - Giardino, Valeria (2016): Envisioning Transformations. The Practice of Topology. In: Larvor, B. (ed.): Mathematical Cultures. Basel: Birkhäuser Science, Springer. 25-50.

Giardino, Valeria (2014): Diagramming: Connecting Cognitive Systems to Improve Reasoning. In: Benedek, András - Nyíri, Kristóf (eds.): Emotion, Expression, Explanation. Visual Learning, vol. 4. Frankfurt/M: Peter Lang Verlag. 23-34.

Giardino, Valeria (forthcoming 2017): Diagrammatic Reasoning in Mathematics. In: Magnani, L. - Bertolotti, T. (eds.): Spinger Handbook of Model-Based Science. Basel: Springer.

Goldman, Alvin (2012): A Moderate Approach to Embodied Cognitive Science. The Review of Philosophy and Psychology 3/1: 71-88.

Goldman, Alvin - Vignemont, Frederique de (2009): Is Social Cognition Embodied? Trends in Cognitive Sciences 13/4: 154-159.

Goody, Jack (2000): The Power of the Written Tradition. Washington: Smithsonian Institution Press.

Hutchins, Edwin (2001): Distributed Cognition. In: Smelser, N. J. - Baltes, P. B. (eds.): The International Encyclopedia of the Social and Behavioral Sciences. 2068-2072.

Johnson-Liard, Philip N. (1983): Mental Models. Cambridge: Cambridge University Press.

Kirsh, David - Maglio, Paul (1994): On Distinguishing Epistemic from Pragmatic Action. Cognitive Science 18: 513-549.

Krämer, Sybille (2014): Trace, Writing, Diagram: Reflections on Spatiality, Intuition, Graphical Practices and Thinking. In: Benedek, András - Nyíri, Kristóf (eds.): Emotion, Expression, Explanation. Visual Learning, vol. 4. Frankfurt/M: Peter Lang Verlag. 3-22.

Lakoff, George P. - Johnson, Mark (1980): Metaphors We Live By. Chicago: University of Chicago Press.

Lakoff, George P. - Nuñez, Rafael E. (2000): Where Mathematics Come From: How the Embodied Mind Brings Mathematics into Being. New York: Basic Books.

Landy, David - Goldstone Robert L. (2007): How Abstract is Symbolic Thought? Journal of Experimental Psychology: Learning, Memory, and Cognition 33/4: 720-733. 
Peirce, Charles Sanders (1976 [c. 1906]): PAP (Prolegomena to an Apology for Pragmatism) (MS 293). In: Peirce, C. S.: The New Elements of Mathematics by Charles S. Peirce. V. 4. Edited by C. Eisele. The Hague, Netherlands: Mouton Publishers. 319-320.

Sinclair, Nathalie - Gol Tabaghi, Shiva (2010): Drawing Space: Mathematicians' Kinetic Conceptions of Eigenvectors. Educational Studies in Mathematics 74/3: 223-240.

Varela, Francisco J. - Thompson, Evan - Rosch, Eleanor (1991): The Embodied Mind: Cognitive Science and Human Experience. Cambridge, MA: MIT Press. 


\section{Daniel L. Golden}

\section{Visual Management of Time}

\section{The Use of Time}

There is a striking contradiction between time as one of the most fundamental constituents of human existence, and as one of our most abstract concepts ever. While - as we can learn from inquiries made by Kristóf Nyíri $(2006,2007,2016)$ the sense of time is deeply embedded in our bodily subsistence from heartbeats to motoric gestures, this kinesthetic-biological background cannot give an exhaustive account of time functioning as a social institution. The importance of the latter was realized by several theoreticians of modern society from the early $20^{\text {th }}$ century. According to Georg Simmel (1903), metropolitan life presupposes the precise coordination of actions via the harmonization of clocks. Max Weber (1922) suggested that modern bureaucracy is developing a so-called technocratic thinking through presenting itself as a machine-like entity yielding to ever better efficiency. Lewis Mumford (1934) envisioned the transformation of organic time into mechanical time in order to put social life under control. In general, modernization will make indispensable reliable time calculating systems which can be accessed through uniform ways for the whole community at any point in time.

Considering the long history of time measuring devices we can see that they all make use of certain natural-physical phenomena. However, the sun moving, water or sand flowing, electrons emitting microwaves, etc. are in themselves insufficient to turn time into something calculable. They need to convey their outcomes in a visible (or sometimes audible) way for human comprehension. Most measurement tools apply a kind of visual translation, i.e. projecting the passing of the abstract time into the factual space; casting a shadow on a display with a calibration, or installing a hand which will point at a certain section of the visually designed surface. In fact, sundials, clockworks, time lines, calendars and time tables all build upon visual components in order to make the abstraction conceivable, communicable, and operable for the human mind. We can even call this the "domestication of natural time," as we may get the impression that we gain the power even to manipulate it by those artificial means. 


\section{Time Management and the Concepts of Time}

The main driving force behind the requirements on timing, tracking, and synchronizing human activities was, of course, industrialization, together with free competition. In that framework consumption of time had to be optimized in the same way as of any other material resource in order to benefit most from production procedures. Frederick W. Taylor (1911/1967) turned that efficiency issue into a scientific problem, making careful research and meticulous experiments with factory workers standing behind the assembly lines. Taylorism became the trademark for the idea that any human activity can be reorganized by identifying the distinct units of it and rationalizing the sequences of their realization.

Since then time economy became one of the basic domains for management studies. As we can learn from a popular book on time management (Johns 2003), the very point to start from is the insight that "time isn't like the Brazilian rain forest: it is irreplaceable". Time in itself may be endless, "but for each one of us the supply is undoubtedly limited" (Johns 2003: 5). That said, what we shall aim at is to take the control over the amounts of time standing at our disposal. "Manage your time or it will manage you," we are told.

It is suggested that there are basically two ways of reacting to increasing duties and tasks. Either we simply elongate our working week: going to work early, staying there late, taking work home, and working at weekends, or we start to manage time much more effectively and productively. The proper use of time is interpreted here as "adding value". Conducive moves will include everything what brings us closer to a meaningful action: planning, exploring, thinking, making decisions; while wasting time will mean 'spending it without added value', i.e. not being engaged in anything reasonable. Efficiency, then, will be formulated as maximizing the proportion of useful events to the time used. The manager's task should be no longer fighting against unexpected threats to his or her company, but pursuing as many additional values in a given interval as it is possible.

This also means that time management can be best defined as the ability of managing ourselves in order to produce the maximum activity within a certain period of time. So, arguably, it is about nothing else than "self-management," the demand for endurance and devotion in working consciously for carefully chosen goals or aims. It will consist of monitoring, evaluating and restructuring our customs in time usage to improve inefficiencies. While managing public time served for the coordination among actions of different members of a society, here we are facing the claim for something similar, but on the individual's level, where distinct activities shall find their optimal order in a personal time frame. This would produce something like a private time, which seems to make an important shift in 
perspectives. Going one step further, we can say that the chasing of a competitive advantage in using time may change the concept of it from the "objective" to the "subjective". It almost seems to have a dual nature: either we can think about it as something built of rigid and unchangeable units, or we may think that there are certain holes in it which can be fulfilled by additional contents.

At this point it seems to be advisable to take a look at the presuppositions about the nature of time behind time management. A first question is whether we shall think about time as linear or cyclical? Shall we say with Heraclitus that "one can never step into the same river," i.e. the flow of time is unstoppable and it stands above any human intervention, or rather share the idea revived from its ancient roots by Nietzsche about the "eternal recurrence," telling us that within the infinite realm of time the same patterns will be necessary repeated again and again.

Probably to get time manageable, we have to assign to both of these aspects. Any planning for the future based on records of the past will have sense only if we think that certain situations will somehow return. But we should also believe that events are not determined forever, so that we will be in the position of making some improvements.

Another question is in what sense we shall take time as a constituent of our world? Newton's absolute time, for instance, is linear, completely homogeneous and linked to mechanical movements, so that it can be split up into measurable units. It is a natural phenomenon entirely inhuman as it obeys natural laws independently of human efforts made for measuring it. This mathematical-physical concept of time can be contested by psychological approaches. Bergson, for instance, contrasted this scientific notion of time with a metaphysical one called real duration. The latter cannot be split up mechanically into smaller parts as the former, and it can be experienced only through the meaningful actions of the individual. It will be more about quality than quantity, as "[...] the positive time manager will say: It isn't the hours you put in, it's what you put into the hours which determines whether you're effective or not" (Johns 2003: 16).

We can make our understanding even more complex if we consider the relativistic challenge presented by Einstein, where activities with different intensity would make differences in the flow of time, thus resulting in incommensurable durations, relative to the personal frame of reference of the observer. On the other hand, from the perspective of Heidegger's existential analysis, authenticity of life depends on the proper use of our time. Against the ordinary concept of linear and infinite time going back to Aristotle, he insists, time is definitely finite, and we shall live our lives having that in mind, grasping all opportunities for giving significance to it. While the lifespan of the human being cannot be stretched over 
its biological or medical limits, at the same time it can be seemingly infinitely widened inwards by acquiring more and more sense for it.

\section{Visualizing Tools and Understanding Time}

Management issues linked to the better use of our temporal resources are generally about the improper occurrence of certain events - too many distractions in the forms of incoming phone calls or face-to-face interruptions, too little delegation of time consuming tasks to subordinates, etc. The results of these are massive overloads of work in a given period. To avoid that, the good manager will make plans as to how to use his or her time more effectively. Data can be examined from different angles: value-added analysis opposes maintenance and crisis prevention to performance improvement and changing management; task-scale analysis investigates whose expectations are coming to fruition, so that there are boss-imposed, system-imposed, subordinate-imposed, customer-imposed, and self-imposed uses of time; finally time-scale analysis makes distinctions among specific purposes such as administration time, communication time, operations time, supervision time, wasted time, and executive time. Based on those successful time management schemes, they must include a realistic estimating of the time necessary for a certain activity, while progress reports give feedback on how much the initial idea measured up to the time units actually utilized. The worst thing to be experienced in this respect is time-pressure, when the planned activity won't fit into the timeframe opened for it. In other words, there is a clash between our personal commitment to accomplishing a task and the impersonal flow of time.

All these, once again, are presented through various visual-spatial depictions. For example, a deadline signed in a calendar gives the impression of a finite spatial area which should be filled densely with purposeful actions. By visualizing, we construct a common, external understanding on the top of our personal, internal experiences of time. We shall note here that the whole procedure seems to be highly conventional, since an abstract concept is represented by symbolic visuals, which will gain their concrete meaning only from usage, i.e. the manipulation of time made possible precisely by them. The visualization of time relations is actually built up in three steps. The first one is spatial metaphorization, the second is visualization of the spatial metaphor, which means the transformation of the abstract temporal relations into factual spatial relations. The third step already consists of the actions realized following the morals drawn from previous records: filling up empty spaces, reducing density, changing sequential order, etc.

One of the most common tools is the daily time schedule in a form of a clock, where each hour is dedicated to a distinct activity (W1). Time tables are also 
widespread for the same reasons: they show life put into logical order, under conscious control. Even the timeline can be regarded as a sequence of events with time stamps presenting how much one succeeded in managing his or her life time (W2). An unusual tool is the chronodex, or hyperdex, or spiraldex (W3), which gives the possibility of managing multitask-work by coloring time periods used for distinct activities.

Besides these static representations, recent ICT developments put some $d y$ namic ones into everyday use as well. By utilizing the possibilities of moving picture these are able to give the feeling of time passing as well. Think of the sidebar showing our actual position within the consumption of a certain media piece, or the download status bar transmitting the information about the state of perfection of the process going on. Both are making an effect on our sense of time by linking spatial proportions to temporal distributions in a dynamic way.

Based on these insights a theoretical framework for the visual interpretation of time can be designed where the key terms will be proportion, resolution, and segmentation.

We may find it quite embarrassing to hear that the secret of time management would be simply to "use all seconds in the day wisely". It is because we feel that the deliberate allocation of meaningful actions at this scaling is beyond the abilities of human beings. Instead, we will find different units of time and certain amounts of them proper for our diverse activities. We will want to count the time necessary for learning for the next school day in hours, preparing for an important exam in months, and the period of our lives dedicated to education in years. These measuring units of time are partly universal and objective, but in a sense also relative to the action in question. Resolution then would mean here, that one can actually zoom in and out over the images of time, so that you will receive different slices of its flow with different depths or perspectives. Management goals will be formulated in terms of proportions - which is a visually based concept coming from geometry - as e.g. "reduce the time spent on telephone calls by half". Increasing efficiency will be executed through the redistribution of a timespan between useful and "unuseful" activities. While resolution defines the units, segmentation will give the scope or range of them to be seen together creating a temporal narrative, bringing into relief a certain amount of units that seem to be somehow linked together to form a meaningful section. Those will be the histories of a person, a family, or a nation.

A unique example for that understanding of time would be the data visualization made by Lev Manovich and Jeremy Douglass (W4) from all 4535 issues of Time magazine published between 1923 and summer 2009. The unit in this 
representation without any surprise will be the week, while different periods of $20^{\text {th }}$ century history can be identified by temporal patterns of different styles, printing techniques and other visuals of the front cover images.

\section{Conclusions}

Dare we say then that, at least in the context of human comprehension, time has a definitely visual nature?

Philosophical considerations behind time management seem to give the possibility of actually reconciling and somehow making use of all contradictory ideas concerning the features and functionalities of time. Visual representations seem not only linking together conceptually the physical and psychical understandings of it, but also merging them, giving the possibility to transform the abstract notion into something like a material resource consisting of practically controllable working units which can be reorganized at one's will.

The visual-spatial external representations of our internal time experiences serve for mitigating, or civilizing the natural phenomenon. Throughout the centuries, dozens and hundreds of smart tools has been developed and constructed in order to give the possibility to seemingly manipulate time. In the place of the hardly conceivable flow of time, we put graphical symbolization of punctual and durational aspects, which can be easily perceived by the eye and the mind.

In that way we end up with a notion of time linked to the presence of meaningful actions, which can give us the hope for utilizing the theoretic phenomenon pragmatically in the scope of our everyday life.

\section{References}

Johns, Ted (2003): Perfect Time Management: All You Need to Get It Right First Time. London: Random House Business Books.

Nyíri, Kristóf (2006): Time and Communication. In: Stadler, Friedrich K. Stöltzner, Michael (eds.): Time and History / Zeit und Geschichte. Frankfurt/M.: Ontos Verlag. 301-316.

Nyíri, Kristóf (2007): Time and the Mobile Order. In: Nyíri, Kristóf (ed.): Mobile Studies: Paradigms and Perspectives. Vienna: Passagen Verlag. 101-111.

Nyíri, Kristóf (2016): Emerging Media and the Philosophy of Time. In: Floyd, Juliet - Katz, James E. (eds.): Philosophy of Emerging Media: Understanding, Appreciation, Application. Oxford UP. 159-170.

Mumford, Lewis (1934): Technics and Civilization. New York: Harcourt, Brace and Co. 
Simmel, Georg (1903/1997): The Metropolis and Mental Life. In: Frisby, David -Featherstone, Mike (ed.): Simmel on Culture: Selected Writings. London: Sage Publications. 174-185.

Taylor, Frederick W. (1911/1967): The Principles of Scientific Management. New York: Norton.

Weber, Max (1922/1978): Economy and Society. Berkeley, CA: University of California Press.

$\mathrm{W} 1$ = http://www.whudat.de/from-mozart-to-dickens-how-historys-greatestthinkers-managed-their-time-14-pictures/.

$\mathrm{W} 2$ = http://www.vertex42.com/ExcelArticles/create-a-timeline.html.

W3 $=$ http://jessversteeg.ca/2015/03/17/chronodex/.

$\mathrm{W} 4=$ https://www.youtube.com/watch?v=d_OceOpCmf8. 

Javier E. Carreño

\section{Husserl on the Right Timing of Depictions}

\section{Chronos and Kairos}

The founder of phenomenology, Edmund Husserl, might not come to mind amongst the foremost thinkers who are sensitive to the history and methods of rhetoric. And yet, at the crossroads of the phenomenological analyses of imageconsciousness, time-consciousness, and aesthetic consciousness, one may be pleasantly surprised to find Husserl grappling with a basic rhetorical problem pertaining to so-called 'static' images (such as representational paintings and busts in the manner of Albertian silhouettes) (Biceaga 2010: 83): how can such images, apparently 'without a time', strike us as having a 'right' timing?

The claim that images are without time has had to reckon that there are manifold concrete ways in which plastic static images convey temporality to us. It is no accident, for example, that a photograph would present a past time; or that an impressionistic painting could convey movement; or that a sculpture could represent an event. Plastic images often reflect a temporality - be it real and historical, or else imaginary - which can be unfolded through acts of pure phantasy. ${ }^{1}$ However, images convey a "perfect timing" or kairos whenever the tension between a depicted time-phase and the possible phantasy continuations is won over by the depicted time-phase on account of the maximal awareness it affords of its subject. While the chronos of an image makes the depicted time-phase simply a part of a greater whole, an image with a kairos gives the depicted time-phase as

1 English translations of Husserl (in the Edmund Husserl Collected Works) have opted to render Husserl's Phantasie into English as "phantasy," amongst others to avoid two shortcomings with the English alternatives of "imagination" and "fantasy". "Imagination" irremediably links Phantasie with the having of "mental images" even though Husserl, as early as the Logische Untersuchungen, criticizes any and all psychologistic "picture theories" of consciousness (Husserl 2001: 125-127). "Fantasy" in turn triggers associations connected with the literary genre and with the imagining of objects with which we are not readily familiar as proximately actual or historical, while I can and often do phantasy with objects corresponding to those of a really possible perception (Husserl 2005: 2). While some commentators do translate Phantasie as "imagination" (Drummond 2008: 106), Husserl's own preference for "phantasy" would appear to be clear from his own entry to the term "fantasie" in André Lalande's Vocabulaire technique et critique de la philosophie (Lalandé 1988: 342). 
a "whole," greater than (or at least preferable to) any of its imaginary temporal continuations (Rodrigo 2009: 180). As I will show, Husserl thus overcomes the binary categories of "static" and "proto-cinematic," which otherwise polarize the study of the temporality of plastic images (cf. Claass 2014: 10).

Several items will need to be addressed shortly, beginning with the peculiar way Husserl's phenomenology understands images as representations of an "absent" time. Next, we will address how our awareness of time in images is different from our perception of time, before we come to terms with how an image might communicate not just a time, but in fact a "right timing".

\section{The Consciousness of an Image 'Now'}

In the order of things, let us begin with how Husserl understands static images as presenting something temporal in the first place. For a phenomenologist, whenever we confront an image, we are not just aware of a thing that happens to resemble another, since things may perfectly resemble something, and yet not serve as images. Rather, when dealing with images, we are necessarily aware "at once" of more than one object. When beholding a portrait, we are aware of 1) a 'subject' or 'motif', that appears in 2) the framed image that renders it. Together with Husserl we call the first the "image subject," and the second the "image object".

Portraits, then, entail a double objectivity. But since they appear on the basis of the sensuous surface of physical things, the phenomenologist further distinguishes between the "image object" and the 3) "physical image thing," such as the paintstained poplar panel (Husserl 2005: 30).

For the phenomenologist, this threefold distinction on the side of images (comprising elements as disparate as the "real" canvas and the "phantasied" image subject) would be altogether impossible without the involvement of a primitive form of conscious intentionality called "image-consciousness". How image-consciousness differs from positing perception is seen in the fact that one who perceives either posits or seeks to posit the existence of what he perceives, whereas whoever beholds an image is not inclined to take the "image subject" as something actually existing before oneself. From the standpoint of normal perception, the image, then, is a sort of "nullity" or illusion ("Schein"). Image-consciousness, however, contrasts with pure phantasy in that the "image subject" is intended mediately, i.e., in and through an image object - and yet not 'emptily', as it might be the case with signitive intentions.

For Husserl, the realization that all depictions are, in a sense, "illusory," raises the important question of why and how images do not trick us. From the side of consciousness, image-consciousness connects at once a 'perception' (Perzeption) 
of the image object with a 'phantasy' of the image subject. The involvement of phantasy here means, amongst other things, that no matter how "ready-made" an image may strike us, all images require the viewer's willful, conscious, and imaginative involvement. And from the side of the "image," Husserl realizes that depictions do not aim to pass for something actually perceived, as images offer an approximate rather than a perfect resemblance of their subjects.

Moreover, image appearances are discontinuous with their perceptual surroundings since what appears in the image does not presently exist within the frame space. It is in this regard that Husserl describes the image as "the appearance of a not now in the now" (Husserl 2005: 47). The image appears in the midst of the field of perception, in the midst of all that is now present - but what appears in an image cannot be intended as something actually present. In contrast with its perceptual surroundings, the image is really a "nothing," although this awareness of an image's perceptual nullity does not prevent our regular dealings with images. On the contrary, when beholding Mona Lisa, we never quite perceive her as present, and she continues to appear in absentia. Thus, image-consciousness implicates a doubling of time, in the sense that what appears in the image is necessarily intended as belonging to a different temporal nexus from that of things that appear perceptually: "this exhibited something can never exhibit the now with which it conflicts; hence, it can only exhibit something else, something not present" (Husserl 2005: 47).

\section{The Temporal Halo of an Image Now}

At first blush, it would appear that Husserl draws an untenable conclusion with regards to images. Why would anybody call the appearing "not-now" in images something temporal? Is not temporality here precisely what is being denied? But for Husserl, a perceptual awareness of an abstract now-point is altogether impossible. Husserl's consideration of the temporality of images, then, coheres with a basic premise regarding our awareness of time.

True to a time honored philosophical tradition, Husserl never defines temporality. He goes as far as to say that we even lack the right words to speak about time. But just as Husserl addresses image objectivities by analyzing their corresponding intentionality, so does he also address temporal appearance by analyzing the consciousness to which duration and succession appear. To be sure, what falls under the purview of time-consciousness is not real or transcendent time, but the time of appearing. And this immanent appearing time "cannot be measured; there is no clock and no other chronometer for it. Here one can only say: now, before, and further before, changing or not changing in the duration, etc." (Husserl 1991:339). 
For the phenomenologist, the temporal awareness of something 'now' or 'present' (something purely temporal or else spatial-temporal) is always already threefold in character. We are aware of an object as present because we experience it (a) in one of its phases as 'now', (b) in one or more of its phases as 'just-having-been now', and (c) still in other forthcoming phases as 'not-yet-now'. But to be aware of anything temporal does not mean that consciousness has to constantly perform a trio of distinct temporal presentations, as if our awareness of time had to piece itself together. On the contrary, Husserl discovers that consciousness always already manifests a temporal structuring, from "the boot, up," so to speak: we are internally and originally aware of the "now phase' of consciousness in "primordial impression" or "primordial sensation"; of the elapsed phases, in "retentions," and of the forthcoming phases in "protentions".

Because of the three-fold structure of perceptual time-consciousness, we can never sensibly experience an object in a now-phase without being conscious of it in those phases that are strictly "not now". For the "now' is irremediably "a relative concept and refers to a 'past,' just as 'past' refers to the 'now"' (Husserl 1991: 68). The same holds in principle for an "image now," even if it is also a perceptual "not now". As Brough puts it, the depicted now-moment "cannot be snatched cleanly from its context with all of its temporal references scrubbed away" (Brough 2000: 236).

Still, the formal necessity of characterizing the "image now" as temporal does not yet answer the question of how a depictive image acquires a 'halo' of past and future temporal phases. Whichever way one considers this problem, it does not appear to be the case that one can simply complete the "imaged now" by intuitively phantasizing a temporal halo for it. For by phantasizing, the Mona Lisa into phases, in addition to the imaged Mona Lisa 'now', one still does not experience a continuous flow. When looking at the Mona Lisa, the only phase that 'appears' is the same Mona Lisa phase time and again: it never flows into retention as a nolonger 'now' phase. As Husserl remarks, "the modes of appearance are firmly shut off, no matter how they may run over into continuations by means of phantasy" (Husserl 2005: 537). Moreover, and unlike the perceptual awareness of time, there is no determinacy of earlier or later Mona Lisa phases: whether she appears the moment her smile no longer broadens, or whether she appears right before her smile broadens, cannot in principle be decided. And even if one were to say that the depicted 'now' "always already" represents temporality; however emptily, the problem remains that the time-phase of the image subject "is 'presented' as detached, and does not abide in time, and is not really an enduring phase" (Husserl 2005: 537). 
One conclusion to be drawn here is that the formal determinations of imageconsciousness and of time-consciousness which made it necessary to speak of an image temporality do not yet suffice to grasp it. For what these formal determinations emphasize is precisely the fact that the temporality of images does not compare to any perceived or purely phantasied duration. If there is time in images, it is certainly not a linear or sequential reconstruction of perceptual time. Thus, when Husserl says that "in the ordinary static image, which depicts by means of an unchanging image object, a movement might appear" (Husserl 2005: 489), it is clear that the latter apparition does not happen by an imposition of intuitive phantasy.

And yet, could one not claim that it is in this transition or passageway between phenomena and the possibility to phantasy along that an image time opens up to us - as a duration that cannot flow in a succession of phases, but cascades from image into phantasy daydreaming? Is this not what we mean by "almost seeing what is about to happen" or almost "seeing what comes from happening" without losing sight of the image now? Is it not precisely in the contracting interstice between a perennial 'now' and an evanescent phantasy temporality that we begin to suspect 'time' on the side of the image since the image, as it were, has begun to re-organize my awareness of its time?

\section{Aesthetics of Kairos and Nonintuitive Phantasy}

In the final part of this paper, I would like to propose that the awareness of the "right timing" of an image is a temporal awareness that an image triggers by intensifying the awareness of the depicted subject in a particular time-phase. And Husserl understands this particular intensification of the awareness of the object in a singular phase takes place, amongst others, in the context of aesthetic experience.

Husserl's comments on aesthetics are on the whole deeply influenced by the Kantian thesis of the disinterestedness of the judgment of taste (Husserl 2005: 145). And Husserl takes up this aesthetic disinterestedness in any case as a matter of abandoning the existential, natural attitude, so as to become attentive to aesthetic forms (Husserl 2004: 134). Whenever depictions are involved in aesthetic experience, however, we derive pleasure not only from how the image object renders the image subject, but also from how we become aware of the image subject as a depicted objectivity (Husserl 2005: 390). Concretely speaking, when I contemplate an artistic depiction I am moved, on one level, by a "maximum stock of sensuous moments and their particular combination” (Husserl 2005: 145). On another level, I am moved by "the clear awakening of the consciousness of the object" (Husserl 2005: 145). This consciousness of the depicted subject, even if 
not positing its existence, nonetheless co-excites to a degree the awareness of an object's function or purpose.

It is safe to say that for Husserl, an image's aesthetic satisfaction is more a matter of expressing than of impressing, and that aesthetic pleasure increases the more clearly recognizable the image subject appears - e.g., in a characteristic position - and the more keenly aware one is of what is happening to the depicted subject in the image world. In the example of looking at an ancient sculpture of an athlete, Husserl is struck by how nothing appears to be random or indifferent: "every nerve, every muscle" seems "attuned to action" (Husserl 2005: 146). We become aware not just of a thing, but more importantly, of the momentary tension between its "doing and suffering". And "[t]hat," says Husserl, "would be a beautiful aesthetic object: A pugilist or discus thrower who simultaneously has a stomachache" (Husserl 2005: 146).

So at first blush Husserl seems to merely suggest that from out of a possible series of objective temporal and spatial phases, the artist selects the one that is ostensibly most expressive. The viewer, in turn, contemplates the image in the awareness of its maximal expressiveness compared to other perceived or freely imagined objective phases. This contemplation of a subject in the manner of its representation is not, per se, an accomplishment of intuitive phantasy.

But Husserl's own aesthetic contemplation of the pugilist, and particularly of the athlete's unapparent inner struggles, rather reveals a deep imaginative engagement with the image world other than by phantasy continuations. It is clear that the viewer who experiences such things before the image has entered into a fictionalizing attitude that attentively responds to what is portrayed. ${ }^{2}$ When the observer takes on this phantasy "fictionalizing attitude," the appropriate timing of an image can dawn upon her as a temporalizing experience. And in the case of a "perfect timing of images," the viewer will be drawn towards the "image now" phase in its completeness to a degree that can even disengage further phantasy continuations.

Allow me to make clear the meaning of my previous statement by referring to Sigmund Freud's famous commentary on Michelangelo's Moses. As it is well known, Freud disagrees with commentators who take the Moses as appearing either at a moment of great anger or "on the point of leaping up from its seat and rushing away to create a disturbance"(Freud 1997: 220). Freud comments that

2 As Husserl remarks, "art is the realm of phantasy that has been given form, of intuitive phantasy, but also, in part, of non-intuitive [unanschaulicher] phantasy" (Husserl 2005: 514). On non-intuitive perceptual phantasy see Carreño (2013). 
at some point this, too, was his expectation, but he was disillusioned by the fact that in repeatedly visiting the statue of Moses at San Pietro in Vincoli, in Rome, he never had the impression that Moses was about to break into movement: "this Moses would remain sitting like this in his wrath forever" (Freud 1997: 221). The sculpture seemed to convey no particular movement or duration. But when Freud focuses on the way that the right hand of the Moses holds a lock of the beard, suggesting a retreating motion, he then completes "in imagination [...] the scene of which this movement, established by the evidence of the beard, is a part" (Freud 1997: 224). More precisely, Freud takes the Moses to appear at the end of the movement and point of completion: "what we see before us is not the inception of a violent action but the remains of a movement that has already taken place" (Freud 1997: 229).

Regardless of whether Freud's interpretation is persuasive, it seems to me to illustrate how the "right timing" of a depictive image operates. Clearly, Michaelangelo's Moses conveys a potent and vivid awareness of the subject in his doing and suffering. But one might fail to see the volume and point of expressiveness altogether by simply and intuitively fantasizing subsequent Moses phases. Having entered into the appropriate "fictionalizing attitude," the viewer might experience his temporal awareness of the image time undergoing a subtle re-organization, e.g., seeing the Moses in a now-phase as the culmination (and not as a beginning) of an event in phantasy time. That other temporal reorganizations are possible is already clear from Husserl's own example of the pugilist appearing like in media res. But the fact that some temporal re-organizations are more suitable than others is a matter settled by how the subject is rendered in the image now - and this is the difference that having a kairos ultimately makes. An image with a kairos gives what it represents as the fruit of a temporal unfolding to a subject that receives it as the seed of a unique aesthetic temporality unfolding in her.

\section{References}

Biceaga, Victor (2010): Picturing Phenomena: Husserl on Photography. Journal of the British Society for Phenomenology 41/1: 78-93.

Brough, John (2000): Plastic Time: Time and the Visual Arts. In: Brough, J. Embree, L. (eds.): The Many Faces of Time. Contributions to Phenomenology vol. 41. Dordrecht/Boston/London: Kluwer. 223-244.

Carreño, Javier (2013): The Many Senses of Imagination and the Manifestation of Fiction: A View from Husserl's Phenomenology of Phantasy. Husserl Studies 29/2: 143-162.

Claass, Arnaud (2014): Du temps dans la photographie. Paris: Filigranes. 
Drummond, John (2008): Historical Dictionary of Husserl's Philosophy. Lanham: Scarecrow.

Freud, Sigmund (1997): The Standard Edition of the Complete Psychological Works of Sigmund Freud. Vol. XII. Translated by James Strachey. London: Hogarth.

Lalande, André (1988): Vocabulaire technique et critique de la philosophie. Paris: PUF.

Husserl, Edmund (2005): Phantasy, Image-consciousness, Memory. Translated by John Brough. Dordrecht: Springer.

Husserl, Edmund (1994): Briefwechsel. Edited by Karl and Elisabeth Schuhmann. Dordrecht: Kluer.

Husserl, Edmund (2001): Logical Investigation. Vol. 2. Translated by J. N. Findlay. London: Routledge.

Rodrigo, Pierre (2009): L'intentionalité créatrice: Problèmes de Phénomélogie et d'Esthétique. Paris: Vrin. 
VISUAL RHETORIC, ICONOGRAPHY 

Petra Aczél

\title{
Rediscovering the Visual in Rhetorical Tradition: Persuasion as Visionary in Suasory Discourse
}

\begin{abstract}
The history of culture is in part the story of a protracted struggle for dominance between pictorial and linguistic signs [...] Among the most interesting and complex versions of this struggle is what might be called the relationship of subversion, in which language or imagery looks into its own heart and finds lurking there its opposite number.
\end{abstract}

(Mitchell 1986: 43)

Given the definition of imagery and language as an array of relationships, it might be easy to conclude that language and imagery are essentially the same.

(Fleckenstein 2002: 13)

\section{Introduction}

In recent years the struggle Mitchell points to has been tamed and transformed into a common academic interest blooming in accordance with the ubiquity of visual information in mediatized human communication. "The growth of scholarly interest in visuality marks a cultural reality: that images have become a predominant means of transmitting information in the 20th century and may be even more so in the 21st," Scott Heller emphasizes (1996: A8). Thus, there seems to be no more need to fiercely fight for the 'rights' of the pictorial in human cognition and communication. Without risking suspicion from academia, one can easily state that the visual plays a dominant role in sensing-cognizing the world, in constructing and concerting meanings, in human coexistence and communication. The prevalence of images has apparently won over the scepticism of science towards the non-verbal and thus we can claim that no thinking, learning and speaking is conceivable without the pictorial-visual taken into account.

Nevertheless, rhetoric, a faculty that has long been identified as organically verbal still owes a lot to the rediscovery of the visual. Although a noticeable paradigm of visual rhetoric (Helmer-Hill 2004) has been built upon the assumption 
that the lexicon of rhetoric is applicable to the pictorial, one may still doubt if this is the main visual potential the discipline of persuasive speech has. Rhetoric is at hand when the source of persuasion in pictures (structure, visual proofs, visual tropes) is to be explained; however, discussions of the visual within the rhetorical, and the visual drive of rhetorical force, stay disperse and remain non-mainstream.

The present chapter is one that endeavours to highlight rhetoric as visual (and not visual as rhetorical). Sixth in a line of discussing the visual capacity of rhetorical communication this paper focuses on persuasion as visionary in suasory discourse. Debated as it is, persuasion is at the heart of rhetorical practice. Though it has been "one of the great continuing mysteries of rhetoric and related discourses" (O'Keefe 2001: 575), we can state that persuasion manifests the capacity of communication to attract attention, move minds, evoke emotions, alter attitudes, facilitate actions, transform people and change situations. Its power has widely been attributed to either the rational (logos) or the emotional (passions) proofs. This misleading duality has led to the political suspicion toward and academic dismay of the non-argumentative rhetorical speech and the overestimation of cognitive thinking and speaking.

With a well-supported audacity we shall claim that behind rhetorical persuasion there is a non-abstract, sensual communicative existence to which visual is the source of knowledge, experience and expression. Founded in the culture of orality, rhetoric has an original connection to seeing. Rhetoric and the rhetorical style is persuasive because of its visionary - making audiences to see, to feel, to enact - potential that is rooted in the speaker's visual-sensual encounter with the world.

As the extensive analysis of rhetorical treatises of two millennia cannot be aimed at here, I limit myself to bring up some of the core ideas and terms justifying this claim. The quest for the visual in rhetorical persuasion will be pursued without chronological rigour - rather, with an eagerness to identify intellectual nods in classical and modern rhetorical tradition that can further center critical contemplations.

As part of a series dedicated to the topic, this present paper strives to highlight relevant elements of the rhetorical system after already having dwelt on ars memorativa (the semi-conventional, picture- and space-based system of remembering texts), phantasia (the inner sense of the speaker and the listener, that entails imagination, cogitation and memory), ingenium (the creative force in meeting, cognizing and expressing the world), enargeia (the energizing force that guide orators to create vivid descriptions and to make their audiences to picture what is said in order to persuade), ekphrasis (the rhetorical description that unfolds 
before the audience's eyes) and acumen (the sharpness in speech that represents and triggers sensual and cognitive discovery). Following the path into the treasury of visual tools in the garden of rhetoric, the function of wonder (thaumazein), the connection between the verbal and visual and between the visionary and the persuasive-charismatic will be investigated. Nota bene, this path sometimes leads us to the margins of rhetorical tradition, a place where logic is replaced with energy, the concrete is preferred over the abstract, and the verbal blends with the visual. It is a place where great authors and grand efforts (like Vico or Condillac) are wasted because of the domineering canon. This is what can make this quest even more invigorating, and hopefully, inspiring.

\section{Honeycomb}

Rhetoric, in the most general sense, can be regarded as a form of mental or emotional energy imparted to a communication to affect a situation in the interest of the speaker. [...] So understood, rhetoric is a feature of all human communication [...]. Even when thought of as the theory and practice of public address in a literate society rhetoric is not solely a western phenomenon. The earliest known rhetorical handbook is The Instructions of Ptahhotep, composed by an Egyptian official sometime before 2000 b.c.e.; it gives advice about how to speak and when to keep silent if brought before a judge or ruler. Some of what is said resembles precepts in the Old Testament, as in Psalm 16: "Pleasant speech increases persuasiveness [...] Pleasant words are like a honeycomb, sweetness to the soul and health to the body" (Kennedy 2007: 7).

Rhetorical language is bound to times, places and personalities; it is situational and subjective.

Working with images and metaphors, rhetoric "make[s] manifest," revealing relationships through sudden and ungrounded insight into the data, issues, and questions philosophy and science approach rationally. It supplies the inventive capacity rational language lacks, the "firsts" without which rational language cannot get under way. Rhetorical language therefore always has a priority "and provides that which deduction can never discover" (Grassi 2001: 97) -

as Crusius writes (Crusius 2001: xiv). Where does this non-deductive sweetness and primacy of words stem? Explanations of natural sign-relations and imitation suggesting that the word imitates (does not represent or describe) the world - offer an answer to this question, but not to the practice and the influence of the rhetor. How are the rhetorical attitudes, sensitivities and influences operated in order to create the non-abstract sensual experience, 'amazement', in order to move the audience? The key to this may be the 'wonder' gained by experience and through speech. 


\section{The Amazing}

By nature, all men long to know. An indication is their delight in senses. For these, quite apart from their utility, are intrinsically delightful and that through the eye more than the others. For it is not only with a view to action but also when we have no intention to do anything that we choose, so to speak, sight rather than all the others. And the reason for this is that sight is the sense that especially produces cognition in us and reveals many distinguishing features of things (The Metaphysics, 980a)

- as Aristotle posits in the famous introductory lines of The Metaphysics (980a). In her effort to base the sources of non-cognitive thinking, Hannah Arendt (1981:58) corrects the first English sentence in the paragraph saying that literally translated it would rather read: "All men desire to see and to have seen". Knowledge then emerges from seeing, from experiencing the world as it is given to the senses.

There is then an immediacy of seeing and being shocked by the world, a sublime trauma, a deep fascination that brings truth with itself. This truth is gained from experience from the world commonly inhabited, from common sense. It may not be irrefutable but is definitely speakable. This is the truth that stands at the roots of philosophy, of rhetorical persuasion and this is the truth gifted through thaumazein, wondering. Wonder is the initial shock of seeing something not yet revealed. It is the shock that arises tension and awakens attention; it is what marks the human encounter with the world. Grassi considers wonder of primary importance to the essence of philosophy and gives a brief explanation of how thauma (wonder) integrates seeing and learning:

The grammarian and lexicographer Hesychius gives in his lexicon the following synonyms for thauma: ekplexis (shock); xenisma (estrangement); and for thaumazein: theasthai (to look) and manthanein (to learn, to understand). [...] The etymological connection established both in antiquity and in modern times between thaumazo and theaomai points to the area in which the interpretation of the term thaumazein is to be looked for: on the one hand in 'seeing', and on the other in the domain of 'immediacy', which establishes the relationship between 'wonder' and 'emerging vision', already present in the prephilosophical use of the term thaumazein. [...] Questions arise only when something demands clarification, because uncertainty would be intolerable. In other words, we must find ourselves in the realm of an originary tension for our 'at-tention' to be awakened. That is why the estrangement referred to by Hesychius in his lexicon is related to shock (Grassi 1994: 5-6).

The wondrous emerges from the connection of events that are not in causal relation, but reveal an inherent, necessary affiliation. It occurs within the system of nature, and brings a surprising consequence with itself. The apparent coincidence, the correlation, the connection that is expressed in the thauma proves itself to be inevitable for the receiver. Mere chance which has no connection with preliminary 
and upcoming events is not wondrous, it has only a short-term effect of surprising us. True thaumaston rather puts us off our everyday experiences and thus awakens emotions. Surprise is swept off by these emotions and we come to the conclusion that 'this must be the way it is' (Simon 1999; Poulakos-Nathan 2012). Arendt comments:

In other words, what sets men wondering is something familiar and yet normally invisible, and something men are forced to admire [...]. The wonder that is the starting point of thinking is neither puzzlement, nor surprise, nor perplexity; it is an admiring wonder. What we marvel at is confirmed and affirmed by admiration which breaks out into speech [...]. In short wonder has led to thinking in words; the experience of wonder at the invisible manifest in the appearances has been appropriated by speech, which at the same time is strong enough to dispel the errors and illusions that our organs for the visible, eyes and ears, are subject to unless thinking comes to their help (Arendt 1981: 143-144).

Wonder sets up a cognitive chain that brings pleasure, passion and learning with it. Aristotle specifies the role of wonder among the aims of genres of speech in his Rhetoric.

And to learn and to admire are usually pleasurable; for in admiration there is desire, so the admirable is desirable, and in learning there is the achievement of what is in accordance with nature. [...] Since to learn and to admire is pleasurable, other things also are necessarily pleasurable, such as, for example, a work of imitation, as in painting and sculpture and poetry, and anything that is well imitated, even if the object of imitation is not in itself pleasant; for the pleasure [of art] does not consist in the object portrayed; rather there is a [pleasurable] reasoning [in the mind of the spectator] that "this" is "that," so one learns what is involved [in artistic representation] (On Rhetoric, 1371b).

The immediacy of wonder, its energizing (epistemological) force to discover the unrevealed and the urge to speak about it is what makes rhetorical speech "touching," "moving" and memorable. The classical orator had to have a general competency to apply the accumulated wisdom of the common culture to the particular case to move his hearers' minds and engage their passions (Halloran 1994: 331-332). The speaker acted in a known world where common sense prevailed over specialized knowledge and where the influence of the speech stemmed not from the actual newness of the information but from the act and expression of wonder with which a new connection between parts of the known could be shown.

Thauma and admiration, shock and discovery, fascination and learning have not failed to serve as the way the speaker can create a situational climate for a persuasive speech. That is, a rhetorical act, which - prior to rational argumentation - utilizes and displays the meeting of the verbal and the visual. 


\section{Visual and Verbal}

We might be able to disconnect image from language. We do this every night in our dreams. However, without language, we cannot do anything with that image except experience it. Imagery lives in the moment and ties us to that moment. To be tugged out of that moment, to be known as anything other than life as it is lived, we need language. Similarly, the process of naming, the meaningfulness of language, is predicated on the existence of imagery. Language that is disconnected from imagery loses its meaning (Fleckenstein 2004: 15).

The verbal and the visual thus are bound in meaningful expression, in rhetorical zooming on the situational and cultural at the same time. They are in kinship: inseparable and inevitable to invigorate the communicative situation. Nevertheless, there is a significant difference between language pairing or framing, recreating or governing the pictorial.

For the classical and renaissance-humanist period, textual vividness and verbal persuasion was embedded into the concerted dynamics of phantasia (imagination) and memory. Francis Bacon conceived of rhetoric as dependent on imagery and reassured that images are more memorable than words. For him, rhetoric's responsibility was

to second the judgments of the reasoning faculty by working on the imagination. If rhetoric is capable of seconding good and true judgment, then it cannot all be misrepresentative. A part of rhetoric's power, and indeed purpose, says Bacon, is to make the remote goods and natures that pure reason perceives appear to the auditor less distant, and thus it tries to overcome the more short sighted affections. Rhetoric, when supporting reason, knocks at the doors of the imagination [...] (Derrin 2013: 9).

Bacon defined rhetoric as "subservient to the imagination as Logic is to the understanding; and the Duty and Office of Rhetoric, if it be deeply looked into, is no other than to apply and recommend the dictates of reason to imagination in order to excite the appetite and will" (The Advancement of Learning Book IV, XVIII. 2.).

From the elements of elocution imitation and description are the best to demonstrate how humanist rhetorical practice translated the visual into the verbal. Imitation was the method with which visions would be encapsulated and imagination could be triggered within the schemata of description. Rhetorical descriptions intertwined the visual and the verbal just as it is elaborated by Henry Peacham's vivid paragraph (1593/1954):

Descriptio is a generall name of many and sundry kindes of descriptions, and a description is when the Orator by a diligent gatherin together of circumstances, and by a fit and naturall application of them, doth expresse and set forth a thing so plainly and lively, that it seemeth rather painted in tables, then declared with words, and the mind of the hearer 
therby so drawen to an earnest and stedfast contemplation of the thing described, that he rather thinketh he seeth it then heareth it.

Growing interest in textual description inspired by Pseudo Longinus' On the Sublime (around $100 \mathrm{AD}$ ) marked French and English belletristic rhetoric of the 18th century. Authors of the age favoured description as an important mode to imitate and capture the visible. Étienne Bonnot, Abbe de Condillac as a pedagogue, philosopher and rhetorician in his L'art d'écrire (1775, Of the Art of Writing, see the compilation of his Philosophical Writings 1982, 1987)

explained the differences between the visual and verbal in this way: The visual world is holistic and is seen instantaneously as a picture. Verbal language is linear, occurring sequentially in units over time. Language decomposes holistic reality, allowing writers to convey what is really seen out there in the world into the mind, where we can once again recompose it to represent the holistic world. It also analyzes that reality by breaking it into bits. For Condillac and others in French belles lettres, the most expressive text is one that tries to re-create this all at onceness - this powerful tableau effect of prelinguistic, visual thought. [...] Thus, the keys to the later process of translation from visual imagery to written text were memory and imagination, closely linked (Hobbs 2002a: 38-39, see also Hobbs 2002b: 111).

For the late humanist of the 18th century, Gianbattista Vico - who named Bacon as his main influence - speaking, language, history and social systems all started with the immediate and emotional experiencing of the world, that is, wonder which involved vision (and the senses). Human experience was apprehended by the power of imagination. Ingenium, ingenuity (Vico 1982: 69-70), the basic process to see and connect experiences - the capacity to invent, perceive relevant similarities, to make parts fit into the whole - was taught in the study of rhetoric. Thus language from its inception was metaphoric and imagistic and rhetoric as a mode of speech, primordial (Vico 1711-1741/1996; Grassi 1994).

In the later era of modernity, however, language seemingly trapped the visual: imagery could gain legitimacy only through language-based frames. Principles of language were and are to be applied to visual operations that are, by their nature, different from the verbal. This is one of the reasons why the visual in rhetoric has been defined as an expressive feature instead of a generative force. Overarching studies of tropes and figures (neo-rhetoric, Dubois et al.: Rhétorique générale, 1970/1981, see also Genette 1982) have limited and categorized the visual into style-formats and excluded it from ways of serious persuasion. The sharp distinction between the emotional and the rational eliminated the archaic storming of the visual and verbal and cut off sensual appeals from the branch of argumentative ones. Persuasive speech has been conceived of in terms of attitude, source, message, receiver and context factors, elaboration (O’Keefe 2002). Imagery as a 
persuasive force was almost exclusively paired with the operations of metaphor and the notions of 'visionary speech' has been reserved for cases to which the terminology of persuasion could not be applied.

\section{Visionary and Persuasive}

What one may miss from contemporary rhetorical theory she will easily find in leadership studies where studies that succeed to identify applicable tools and ways to the formation of great, charismatic leaders are of true significance. For the sake of the present discussion charisma of the leader (Weber 1947; Simonton 1988) can be considered as a complex of abilities (and a joint perception) that captivates and moves receivers to act in accordance with a vision the speaker holds.

House and Shamir (1993) examined eight theories of charismatic, visionary, and transformational leadership in order to clarify an overarching theory of charisma. Only one of 11 behavioural dimensions was represented in all eight theories: visionary behaviour, that is, the articulation of "an ideological goal [...], that emphasizes fundamental values such as beauty, order, honesty, dignity, and human rights" (House-Shamir 1993: 97; Emrich et al. 2001: 527). In terms of visual and visionary rhetoric this articulation is what turns out to be decisive. Visionary rhetoric is a discourse aimed to challenge the future and generate change persuasively. With its frame (expectations, norms, knowledge)-breaking and frame-realigning methods, visionary speeches paint the world and the future with words with lush, imagery-laden language. Persuasive as they are, they require elaboration; that elaboration occurs in terms of mental simulation of the situation being described by the content (Fauconnier 1994; Coulson-Oakley 2006).

Vision content research has investigated the effects of imagery-based versus concept-based contents. Assumptions have held that image-based (concrete, emotional) content tends to evoke emotional, while concept-based content tends to evoke cognitive (hot or cold systems, see Metcalfe-Mischel 1999) responses from receivers respectively [...]. Researches on the relation between charismatic leadership and imagistic speech have mostly framed their methods on the basis of either Martindale's Regressive Imagery Dictionary (1975), a content analysis coding scheme designed to measure primordial (associative, concrete) versus conceptual thinking (abstract, logical), or the Paivio, Yuille, Madigan noun pool (1968) or the Toronto Word Pool. All of these databases entail counts, lists and item value ratings that exhibit imagery- versus concept- and the concrete- versus abstract-based words. According to Emrich et al. (2001: 530) "the essential difference between these two types of words resides in the extent to which each arouses a sensory experience in the minds of listeners. Image-based words more easily 
evoke sensory experiences, whereas concept-based words appeal more strongly to listeners' logical interpretations".

The findings of studies investigating the correlation between successful, charismatic (presidential) leadership and the use of imagery (for example 'I have a dream' instead 'I have an idea') have consistently demonstrated that there is a significant positive relationship between the skillful use of imagery and leaders' ability to persuade people to accept and enact their visions, to be perceived and rated charismatic (Maranell 1970; Murray-Blessing 1994; Emrich et al. 2001; Naidoo-Lord 2008). Moreover, case studies (Willner 1984) and qualitative research that tested the effect of metaphor on presidential/leader charisma (Mio-Riggio-Levin-Reese 2005) further justified that speeches by leaders perceived as charismatic have a higher amount of metaphor density as opposed to non-charismatic ones. Consequently, charismatic leaders use metaphors as a rhetorical tool to inspire and motivate followers (Shamir 1995; Mio-Riggio-Levin-Reese 2005). These findings support the research of metaphors and metaphorical messages as persuasive tools. As metaphorical thinking may engage substantial image-based processes (Zaltman-Coulter 1995) metaphors can constitute intense (Hamilton-Stewart 1993) or vivid (NisbettRoss 1980) language which can arouse greater effect on the audience and lead to more persuasion (Siltanen 1981). Metaphorical messages are likely to produce greater attitude changes relative to their literal counterparts (Sopory-Dillard 2012).

As Emrich et al. assumed (2001: 529) "leaders who use words that evoke pictures, sounds, smells, tastes, and other sensations tap more directly into followers' life experiences than do leaders who use words that appeal solely to followers' intellects. By engaging followers' senses, not only their minds, leaders make their messages more immediate, real, and appealing to followers". The usage of imagebased rhetoric results in a vivid performance which has the capacity to grasp listeners' attention, facilitate their comprehension, evoke emotions and incite elaboration and motivate their memory.

Rhetoric that is crafted to be image-based, image-evoking, concrete is easier to process, to relate to and to interpret emotionally (Miller-Marks 1997) and to elaborate than its non-imagery counterpart. Vivid speakers seem and sound more active and dynamic and their audiences feel more inclined to judge them as competent and visionary.

As for stimulating memory processes: imagery produces superior memory for verbal material (Kieras 1978; Paivio 1986).

When a follower hears, comprehends, and is motivated to store in memory a leader's message, an image-based message will be stored in more "places" and in richer detail than a comparable concept-based message. Therefore, when it is time to act, followers will have 
greater success retrieving a leader's image-based than a concept-based message and will have on hand a richer, more detailed and, hence, potentially more instructive guide for action (Emrich et al. 2001: 533).

In short, research findings confirmed that messages of leaders/speakers are more influential when they are high, rather than low, in imagery; the speaker's ability to convey images in words plays a key role in visionary behaviour and that effects of imagery in speech positively correlates with persuasive communication and the perceptions of speakers as charismatic.

\section{Epilogue in Lieu of Conclusions}

The initial shock of experiencing what is unrevealed in the world, co-existence of the verbal and visual in thinking and speaking, the imitation of vision in words, and visionary oratory all belong to the tradition of rhetoric. However, the study of textual products and logical procedures has apparently overcome the consideration of visual processes in rhetorical speeches, leaving the faculty and its pedagogy without two of its most discerning characteristics: visual thinking and the sensualizing of language. Thauma, phantasia, ingenium, enargeia, charisma these constitute the vocabulary of visionary rhetoric, a mode of speech the usage of which could re-penetrate contemporary rhetorical theory - the lexicon of structure, logic, argumentation, style - in order to see clearer the function and influence of vision and imagery in persuasive communication. Sparkling ideas of theoretical forerunners and the strong body of research evidence support any scholarly ambitions which aim to dive for more visual in the rhetorical. The present chapter meant to be a humble contribution to further quests of the brave ones.

\section{References}

Arendt, Hannah (1981): The Life of the Mind. The Groundbreaking Investigation on How We Think: Thinking, Willing. Orlando, FL: Mariner Books.

Aristotle (2007): On Rhetoric: A Theory of Civic Discourse. New York: Oxford University Press.

Aristotle (1999): The Metaphysics. London: Penguin Classics.

Bacon, Francis (1998 [1605]): The Advancement of Learning. Renascence Editions (Online repository) 1861/1998.

Coulson, Seana - Oakley, Todd (2006): Purple Presuasion: Deliberative Rhetoric and Conceptual Blending. In: Luchenbroers, J. (ed.): Cognitive Lingustics: Investigations Across Languages, Fields and Philosophical Boundaries. Amsterdam: John Benjamins Press. 47-65. 
Crusius, Timothy W. (2001): Foreword. In: Grassi, Ernesto: Rhetoric as Philosophy. The Humanist Tradition. Carbondale: Southern Illinois University Press. xi-xix.

Derrin, Daniel (2013): Rhetoric and the Familiar in Francis Bacon and John Donne. Plymouth: Fairleigh Dickinson University Press.

Dubois, J. - Edeline, F. - Klinkenberg, J.-M. - Minguet, P. - Pire, F. - Trinon, H. (1970/1981): A General Rhetoric. Baltimore: The Johns Hopkins University Press.

Emrich, Cynthia G. - Brower, Holly H. - Feldman, Jack M. - Garland, Howard (2001): Images in Words: Presidential Rhetoric, Charisma and Greatness. Administrative Science Quarterly 46: 527-557.

Fauconnier, Gilles (1994): Mental Spaces: Aspects of Meaning Construction in Natural Language. Cambridge: Cambridge University Press.

Fleckenstein, Kristie S. (2002): Inviting Imagery into Our Classrooms. In: Fleckenstein, K. S. - Canderillo, L. T. - Demetrice, A. W.: Language and Image in the Reading-Writing Classroom: Teaching Vision. Mahwah, NJ: Lawrence Erlbaum Associates. 3-26.

Genette, Gerard (1982): Rhetoric Restrained. In: Genette, Gerard: Figures of Literary Discourse. New York: Columbia University Press. 103-126.

Grassi, Ernesto (1994): The Primordial Metaphor. New York: Italian AcademyBinghamton.

Grassi, Ernesto (2001): Rhetoric as Philosophy. The Humanist Tradition. Carbondale: Southern Illinois University Press.

Halloran, Michael S. (1994): On the End of Rhetoric, Classical and Modern. In: Enos, T. - Brown, Stuart C. (eds.): Professing the New Rhetorics. A Sourcebook. Boston: Blair Press. 331-343.

Hamilton, Mark A. - Stewart, Becky L. (1993): Extending and information processing model of language intensity effects. Communication Quarterly 43: 231-246.

Heller, Scott (1996): Visual Images Replace Text as Focal Point for Many Scholars. The Chronicle of Higher Education 1996, July 19, A.8. Online: http://chronicle. com/article/Visual-Images-Replace-Text-as/93993.

Helmer, Marguerite - Hill, Charles A. (eds.) (2004): Defining Visual Rhetorics. Mahwah, NJ: Lawrence Erlbaum Associates.

Hobbs, Catherine L. (2002a): Learning From the Past: Visual Literacy in Early Modern Rhetoric and Writing Pedagogy. In: Fleckenstein, K. S. - Canderillo, L. T. - Demetrice, A. W. (eds.): Language and Image in the Reading-Writing Classroom: Teaching Vision. Mahwah, NJ: Lawrence Erlbaum Associates. 27-44.

Hobbs, Catherine L. (2002b): Rhetoric on the Margins of Modernity: Vico, Condillac, Mondboddo. Carbondale, IL: Southern Illinois University Press. 
House, Robert J. - Shamir, Boas (1993): Toward the Integration of Transformational, Charismatic, and Visionary Theories of Leadership. In: Chemers, M. Ayman, R. (eds.): Leadership: Perspectives and Research Directions. New York: Academic Press. 81-107.

Kennedy, George A. (2007): Introduction. In: Aristotle: On Rhetoric: A Theory of Civic Discourse. New York: Oxford University Press. 1-25.

Kieras, David (1978): Beyond pictures and words: Alternative information processing models for imagery effects in verbal memory. Psychological Bulletin 85/3: 532-554.

Maranell, Gary M. (1970): The Evaluation of Presidents: An Extension of the Schlesinger Polls. Journal of American History 57: 104-113.

Metcalfe, Janet - Mischel, Walter (1999): A Hot/Cool-System Analysis of Delay of Gratification: Dynamics of Willpower. Psychological Review 106/1: 3-19.

Miller, Darryl W. - Marks, Lawrence J. (1997): The Effects of Imagery Evoking Radio Advertising Strategies on Affective Responses. Psychology and Marketing 14: 337-360.

Mio, Jeffery Scott - Riggio, Ronald E. - Levin, Shana - Reese, Renford (2005): Presidential Leadership and Charisma: The Effects of Metaphor. The Leadership Quarterly 16: 287-294.

Mitchell, W. J. T. (1986): Iconology: Image, text, ideology. Chicago: University of Chicago Press.

Murray, Robert C. - Blessing, Tim H. (1994): Greatness in the White House: Rating the Presidents. University Park, PA: Pennsylvania State University Press.

Naidoo, Loren J. - Lord, Robert G. (2008): Speech imagery and perceptions of charisma: The mediating role of positive affect. The Leadership Quarterly 19: 283-296.

Nisbett, Richard E. - Ross, Lee (1980): Human Inference: Strategies and Shortcomings of Social Judgement. Englewood Cliffs, NJ: Prentice Hall.

O'Keefe, Daniel J. (2001): Persuasion. In: Sloane, Thomas O. (ed.): Encyclopedia of Rhetoric. New York: Oxford University Press. 575-583.

O'Keefe, Daniel (2002): Persuasion. Theory and Research. Thousand Oaks, CA: Sage.

Paivio, Allan U. (1986): Mental Representations. New York: Oxford University Press.

Peacham, Henry (1954 [1593]): The Garden of Eloquence. Gainesville, FL: Scholars Facsimiles \& Reprints. 
Philosophical Writings of Etienne Bonnot, Abbe de Condillac (1982, 1987). Edited by F. Philip and H. Lane. Book 1-2. New York: Lawrence Erlbaum AssociatesPsychology Press.

Poulakos, John - Crick, Nathan (2012): There is Beauty Here, Too: Aristotle's Rhetoric for Science. Philosophy and Rhetoric 42: 295-311.

Shamir, Boas (1995): Social Distance and Charisma: Theoretical Notes and an Exploratory Study. The Leadership Quarterly 6: 19-47.

Siltanen, Susan A. (1981): The Persuasiveness of Metaphor: A Replication and Extension. Southern Speech Communication Journal 47: 67-83.

Simon, Attila (1999): A csodálkozás és a csodálatos: Az arisztotelészi Poétika thaumaszton-fogalmának antropológiai vonatkozásai. Gond 18-19: 83-104.

Simonton, Dean K. (1988): Presidential Style: Personality, Biography and Performance. Journal of Personality and Social Psychology 55: 928-936.

Sopory, Pradeep - Dillard, James Price (2002): Figurative Language and Persuasion. In: Dillard, J. P. - Pfau, Michael (eds.): The Persuasion Handbook. Developments in Theory and Practice. Thousand Oaks, CA: Sage. 407-426.

Vico Selected Writings edited and translated by Leon Pompa (1982). Cambridge: Cambridge University Press.

Vico, Giambattista (1711-1741/1996): The Art of Rhetoric. Amsterdam: Rodopi.

Weber, Max (1947): The Theory of Social and Economic Organizations. Translated by A. M. Henderson and T. Parsons. New York: Free Press.

Willner, Ann R. (1984): The Spellbinders: Charismatic Political Leadership. New Haven, CT: Yale University Press.

Zaltman, Gerald - Coulter, Robin H. (1995): Seeing the Voice of the Consumer. Metaphor-based Advertising Research. Journal of Advertising Research 4: 35-51. 



\section{Timothy Barney}

\section{The Rhetorical Lives of (Cold War) Maps}

The September $17^{\text {th }}, 1951$, issue of Time magazine featured a peculiar and striking image over a two-page spread - a map of the sprawling Soviet Union. The map reveals a network of red circles, shaded areas, and pink hammer-and-sickle icons dotted all over the topography of a stark gray and white Soviet landscape, each indicating the location of "Gulag" system prison camps. The accompanying text in Time tells a story of the map's provocation of an incident between the U.S. and the Soviet Union at the 1951 San Francisco conference to inaugurate a Japanese peace treaty. Here the "Gulag-Slavery, Inc." map became a cartographic weapon when Missouri's Congressman O.K. Armstrong walked up to Soviet Deputy Minister of Foreign Affairs, Andrei Gromyko, and asked him if he wanted to see a map of Russia. "I'd be delighted," said Gromyko. Unfolding the map, Armstrong helpfully explained: "It happens to contain an accurate portrayal of every slave labor camp in the Soviet Union". Gromyko blinked at the map, mumbled "No comment," and handed it to an aide who tossed it into the aisle. Indeed, below the imposing map are before/after-style photos of the "incident" - on the left, we see Republican Rep. Armstrong unfolding the map before a sitting Gromyko; on the right, we see a stone-faced Gromyko staring ahead, as the map sits beside him on the floor of the conference room (News in Pictures 1951:28-29).

Of course, the Armstrong-Gromyko exchange can be added to a long list of the minor anecdotes in the history of chilly, Cold War diplomatic relations. Yet, a deeper exploration of this map reveals a compelling case about both the strategic and ideological functions of mapping. Before the map became a kind of diplomatic prank in the hands of Congressman Armstrong, it began as a collaboration in a global labor research project between the AFL-CIO and the United Nations Economic and Social Council, authored by a Russian emigrant ghostwriting journalist, underwritten by the CIA, and publicized internationally by The Voice of America radio. The many uses and appropriations of the piece has led to its citation as "one of the most widely circulated pieces of anti-Communist literature" (Young 1958: 601).

In this era, maps were constantly appropriated, debated, revised, and reappropriated. Cold War maps lived; they were active and malleable documents. Such a seemingly, bi-polar, universal, and fixed conflict as the Cold War required immense work to maintain an image of fixity. Maps, thus, had to continually 
reproduce and maintain the essential artifice of the conflict. Bruno Latour has written of the concept of "immutable mobiles," in which a visual image of scientific data is frequently seen as a fixed and finished product, hence immutable, yet at the same time an image that is constantly moving and reproducible for a multitude of contexts (Latour 1990: 26). A map has an age-old power, then: to appear as an unimpeachable representation of the world, while its easy usability makes for a remarkable flexibility in what it can offer its users (Raffestin 2000: 9). The hardened lines between the U.S. and the Soviet Union (and by extension America's allies and satellite adversaries in its so-called "spheres of influence" across the globe) may appear immovable and essential on Cold War maps; however, the hardening of these lines only comes from the maps' ability to draw and be drawn into the active construction of the Cold War.

These active constructions can be traced through a specific, critical approach to analyzing cartography. A map possesses what I would call a "rhetorical life". In other words, a map has a particular lifespan in which it exists as a communicative practice, as it works through the intersections of public and private spaces, institutional and popular contexts, and artistic and scientific modes of collection, synthesis, and expression. By noting the concept of a rhetorical life, though, I am not concerned with some kind of defined origin point or "end of life" death moment for a map. Such points are always debatable and shifting, depending upon context - and therein lies the point: a map is never a finished product (Hartnett 1998: 287-288). Rather, the notion of a map's "rhetorical life" merely points to how a map reflects and shapes its multitude of contexts, as it lives and functions as a usable, material document (see also Certeau 1984: 121). Finding the connections, say, between the production techniques of a map, and the ways in which that map is re-used and re-copied allows us to keep the business of cartography properly historicized and dynamic across wide expanses of time (Pickles 1992: 219-220). Cara Finnegan has written of the "eventfulness" of visual images, specifically photographs, wherein the meaning-making of an image stems from the contexts of its production, the details of its composition, and the movement of that image through the complex contexts of its immediate reproduction, its circulation, and in the variety of responses from audiences (Finnegan 2010:251). For the lives of Cold War maps, we can similarly trace the residues of a map as it moves through the culture, and how it assumes a diversity of particular roles for its users.

The concept of a rhetorical life emphasizes the engagement of a map with its immediate context, but also with other Cold War artifacts. Denis Wood and John Fels have argued that the map continually advertises itself to be taken authoritatively, and that advertisement takes the form of a paramap. The paramap is a 
construction that goes beyond the map itself and includes all of "the verbal and other productions that surround and extend" a map's presentation (dedications, inscriptions, epigraphs, prefaces, notes, illustrations) (Wood-Fels 2008: 8-9). In addition, the paramap includes all of the elements not just appended to the map, but circulating in the social space around the map (advertisements for the map, reviews, production information); for Wood and Fels, "ultimately it is the interaction between map and paramap that propels the map into action" (Wood-Fels 2008: xvi). What this approach seeks to prove is that a map is never just a map, but a confluence of social forces that constrains a culture's sense of its relationship to, and in, the world. Maps are central, then, to a concept prevalent amongst geographers and historians, of a "geographic imagination" where cultures obtain and circulate geographic knowledge. ${ }^{1}$

The idea of the paramap can extend to how mapping is described and accounted for by its practitioners and circulators. Shawn Parry-Giles has emphasized the need to examine not only the public discourses of the Cold War, but also the need to evaluate and weigh the covert actions and motives of its powerful actors (Parry-Giles 2002: 183-186). How these agents, often behind-the-scenes, actually talk about and conceive of their roles and their messages reveal the very fluidity and the constructed nature of the Cold War, as well as what kinds of collaborations and contestations brought certain ideologies forward while relegating others to the background. Map producers and users wrote and spoke often about the role of space and how geopolitics positioned the United States in particular ways, and thus that "cartographic talk" is as important as the maps they accompanied. While the finished displays of Cold War maps often rested upon an aura of "truth" and objective detachment so common to scientific work of the era, the producers and users of maps showed a remarkable understanding of how maps could be molded to create very specific visions and advance complex arguments (Harley 2001: 37; Pickles 1992: 219).

This kind of movement of a map through Cold War culture, as well as the ways in which cartography is contested and debated by its users, is borne out through examples like "Gulag-Slavery, Inc." Across an enlarged Russian Caucasus was a rash of red dots indicting what Soviet officials were denying in international media. This AFL map is certainly important for how its visual codes and symbols politicize the space of the Soviet Union as a landscape of secrecy and oppression;

1 Derek Gregory has provided a full theoretical treatment of this "geographic imagination" concept (Gregory 1994). Another rich historical application of these notions can be found in Schulten 2001. 
yet, adding to the map's display on the page is its provenance and its remarkable life as an active, evidentiary weapon. The Gulag map was a collaboration between popular journalists, the State Department, and an AFL looking to strengthen its anti-communist credentials. And the map arrived in a political culture rife with Holocaust memory and visuality as well as with the charged discourse of "slavery" against ideological foes. Lawmakers quickly adopted the map as an icon for hardline anti-communism, American teachers used the map to teach current affairs in classrooms, overseas labor unions circulated the map to their "brothers" to protest working conditions, and official Soviet reaction to the map (in charged diplomatic exchanges and even in seizures of it on the streets of Eastern Europe) brought out the hostility against Western propaganda.

Other examples from the period offer intertextual support to the "life" of the Gulag map. Also in 1951, the American Geographical Society, through sponsorships from Army and Navy research grants as well as major pharmaceutical companies, embarked ambitiously on a project to map current knowledge of diseases and health epidemics such as polio, malaria, yellow fever, even starvation. The resulting Atlas of Disease produced an influential series of innovative, detailed maps between 1950 and 1955 that showed a world filled with parasitical invaders. ${ }^{2}$ Particularly during a tumultuous period of decolonization, the Atlas of Disease visualized the so-called "three worlds" that theorists and practitioners of development and modernization were using to "bring up" the "diseased" sub-equatorial nations. But, again, more than mere visualization, the lives of the Atlas of Disease maps showed the active movement of cartography into Cold War spaces: used by corporations such as Pfizer to develop international markets where its drugs could yield the best profits, brought into the Army to study the viral encephalitis that U.S. troops in Korea were suffering from, re-drawn in Congress to support funding and expansion of the Mutual Security Act, and used to study where "advisers" could safely tread in Vietnam.

Despite their different aims, the Gulag map and the Atlas of Disease maps are united in the ways they fuse institutional and popular discourses together, and in the ways that their eventful rhetorical lives made them usable, material documents. Both also intersect with the immensity of Cold War state power in the United States as they reify the importance of spatial perception in defining American interests vis-à-vis the Soviet Union and the so-called rest of the world.

2 These materials are collected in the Jacques May Papers Collection and the American Geographical Society Medical Geography Archives at the American Geographical Society Library (AGSL), University of Wisconsin-Milwaukee. 
The Gulag map served to edify the stark lines of the East/West dichotomies of the early post-World War II era, while the Atlas of Disease foreshadows the ways in which new North/South dichotomies would come to constrain the decolonizing Cold War landscape and America's increasingly intervening hand. Such rhetorical lives even show the kind of important conversations that maps, in a sense, shared with other maps. At one point, for example, the producers of the Atlas of Disease consulted with the leaders of the American Federation of Labor and their Gulag map data to pinpoint where the Soviet government was holding its prisoners, in order to plan their own map of human starvation. ${ }^{3}$ Even small connections like these create a tangible sense of a wide cartographic scope that encompassed the Cold War and the compelling ways that American officials and other prominent institutions were dependent on particular cartographic perceptions of the world.

Cases like these affirm that cartography, and by extension, the production of Cold War space, was above all, a practice. The "production of space" is often a term that is invoked vaguely - an idea easier to theorize about in the abstract than it is to see in everyday interaction. And yet, as geographer Jouni Hakli notes, "cartography offers a productive momentum to political practices"; in other words, the relevance of maps is based on the "immutability in the relationships that maps establish between cartographic representation and the world of practice within which they emerge" (Hakli 2009: 28).

Maps like the Gulag project, for instance, reveal what geographer Trevor Barnes and others have called the "mangle" of collaborations and competitions between the foreign policy institutions of the executive branch of the U.S. government, the defense apparatuses of the armed forces, private and independent organizations such as the AFL, the popular journalism at outlets such as Time, and even supranational powers like the United Nations (Barnes 2008: 7). Common amongst these groups was the impulse to work out the spatial parameters of what exactly the Cold War was, and how it should be, or should have been, fought. And while the rhetorical presidencies of central figures such as Truman and Eisenhower remain vital to Cold War study, as does the critique of its famed architects like George Kennan and Walt Rostow, one of the best ways to trace Cold War space is to follow its mid-level bureaucrats, practitioners, and policymakers who were actively writing world space and circulating geographic visions (this approach is modeled in Farish 2010).

3 Specifically, this information is archivally drawn from: Letter From A. Larkin to Jacques May, 22 June 1953, Folder 1: Plates 8 and 9, Correspondence 1952-54, Box 3, Series 1: Professional Records, 1943-1960, Jacques May Papers, AGSL. 
To take Bruno LaTour too far, though, is to see maps as actually immutable; rather, the perception of maps as immutable is what powers cartography. Maps are fundamentally insecure.

Rob Kitchin and Martin Dodge express that a map is:

[...] brought into the world and made to do work through practices such as recognizing, interpreting, translating, communicating, and so on. It does not re-present the world or make the world (by shaping how we think about the world); it is a co-constitutive production between inscription, individual and world; a production that is constantly in motion (Kitchin-Dodge 2007: 335).

Maps, then are "always mapping," attempting to appear representative, and this process is what makes maps so dynamic in Cold War culture (Kitchin-Dodge 2007: 337).

Thus, from the origins of particular Cold War maps and their techniques of production and data management into their appropriated usages and diverse interpretations by sometimes competing and sometimes collaborating Cold War institutions and audiences - the story of how the U.S. mapped itself and the world in the second half of the twentieth century is a vital story about the synthesis, the framing, and above all, the practice and the movement of America's international power. For geographers Denis Wood and John Fels, to map is to claim that "this is there" - and America required images of strength and commitment in maps to legitimize its self-interest as commensurate with the interests of the rest of the world, and for those images to have productive (and inevitably contentious) lifespans across a wide array of contexts (Wood-Fels 2008: xvi).

\section{References}

Barnes, Trevor J. (2008): Geography's Underworld: The Military-Industrial Complex, Mathematical Modeling and the Quantitative Revolution. Geoforum 39: 3-16.

Certeau, Michel de (1984): The Practice of Everyday Life. Translated by Steven Rendall. Berkeley: University of California Press.

Farish, Matthew (2010): The Contours of America's Cold War. Minneapolis: University of Minnesota Press.

Finnegan, Cara (2010): Studying Visual Modes of Public Address: Lewis Hine's Progressive-Era Child Labor Rhetoric. In: Parry-Giles, Shawn J. - Hogan, J. Michael (eds.): The Handbook of Rhetoric and Public Address. Malden, MA: Wiley-Blackwell. 250-270.

Gregory, Derek (1994): Geographical Imaginations. Cambridge, MA: Blackwell. 
Hakli, Jouni (2009): Mapping Politics. Political Geography 28: 335.

Harley, J. B. (2001): The New Nature of Maps: Essays in the History of Cartography. Edited by Paul Laxton. Baltimore: Johns Hopkins University Press.

Hartnett, Stephen (1998): Michel de Certeau's Critical Historiography and the Rhetoric of Maps. Philosophy and Rhetoric 31: 283-302.

Kitchin, Rob - Dodge, Martin (2007): Rethinking Maps. Progress in Human Geography 31: 331-344.

Latour, Bruno (1990): Drawing Things Together. In: Lynch, Michael - Woolgar, Steve (eds.): Representation in Scientific Practice. Cambridge, MA: MIT Press. 19-68.

N.A. (September 17, 1951): News in Pictures: Gulag-Slavery, Inc. Time. 28-29.

Parry-Giles, Shawn J. (2002): The Rhetorical Presidency, Propaganda, and the Cold War, 1945-1955. Westport, CT: Praeger.

Pickles, John (1992): Texts, Hermeneutics, and Propaganda Maps. In: Barnes, Trevor J. - Duncan, James S. (eds.): Writing Worlds: Discourse, Text \& Metaphor in the Representation of Landscape. London: Routledge. 193-230.

Raffestin, Claude (2000): From Text to Image. Geopolitics 5: 7-35.

Schulten, Susan (2001): The Geographical Imagination in America, 1880-1950. Chicago: University of Chicago Press.

Wood, Denis - Fels, John (2008): The Natures of Maps. Chicago: University of Chicago Press.

Young, William R. (1958): Gulag-Slavery, Inc.: The Use of an Illustrated Map in Printed Propaganda. In: Daugherty, William E. (ed.): Psychological Warfare Casebook. Baltimore, MD: Johns Hopkins University Press. 597-601. 

Orsolya Endrődy-Nagy

\section{Paintings and Illuminated Manuscripts as Sources of the History of Childhood: Conceptions of Childhood in the Renaissance}

\section{Opening Remarks. Aims of the Research}

"The history of childhood" refers to a discipline, including Renaissance views on children, children's lives, and child-rearing practices, as well as their environments and surroundings changing over time (from past to present). Paintings and other visual documents from this time could help us interpret childhood and the world of children from their perspective. This article will introduce the aims of a study and doctoral thesis, and review the possible iconographical, semiotic, visual anthropologic and visual sociological picture analysis methods of pedagogical research. The goal of the thesis is to describe how the conceptions of childhood changed in a specific period during the 15 th and 16th centuries. Why did we choose 1455-1517? It is important to understand how the inventions of printing and the Reformation affected the way of thinking about child-rearing practices. The doctoral thesis was published by Eötvös Publishing House in 2015, and will hopefully help other researchers to understand the problems parents faced in part of the Renaissance era.

The goals of the research are the following:

1. To introduce possible visual analysis methods for qualitative research methodology.

2. To introduce new sources for history of childhood and education - such as old-prints (incunabuli), woodenblock-prints and illuminated manuscripts.

3. To understand conceptions of childhood within a special era, specifically Late Renaissance narratives about childhood.

Why did we consider part of the Late Renaissance (1455-1517) as a possible era of such research? We wished to understand how the inventions of printing and the Reformation affected the way of thinking about child-rearing practices. The importance of these decades in art history is also considered very high: painters such as Mantegna or Dürer used a special viewpont, analysed the human body, observed anatomy, applied the Golden Section, used new colors and techniques. In the Christian canon, the theories changed from Christ as a human to Christ as 
a child. There is a gap in the secondary sources of history of childhood regarding the following theoretical works: Shahar (2000), Pollock (1983), Heywood (2001), Cunningham (2005) and Szabolcs (1995). Some of the secondary sources end the Renaissance era in 1500 . We will examine some decades earlier than 1500 as a starting point of "modern" history.

\section{Theoretical Framework}

This is an interdisciplinary study, containing communication and visual studies, history of art and iconography, history of education, with history of childhood and sociology. There are however some more possibilities, for example psychology, demography, ethnography, and anthropology.

\subsection{Theoretical Issues on the History of Childhood}

According to Colin Heywood, there is a definition of childhood - it is an abstraction, referring to a particular stage of life, which changes over time and varies between social and ethnic groups within any society. Historians wish to recreate the day-to-day experiences of children in the past. This is the social history of children (Heywood 2001). At the end of 1970 most historians agreed that the history of childhood was a history of progress, and that the conditions of children had improved over time. The first work of this paradigm - Centuries of Childhood was from the French philosopher, Philippe Ariès. He represents this progress by comparing and contrasting the present to the past centuries. The other theoretical work about the history of childhood is Lloyd DeMause's work, called: The History of Childhood (DeMause 1974). The central tenet of this book is the psychogenetic interpretation of history; the subtitle of this work - The Evolution of Parent-Child Relationships as a Factor in History - represents this concept as well. DeMause periodised parent-child relations in six modes (Szabolcs 1995; Pukánszky 2001).

The British historian Edward Shorter published his thesis Good Mothering is the Invention of the Modern, which shows us, for example, the practice of not sending children off to a wet-nurse, which had been common in the past. Ariès, DeMause and Shorter had one thing is common - they believed that there had been over time major changes in the attitudes and treatment of childhood. A new paradigm by Linda Pollock was published in Forgotten Children: Parent-Child Relations from 1500-1900 (Pollock 1983). Pollock made a systematic study of diaries and autobiographies in Britain and North America concerning child-rearing between 1500 and 1900. She pointed out in this research that lower class child-rearing practices did not differ fundamentally from upper-class practices (Cunningham 2005: 9). 
Shahar disproved the previously popular thesis that medieval infant mortality rates caused the parent's lack of love for their children, assumed to be less loving than modern parents. There were some different child-rearing practices, however; some elements are part of our views nowadays too. According to his research which was published in his second book, Children in the Middle Ages - the child's world was deeply integrated to adult's lives (Shahar 2000).

We must not compare present childhood conceptions to the past ones using the modern perspective. We have to accept the mentality of the time, as we must, for example, with medical practices of the specific era. Sociologists James and Prout (James-Prout 1997) published their theory about childhood as a social construction. The new paradigm is potentially fruitful for historians. If we analyse paintings with iconographic methods, we can see children as social actors. Paintings could help us to assess the interpretations of childhood and the world of children. Hendrick pronounced the child as a social actor (Hendrick 2000) so I will use this term in my analysis. We should never compare children to adults, yet they are social actors too.

To conclude this theoretical schema, we can say that the narrative of childhood can be seen in many different ways, such as our specific conception of childhood. We will not, however, state an unequivocal global conception of childhood (Szabolcs 2004).

\subsection{Paintings and Photos as Sources of Interpreting Childhood}

It is possible that paintings could influence child-rearing practices and theories of children and childhood. If paintings are considered a type of media, and media had similar roles in people's lives as today, then paintings could have such effects on people's way of thinking. In order to observe this idea, we analysed over a hundred Italian, French and Dutch paintings, illuminated manuscripts and old-prints from fifteenth to sixteenth century.

Flemish artworks were satirical representations of peasant lifestyle and everyday life. Dutch colors are vivid, and the technique is meticulous. Flemish painters observed every detail precisely. Italian painters, on the other hand, used their works to demonstrate their own education, knowledge of theological discourse and philosophy; they were proud of their virtuosity in technical issues, such as Andrea Mantegna's innovations on perspective. Mantegna became a master of realistic figure depiction too (Turner 2000: 281).

The inventors of oil paintings were Flemish brothers: Hubert and Jan van Eyck. At both parts of the Low Countries you can see an intimate atmosphere in the pictures. We must note the reinvention of the female portrait tradition in the Mona 
Lisa by Leonardo, which is the visual representation of the living soul, and which has entered every viewer since (Sperling 2003: 51). The art of Michelangelo and Raffael perform as the examples of intellectually complex puzzles for scholars.

A lively exchange between north (Flemish masters) and south (Italian masters) got under away. Rogier van der Weyden visited Rome in 1450; Antonello da Messina united Italian and Flemish traditions, since he studied in the Netherlands and later worked for the court in Naples. Late Gothic forms in paintings such as elongated figures, sculptural modelling and vibrant lively lines were dominant in both areas, e.g. Benozzo Gozzoli and Sandro Boticelli in Italy, Hugo van der Goes in the Netherlands. The display of Hugo van der Goes's Portiniari Altarpiece in Florence in 1483 was a milestone (Turner 2000) (Figure 1).

Figure 1: Portiniari Altar by Hugo van der Goes, Uffizi, Florence, oil on wood, (c. 1475), $253 \times 586 \mathrm{~cm}$
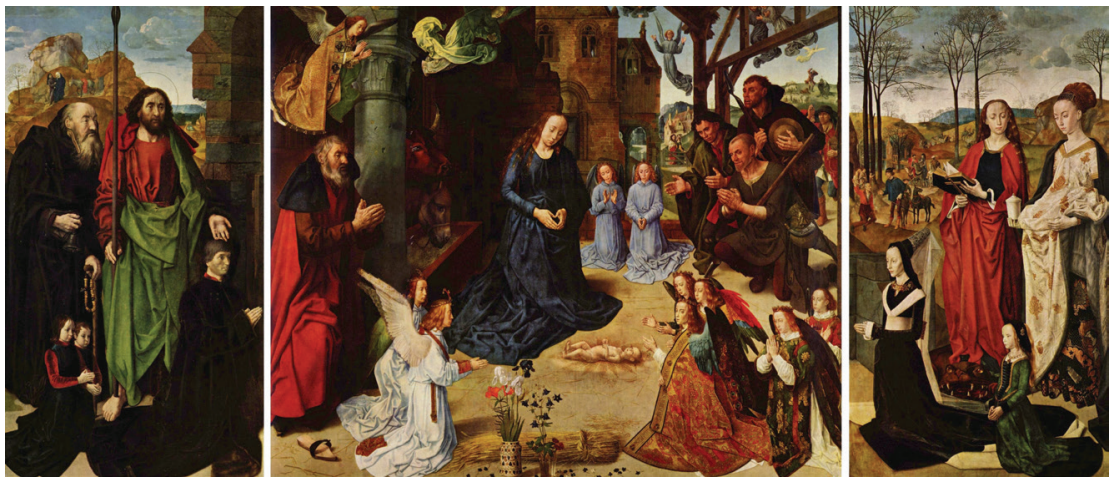

\section{Introduction of the Research Methods and the Sources}

"Images are helpful for what they tell us about educational situations, breaking the prevailing silence regarding the specific character of educational and child rearing processes, they also seek to convey an educative message in themselves" (Depaepe 2000: 15). Kress and Leuween declared in their book Reading Images (Kress-Leuween 2006) that social relations can be encoded in images. It is often said that the producer and the viewer differ in a fundamental aspect: the producer is active, while the viewer is passive. The articulation and understanding of social meanings in images derives from "face-to-face" interaction; the spatial positions allocated to different kinds of social actors in the interaction (Kress-Leuween 2006: 116). Pictures have the capacity to convey information that cannot be coded 
in any other way (Nyíri 2009). Sources can be any kind of document within the presence of a human being: written words, photos, artefacts and oral testimonies. I analyze paintings, manuscripts, incunabulis (old-prints) and wooden-block prints, using qualitative analysis methods such as semiotics, iconography, visual anthropology and visual sociology.

Iconography is originally a sub-discipline of art history, which concerns itself with the subject matter or meaning of works of art (Panofsky 1972: 3). Iconography as a research method derives from this branch of art history and other visual arts (Géczi 2010). Erwin Panofsky, who published his theory about image analysis and influenced iconographical studies for decades, declares the stages of the iconographical analysis for the history of art. This iconographical analysis is based on three phases of the reception of an image. The acts of interpretation are the pre-iconographical description, the iconographical analyses, and the iconographical synthesis (deeper analyses). Iconographical analysis is dealing with images, instead of motifs (Panofsky 1972: 3-33). In order to understand the meaning of the painting for another discipline, such as history of childhood, we need to find another analysing process of images.

Although this research is focusing on paintings, old-prints and woodenblock prints, it is very important to mention Mietzner's and Pilarczyk's thesis about categorization and classification. Their theory is based on photo analysis; however, it is a handhold for the paintings too. Mietzner and Pilarczyk have analysed more than 10,000 educational photos so far. They understood the deeper meanings of images which represented educational interactions or child-rearing processes in wider contexts (Mietzner-Pilarczyk 2005). There is a visual analysing method invented by a French researcher called Bouteaud (1989), and this method focuses on the technical information of each picture. A serial visual anthropologic method invented by Collier (2010) could be fruitful for researchers, who need a comparison method for pictures with similar topics. This paper is an introduction of a possible analysis method based on the methods mentioned above.

The topics of the selection of the pictures is based on Heywoods' paradigm about the themes of the Renaissance conceptions of childhood: child-birth, the life of new-born babies, mortality (Heywood 2001). It is followed by one more topic which was absent from Heywood's paradigm: the games or toys of children. 


\section{Sample Picture from the Research}

Figure 2: Andrea Mantegna, Madonna with Sleeping Child, 1465-70, Tempera on canvas, $43 \times 32 \mathrm{~cm}$, Staatliche Museen, Berlin

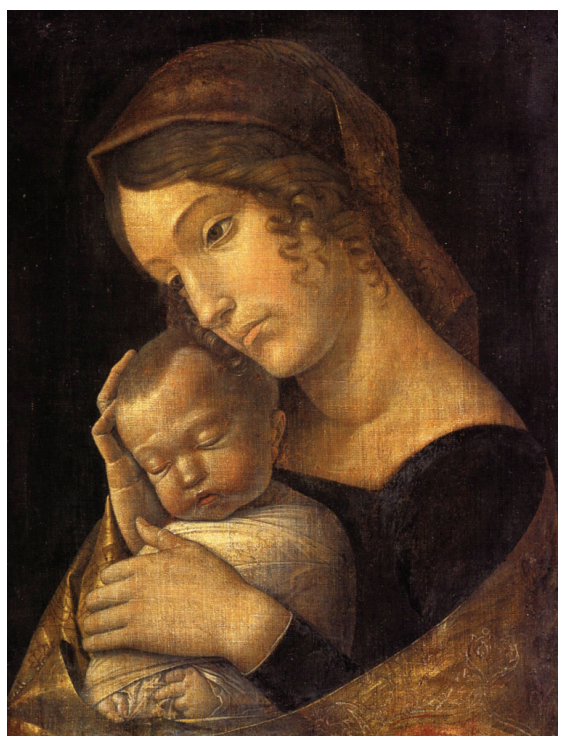

\section{Classification (Figure 2)}

1. Date: circa $1465-70$.

2. Place: Italy, Mantua

3. Authorship: Andrea Mantegna

4. Use: It was an altarpiece.

Mary looks extremely young in this painting. Their clothes could be similar to the gowns they wore in this decade. Jesus' tight swaddling-clothes were typical of this time period. Jesus' body looks babyish; however, his face looks much older (late adulthood). The goal of the painting was to show the virginity of Mary. Mary expresses fear and protection with the gesture of both hands. We can see

1 We would now like to mention the most important museums and libraries where the research took place: The Bibliotheca Communale dell' Archiginnasio, Bologna; The Biblioteque Denis-Diderot, Lyon; The Semmelweis Museum of Medical History, Budapest; The Library of Congress, Washington DC; The Museum of Fine Arts, Budapest; Albertina, Wien. 
love, tenderness and anxiety in her eyes. Since she cradles the sleeping baby, she is protecting him. Her brooding gaze suggests a presentiment of some kind. She will hold her son for the last time as Pieta, later. The tenderness of Madonna might catch our glimpse. We could wonder about the relation of mother and child. Whether the childhood mortality rate was high or not, mothers loved their children as much as they do nowadays. Child-rearing practices were based on love and harmony.

\section{Results of the Research}

Using qualitative analysis methods such as semiotics, iconography, visual anthropology and visual sociology, children can be seen as wondering, nosey, playful human beings in the Renaissance Era, between 1455-1517 in Europe. Using microhistorical perspectives we can understand several more situations, and aspects of everyday life and mentality.

The conclusions and tendencies are the following:

The love of the mother towards their children contains the attitude of fear. The value of the life of the children is above the value of the mother's life. They baptised their newborns as early as possible. Children's games were as important then as they are today, or even more important. Breast-feeding is more important and more common regarding the pictures, than we expected.

The most interesting topic is the swaddling-tight, which began disappearing from paintings in the 1480s. It would be interesting to examine these traditions with a wider basis of visual sources focusing on the Northern or Southern part of Europe.

Regarding the analyzed pictures, the children received more attention than their mothers. For example, while we have no evidence of the bathing traditions of the mothers, we could find a wide range of pictures of bathing children. The representation of Death could be grotesque, fatal or ludicrous, because of the powerlessness regarding the high ratio of mortality.

To look into the Renaissance paintings, manuscripts, old-prints and woodenblock prints - using my iconographic method, we could see conceptions of the childhood of the Renaissance era. However, children were much more vulnerable than today, they learned to live dealing with mortality. They baptised their newborns as early as possible. Children's games were as important as today or even more important. Using microhistorical perspectives we explored several situations and aspects of everyday life and mentality. 


\section{References}

Boutaud, Jean-Jacques (1989): Application des recherches en iconographie publicitaire á la pédagogie de l'expression en I.U.T. Lille 3, France: ANRT.

Collier, Malcolm (2010): Approaches to Analysis in Visual Anthropology. In: van Leeuwen, Theo - Jewitt, Carey (eds.): Handbook of Visual Analysis. Los Angeles - London - New York: Sage.

Cunningham, Hugh (2005): Children and Childhood in Western Society since 1500. Harlow, UK: Pearson Ed. Ltd. (Longman firm).

DeMause, Lloyd (1974): The History of Childhood. New York: The Psychohistory Press.

Depaepe, Marc - Henkens, Bregt (2000): The History of Education and the Challenge of the Visual. Paedagogica Historica 36.

Géczi János (2010): A szocialista nevelésügy két képi hangsúlya. Iskolakultúra 1: 79-91.

Hendrick, Harry (2000): The Child as a Social Actor in Historical Sources - Problems of Identification and Interpretation. In: Christianssen, Pia - James, Allison (eds.): Research with Children: Perspectives and Practices. Oxon: Routledge Falmer, Taylor \& Francis Group. 36-57.

Heywood, Colin (2001): History of Childhood. Malden, USA: Blackwell Publishers. James, Allison - Prout, Alan (1997): Constructing and Reconstructing Childhood: Contemporary Issues in the Sociological Study of Childhood. London Washington, D.C.: Falmers Press, Taylor \& Francis Group.

Kress, Gunther - Leeuwen, Theo van (2006): Reading Images, The Grammar of Visual Design. London - New York: Routledge, Taylor \& Francis Group.

Mietzner, Ulrike - Pilarczyk, Ulrike (2005): Methods of Image Analysis in Research in Educational and Social Sciences. In: Mietzner, Ulrike - Myers, Kevin - Peim, Nick (eds.): Visual History, Images of Education. Bern: Peter Lang. 109-129.

Nyíri, Kristóf (2011): Gombrich on Image and Time. Journal of Art Historiography 1: 9-32.

Panofsky, Erwin (1979): Studies in Iconology, Humanistic themes in Art of the Renaissance. Oxford, UK: Westview Press. 3-33.

Peim, Nick (2005): Introduction: The Life of Signs in Visual History. In: Mietzner, Ulrike - Myers, Kevin - Peim, Nick (eds.): Visual History, Images of Education. Bern: Peter Lang. 7-35.

Pollock, Linda (1983): Forgotten Children: Parent-child relations from 1500 to 1900. Cambridge: Cambridge University Press.

Pukánszky, Béla (2001): A gyermekkor története. Budapest: Műszaki Kiadó. 
Shahar, Shulamith (1992): Childhood in the Middle Ages. New York: Routledge. Sperling, Lynda Joy (2003): Famous Works of Art in Popular Culture. A Reference Guide. Westport, Connecticut, London: Greenwood Press. 50-67.

Szabolcs, Éva (1995): Fejezetek a gyermekkép történeti alakulásából. Budapest: ELTE BTK Neveléstudományi Tanszék.

Szabolcs, Éva (2004): „Narratívák” a gyermekkorról. Iskolakultúra 3: 27-31.

Turner, Jane (ed.) (2000): From Renaissance to Impressionism, Styles and Movements in Western Art, 1400-1900. The Grove Dictionary of Art. Macmillan. 277-288. 

Online Visuality 

Krisztina Szabó

\section{Digital and Visual Literacy: The Role of Visuality in Contemporary Online Reading ${ }^{1}$}

\section{Introduction and Background}

Discussing the notion of contemporary online reading in the new media age, it is clear that the shift from printed to online is not just a change of instruments or data media, but also text comprehension. In connection with the latter, we usually come up against the problem of visuality. The line between textuality and visuality seems to blur, their traditional hierarchical order is gradually disappearing, and the problem of reading literacy and its surveys become more complicated. It is obvious that the enormous amount of visual elements which turn up in almost every online text have a significant role in the reading processes. But what is this "significant role"?

In my paper, beginning with this question, I will focus on the role of visual elements in online texts. I will state that visual elements have at least an equal or even dominating role over text in the online reading processes.

In the time of the so-called new media age, many questions are raised concerning the constantly changing way of reading, originating from the issue of the digital devices that have come into use, that can easily substitute for printed books and newspapers. While there are debates and predictions about the future of books and reading itself, more and more attention is being turned to the nature of reading literacy (Ulin 2009; Fekete-Hegedüs-Kis 2010; Cull 2011; Rich 2008; Dougherty 2011). Researchers have the assumption that new types of reading devices contain new types of texts that needs new types of reading skills and methodology (Smolin-Lawless 2003; Coiro-Dobler 2007; Walsh 2010; Murnane-Sawhill-Snow 2012). The shift from printed to digital is so significant that it is better to narrow the focus and talk about digital literacy as a new field of understanding reading.

However, "digital" is not the only essential feature of the issue, but also the online space as well, that lets us wander from one text to another throughout a web

1 This ongoing research is conducted in the framework of Integral Argumentation Studies, OTKA - K-109456 at the Doctoral School of Philosophy and History of Science, Budapest University of Technology and Economics.

Special thanks go to János Tanács $\mathrm{PhD}$, István Danka $\mathrm{PhD}$ and all colleagues at the Department of Philosophy and History of Science, Budapest University of Technology and Economics, who helped me with their professional advice during my research. 
of links. The shift from printed to online is not just a change of instruments or data media (like the ones from papyrus to paper, scroll to newspaper and book, or book to e-book), but also a significant change of comprehending texts, hence a distinction has to be made between digital (offline) and online reading. During online reading, we meet special and, in some ways, new types of text, a kind of visualized hypertext. The line between text and visuality, or text and pictures, seems to blur, and their traditional hierarchical order (in texts the written enjoys priority over pictures) is disappearing (Kress 2003; Youngs-Serafini 2011). Thus, in this paper I am focusing on the role of visuality in contemporary online reading. I state that visual elements, especially pictures, are neither just illustrations nor just explanatory additional elements, nor secondary qualities beside texts, but they have at least an equal, or even dominating role, over text in the online reading process.

In order to confirm my hypothesis, I will discuss the complex connection between online and offline reading and visuality, showing the role of images in the reading process and focusing especially on online reading. My aim with this research in the long run is to help create and develop online reading literacy surveys of PISA (Programme for International Student Assessment), by making the methodological framework more adequate. In 2018, reading literacy will be the major domain of the surveying process, till then both the actual framework and terms should be updated. ${ }^{2}$

\section{About the Complex Connection between Reading and Visuality}

Before turning to the role of visual elements in the online reading processes, we should examine the issue of offline reading, too. The whole topic of literacy tradition, from picture reading to picture books, comic books, illustrated workbooks, etc., is so diversified and concerns such a wide range of scientific fields that it goes beyond the scope of this essay. The present focus is on the nature of text itself that originally has a sort of visuality. The "[...] name for a group of signs is text - a collection of signs which organized in a particular way to make meaning. The meanings made will depend on which signs are brought together, and how they are arranged in relation to one another" (Schirato-Webb 2004: 8). The fact that reading is to comprehend signs - which are visual elements with special characteristics such as font style, size and arrangement - means that the whole reading process is subordinated to visuality (Figure 1 and 2).

2 For more details and critics about the PISA-subject see my previous articles: Szabó $2014 ; 2015 a$. 
Figure 1: A sample list of fonts installed with Microsoft Windows Vista and Windows 7

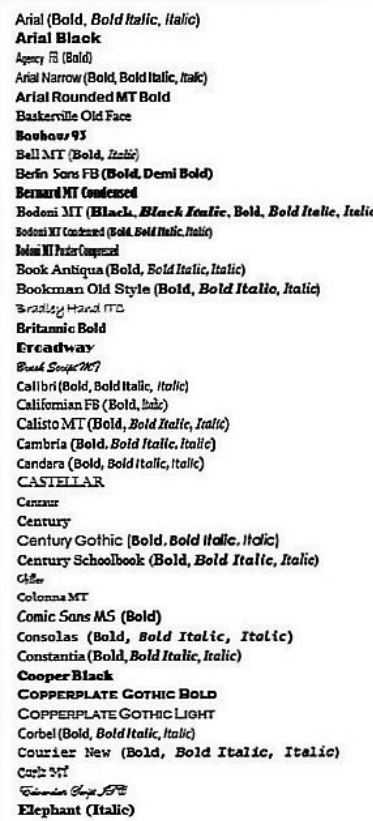

EraxBold ITC (Demi, Eas Light, Eras Medium)

Euphemia

FEIXIIING

FootlightMrT Light

Forte

Franklin Gothic (Book, Bookitalic, Demi, Demi Cond.

Frankdin Gothic Medium (tralic)

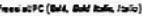

fimpist

ID

Gubiols

Gramond (Bold, Itefif)

Georgia(Bold,BoldItaEkc,Italic)

givi

Gill Sans MT (Bold, Bold Itrolic, halic, Condeased, in (ntoud the

Gill Sans MT (Bold, Bold Irobic, halic, Co

Cloutesta KI Eun Condeased

Goudy Old Style (Bold, Iratic)

GOUDY STOUT

Bellensthweler

Horrington

High Tower Text (Italic)

tmpaet

Imprint MT Shatow

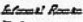

Jokernan

idanir

Kristen ITC

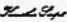

Lucida Bright (Italic, Demibold Demibolditralic

Lucida calfigrapfiy

Lucida console

Lucida Fax (tralic, Demibold, Demibold ftalic)

Lucida ftandwruting.

Lucida Sons (Demibold Roman, Demibold

italic)

Lucida Sans Typerriter (Bo7d)

Mapreater

Maiandra GD

Matum MV7 Seripe Capitale

MicrosoftSans Serit
Motul

Sodem Xa 20

Momotye Conita

Ixpre

lizpratit

Nyals

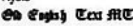

mi

Pansor

Palatino Linotype (Bold, Bold Itelic, Italic)

Papyrus

Papetua (Bold, Bold Itolic, behte)

PERPETUA TITIINGMIT (BOLD)

Plantagenet Cherokee

Fath

Poor Richard

OWing

Raavi (Bo/d)

Reavie

Rockwell (Bold, Bold Italic, Italic)

Rechell Casdiased (Bold)

Rockweul Ixtra Bold

Sotpt.1L T Dald

Segoe Print (Boid)

Segoe Script (Bold)

Segoe UI (Bold, Bold htalic, trolic, Light, Semibold)

sHoweapd COTHC

Snop ITC

STEXCII

Sylfaen

Tahoma (Bold)

Tempus Sans ITC

Times New Roman (Bold, Bold Italic, ftalic)

Trebuchet MS (Bold, Bold Italic, Italic)

TW Con MT (Bold, Bolditolic, It dic)

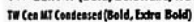

Verdana (Bold, Bold Itallic, Italic)

Viner Hand ITC

Qrade

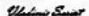

piaciatin

(source: W1)

Figure 2: Example for font-arrangement

warm chewy
gingerbread man,
made in some oven
while lying in a pan.
people are waiting
to eat his hand.
why is it they will
ostly nibble on his limbs?

mostly nibble on his limbs? wondering just what he'd done to them? this punishment is a bit harsh it seems

only just for giving them oh, such tasty dreams. children all begging

they want to taste too.

be sure there's enough

if it's the last thing that you do. more are waiting cut them out fast, although we try $\mathrm{Im}$ pretty sure they're not

(source: W2) 
Even so, normally we think on the contrary, and make a distinction between text built up by words, built up by letters and other additional visual elements (for e.g. pictures). We are proud to say that we are over the ages of picture-reading and we do not need any visual help for comprehending a text (see the practice of European education starting from recognizing pictures [signs] and aiming to read long texts fluently; Youngs-Serafini 2011; Adamikné 2006; W4). In this sense visual elements only illustrate texts, and complete and explain the meaning of words, if necessary. If it is not, never mind: a well-written text is thought to be understood without any visual support. Thus, in traditional reading, a literacy survey's text is at the centre, and readers should be able to separate the text (to be read as a task) from its context and comprehend it on its own sake.

This process becomes much more problematic if we would like to survey the reading methods of picture books, workbooks or comics - in these cases we deal with multimodal texts. It means a triple signal system: written language/text, picture/visual elements and a "third quality" (Youngs-Serafini 2011; Szabó 2015b), the latter connecting the two previous levels. In these cases visual elements give meaning and drive the reader's attention, so there is an interplay between texts and visual elements (Szabó 2015c). At this point, the clear distinction between text and context, text and visual elements fails, and the problem of reading literacy and its surveys become more complicated. Now, suffice to say that the role of visuality in reading literacy is quite important even in the case of offline texts. In the next section I will turn to online texts and the role of visuality in the online reading process.

\section{Online Reading and Visuality}

In online reading the online text itself is visual. But this implies there to be a different and more complex phenomenon compared to the case of printed texts. An online text is built up from characters (which we can also call signs) and "multiple communication modes" visual elements, for instance image, audio and video. They "are governed by distinct logics [which] change not only the deeper meaning of textual forms but also the structure of ideas, of conceptual arrangements, and of the structures of our knowledge" (Kress 2003: 16, in Weasenforth 2006: 1). This statement underpins the necessity of my previous distinction between digital and online reading: the latter means not just a medium-shift but also a text-comprehending issue. "The world told is a different world to the world shown" (Kress 2003: 1). Writing is for "to tell" while visual elements (for instance images) are for "to show" (Kress 2003). The main difference between them is that "[...] writing [...] is governed by the logic of time and by the logic of sequence and its elements in time, in temporally governed arrangements" (Kress 2003: 1). 
Contrarily, "the organization of image is governed by the logic of space and by the logic of simultaneity of its visual/depicted elements in spatially organized arrangements" (Kress 2003: 1). However, I must disagree - even in the special case of printed picture books, workbooks and comics. Take the latter as an example: in comic books, pictures are also governed by the logic of time, they are in temporally governed arrangements whereas they are also governed by the logic of space. And the same phenomenon could be easily noticed vice versa. The issue is the same in the case of the online version of picture books, workbooks and comic books (Youngs-Serafini 2011). Take an average text on the Internet rather than these specific types of texts. The label "average" is problematic; there are debates on the question of what it means to be a "text" in the online space (Cull 2011; Bolter 2001; Szabó 2015c; Dyson-Kipping 1998). This vagueness is rooted exactly in the nature of visuality that interweaves the online contents. An online text is more than a digitalized version of an offline text, because the online nature of it essentially modifies its reading, meaning and comprehension. Researchers call these "hypertexts," which are "linked to each other with hyperlinks so we can easily switch and jump between them, like in a kind of eternal, never-ending and always refreshed text" (Szabó 2015c: 171). Hypertexts, also because of the online space, naturally "live together" with visual elements. This connection could be so complex that sometimes it is difficult to decide what is related to the main text, and what is just an additional illustrative or design element or a supporting icon of the digital device. This could be a problem for instance in online literacy surveys: if we do not have exact notions about the texts that are to be read, then we will easily conclude inappropriate results about readers' skills and the reading process as well.

However, this should not be too surprising: if the connection between an offline text and visuality is so strong and complex, then it should be at least the same in the case of online texts, too. It is vital to emphasize that the observation of online texts should start from the thought which discusses texts and visual elements as interplay and a sort of interlock. Thus, texts and visual elements in the online space are at least not subordinated but they supplement each other. As we will see in the next section, visual elements have a much stronger and inevitable role in online texts and online reading comprehension.

\section{The Special Role of Visual Elements in Contemporary Online Reading}

Researchers investigating the nature of online text comprehension regularly indicate the following observations. First, defining online text is problematic because of the strong presence of visuality. Second, visual elements significantly influence 
and modify the meaning of a text, thus we should examine the mutual effects of texts and visual elements on each other in online reading processes (Szabó 2015c). Above, I have already shown that visual elements, both in the case of printed and online texts illustrate, complete and explain the main text - on the first level of comprehension. Furthermore, they give meaning to the texts and drive the reader's attention during the reading process. In short, there is interplay among the text and visual elements. Now, I claim that visual elements have at least an equal or even a dominant role over text in the online reading processes. Visual elements do not just support comprehension, but dominate or even replace online texts. "[R]eaders' imagination is a matter of ordering elements in contrast to filling traditional text with meaning. [...] readers do fill images with meaning also" (Weasenforth 2006: 27). Moreover, "images are plain full of meaning, whereas words wait to be filled" (Kress 2003: 3). Thus, "the conceptualization of textuality is changing as images seem to dominate text and as screen overtake paper [...]" and "writing becoming subordinated to the logic of the visual" (Kress 2003: 5). This is a cardinal change in comparison to traditional theories about printed texts, claiming the dominance of texts over visual elements. In this sense we could talk about the rediscovery of the visual.

It is time to reflect on the topic called visual literacy. Visual literacy is the "ability to decode, interpret, create, question, challenge and evaluate texts that communicate with visual images as well as, or rather than, words. Visually literate people can read, interpret the purpose and the intended meaning, and evaluate the form, structure and features of the text. They can also use picture and word images in a creative and appropriate way to express meaning" (Carry n. a.: 13). This definition is based on a theory implying that "picture books, magazines, newspapers, advertisements and films create meaning through shape, line, colour, actions, eye paths and angles" (W3:3). Thus, here again, the main issue is the role of visual elements embedded into some kinds of texts. The connection between text and visual is so strong that in some cases - e.g. in online reading - the text is subordinated to the visual. To be "[...] able to make sense of what we see in images and understanding how these pictures relate to the writing associated with them" (W3:2) is the main issue of visual literacy - and online reading literacy, as well.

There is continuity in the printed - digital - online reading triad and visuality has its own important, variant and intensifying role in every step of this path. Focusing on online reading, the special role of visual elements could be the following (Figure 3). 
Figure 3: The role of visual elements in online reading

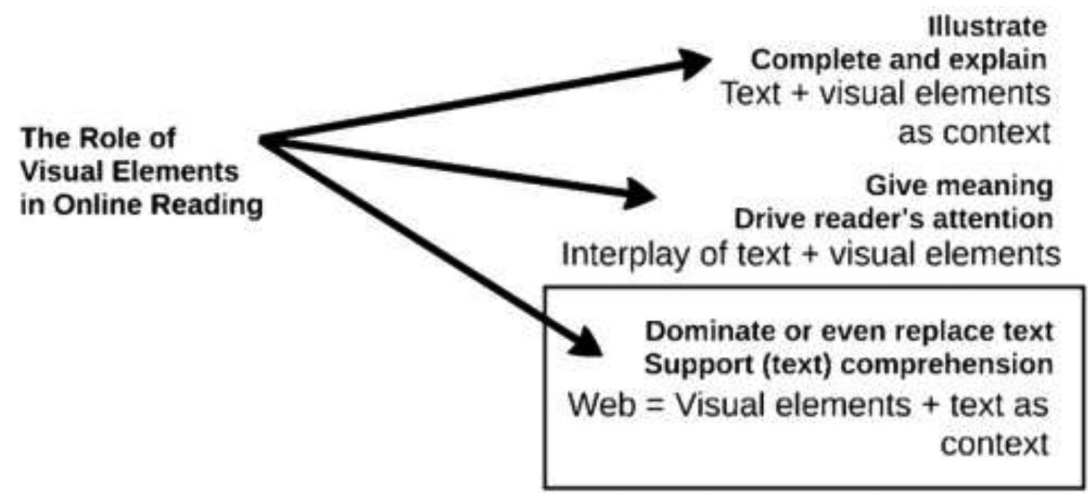

(source: image created by the author)

With this we have returned to the question of what it means to be "text" in the online space. With taking the notion of visual text we get an even more complex picture, where we should take the following features into consideration as well (Figure 4).

Figure 4: The complexity of visual texts

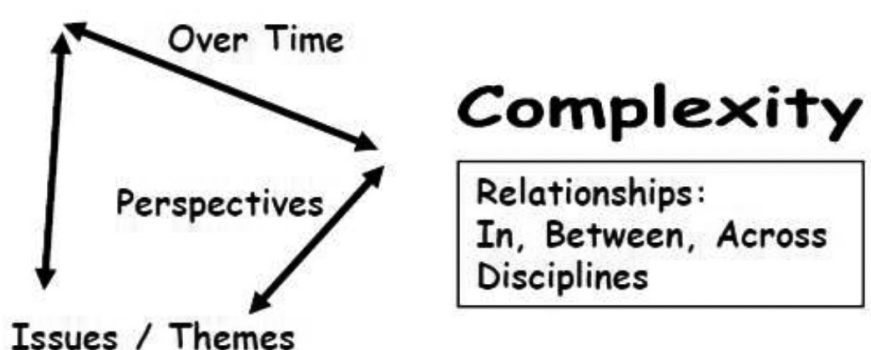

(source: Carry n. a.: 8)

According to the above, the answer would be: online text is like the web itself. It is a sort of content composed from text (characters, words, sentences) and visual elements (pictures, images, graphics, etc.). With this definition, the already fuzzy concept of online text comprehension may become even more complex, but it could serve as a step forward to get a better understanding on online reading literacy. 


\section{Conclusion}

In my paper I focused on the special role of visuality in the online reading process. I claimed that visual elements are neither just illustrations, nor just explanatory additional elements nor secondary qualities beside texts, but they have at least an equal or even a dominating role over text in online reading processes. First, to support my hypothesis, I separated the notions of printed, digital and online reading from each other and then I examined the connection between offline reading and visuality in the traditional sense. Second, I discussed the role of visual elements in the case of printed text and online texts as well as visual texts, and referred briefly to some special cases, too. I demonstrated on three levels that visual elements have three important roles in online texts and - contrary to traditional views - texts do not dominate the visual anymore. Moreover, visuality has gained dominance over text in the online space, and it is better to talk about texts as webs or contents which built up from characters and visual elements.

This shift in the hierarchy of texts and visual elements is so significant that it basically modifies and influences online reading and text comprehension - thus we should take it into account in contemporary reading literacy research and surveys as well.

\section{References}

Adamikné Jászó, Anna (2006): Az olvasás múltja és jelene. Budapest: Trezor Kiadó. Bolter, Jay David (2001): Writing Space: The Computer, Hypertext, and the Remediation of Print. Second edition. Mahwah, NJ, London: Lawrence Erlbaum.

Carry, Diana Dumetz (n. a.): Visual Literacy: Using Images to Increase Comprehension. https://readingrecovery.org/images/pdfs/Conferences/NC09/Handouts/ Carry_Visual_Literacy.pdf.

Coiro, Julie - Dobler, Elizabeth (2007): Exploring the Online Reading Comprehension Strategies Used by Sixth-Grade Skilled Readers to Search for and Locate Information on the Internet. Reading Research Quarterly 42/2: 214-257.

Cull, Barry W. (2011): Reading Revolutions: Online Digital Text and Implications for Reading in Academe. First Monday 16/6. http://firstmonday.org/ojs/index. $\mathrm{php} / \mathrm{fm} /$ article/view/3340/2985.

Dougherty, William C.(2011): The Book is Dead, Long Live the Book! Managing Technology. http://www.sciencedirect.com/science/article/pii/S0099133311001959.

Dyson, Mary Clare - Kipping, G. J. (1998): Exploring the Effect of Layout on Reading from Screen. In: Hersch, Roger D. - André, Jacques - Brown, Heather (eds.): Electronic Publishing, Artistic Imaging, and Digital Typography. Seventh 
International Conference on Electronic Publishing: Proceedings. Berlin: Springer. 294-304.

Fekete, Márton - Hegedüs, Nikolett - Kis, Andrea (2010): A megváltozott olvasás. Szkholion 2010/2: 72-80.

Kress, Gunther (2003): Literacy in the New Media Age. London: Routledge.

Murnane, Richard - Sawhill, Isabel - Snow, Catherine (2012): Literacy Challenges for the Twenty-First Century: Introducing the Issue. The Future of Children 22/2: 3-15.

Rich, Motoko (2008): The Future of Reading. Literacy Debate: Online, R U Really Reading? Series-NYTimes.com. http://www.nytimes.com/2008/07/27/ books/27reading.html.

Schirato, Tony - Webb, Jen (2004): Reading the Visual. Crows Nest: Allen \& Unwin.

Smolin, Louanne Ione - Lawless, Kimberly A. (2003): Becoming Literate in the Technological Age: New Responsibilities and Tools for Teachers. The Reading Teacher 56/6: 570-577.

Szabó, Krisztina (2014): A digitális szövegértés felmérésének kihívásai. Megfontolások a PISA-tesztek módszertani fejlesztésével kapcsolatban. In: Csiszár, Imre Kőmíves, Péter Miklós (eds.): DOSZ. Tavaszi Szél 2014 Konferenciakötet. IV. Debrecen: Doktoranduszok Országos Szövetsége. 429-438.

Szabó, Krisztina (2015a): A digitális szövegértés felmérése. A 2009-es PISA-teszt definíciós problémái. In: Schaub, Anita - Szabó, István (eds.): IDK 2014 Pécs Konferenciakötet. Pécs: Pécsi Tudományegyetem Doktorandusz Önkormányzat. 537-548.

Szabó, Krisztina (2015b): Digital Literacy: Is Digital Reading Similar to Comic Reading? Opus et Educatio 2/1: 48-56.

Szabó, Krisztina (2015c): Digital Reading and Text Comprehension: Comic Reading as a New Metaphor for Digital Reading. In: Beseda, Jan - Machát, Zbynek (eds.): DisCo 2015. From Analog Education to Digital Education. 10th Conference Reader. Prague: Center for Higher Education Studies. 167-178.

Ulin, David L. (2009): The Lost Art of Reading. Los Angeles Times. http://articles. latimes.com/2009/aug/09/entertainment/ca-reading9.

Walsh, Maureen (2010): Multimodal Literacy: What Does it Mean for Classroom Practice? Australian Journal of Language Literacy 33/3: 211-239.

Weasenforth, Donald (2006): Review of Literacy in the New Media Age. Language Learning \& Technology 10/2: 25-28.

Youngs, Suzette - Serafini, Frank (2011): Comprehension Strategies for Reading Historical Fiction Picture Books. The Reading Teacher 65/2: 115-124. 
$\mathrm{W} 1=$ A sample list of fonts installed with Microsoft Windows Vista and Windows 7. http://ptgmedia.pearsoncmg.com/images/chap3_9780789749550/ elementLinks/03fig23_alt.jpg (Figure 1).

$\mathrm{W} 2$ = Example for font-arrangement. http://mrfletcher.weebly.com/shape-poems. html (Figure 2).

W3 = Every Picture Tells a Story. Accessing Visual Text. https://dei.eduone.net.au/ projectresources/media/AccessingVisualTextFinal.pdf.

W4 = Módszertani kézikönyv a magyar nyelv tanitásához az 1. osztályban. 2009. http://www.szmpsz.sk/szmpsz/hir/2009/0902_abeceskonyv/metodika.pdf. 


\section{Gergely Havasmezői}

\section{Images in the Hungarian Online News}

\section{Visual Elements in the New Media}

The traditional, illustrative role of images in journalism is changing. "Digital media environments usually demand from the journalist to combine and mix text, images, video, audio and other visual graphics [...]," states Fondevila-Gascón et al. (2013: 1). This fits into the much debated thesis of the "pictorial turn": that images (again) take more important roles in our communication. "People first think in images, only later in abstract words," states Kristóf Nyíri (2000). "The ratio of the images is increasing on the internet and in the printed press (e.g. in the tabloid press) too. Pictorial communication is turning quotidian," writes Ágnes Veszelszki (2008).

All these permit online organs to use visual elements more boldly and in new roles. The online audience got used to images appearing as self-standing contentual elements - that is, images carry decodable meaning independently of the text, and they contribute to the content of the article equally with the text. Infographics, which speeds up information processing by compression (Veszelszki 2014) is a good example.

However, not all media use these opportunities. Traditionally, the media used mainly photographs (Fondevila-Gascón et al.2013: 52), and although online editors tend to like technical novelties, their journalistic attitude and practices often lag behind (Steensen 2011).

In this study we analysed the image usage of the most visited Hungarian online journals, divided into two groups: "traditional" media (those that have a print version, their online versions thus being of secondary importance) and "new" media (those exclusively online). Our theses are: 1) there are significantly more visual elements in the articles of the "new" media; 2) significantly more visual elements have self-standing contentual value in the "new" media and they appear in roles that does not exist in the "traditional" media at all.

\section{Methods}

The eight most visited Hungarian general-interest news portals were selected based on publicly audited data. 168 Óra Online, Magyar Nemzet Online, Népszabadság Online and Válasz.hu belongs to the "traditional" media group;!!444!!!, Index, Origo and VS.hu belong to the "new" media group. We saved the papers' 
own articles that appeared on the homepage at the time of the sampling (5-6pm) and had a publishing date of that day (between 20 and 23 July 2015).

We decided to use every visual element that was edited purposefully into the article. The reason for this is that boundaries are blurred between objects and images, both in appearance and functionality: a "gif image" is essentially a small video; a real video may be started by clicking on a static cover frame; maps are moveable and zoomable; a Facebook insert may contain comments and other elements; charts are often interactive. Simple photos can be interactive, too: clicking on them may open a full screen image or a photo gallery.

\section{Results}

\subsection{Frequency of Visual Elements}

One hundred thirty-four articles appeared in the "traditional" media, and one hundred seventy-two in the "new" media. VS.hu leads with 6.21 images per article on average; Magyar Nemzet Online finishes the list at 0.38 per article. "Traditional" papers publish on average 0.60 visual elements in an article; "new" media publish 2.32, almost four times more (for more data see Figure 1). If we count images against the total character numbers of all articles, "traditional" media publish one image in 4,555 characters, and "new" media publish one in 976.

Figure 1: Visual elements per article. The leading place of VS is somewhat difficult: a single article, which we will analyze later, contributes with 78 visual elements. However, it is reasonable to include it since the paper frequently publishes articles of this kind

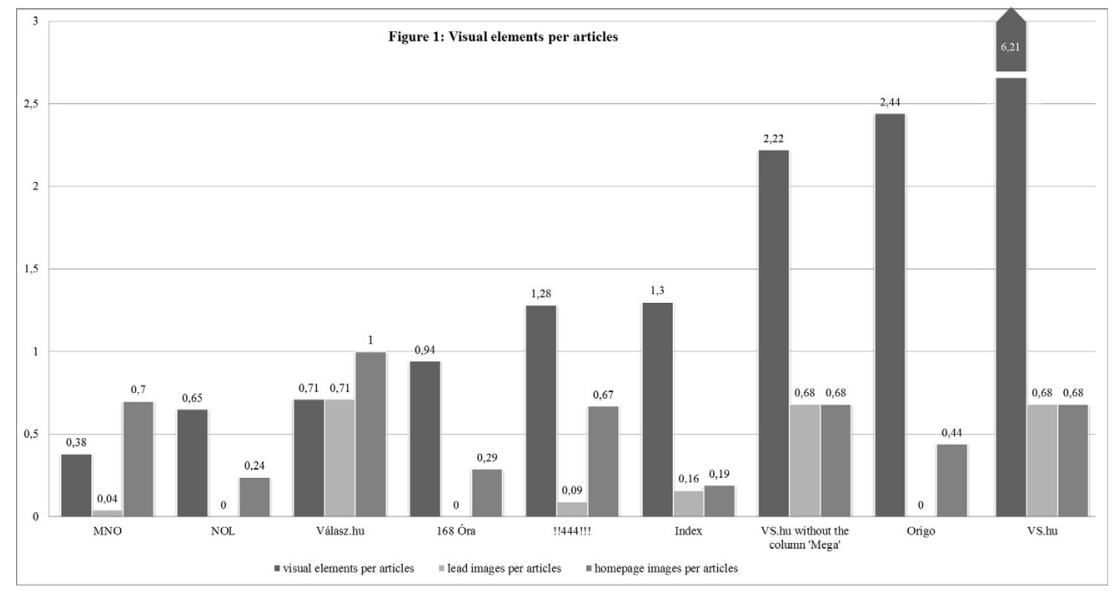

(source: diagram created by the author) 
It is rare in the online media to use lead images (images appearing in the "lead," illustrating the whole article). The usage of homepage images differs widely, too (the term meaning here that the article's title and lead appears on the homepage illustrated by an image). Some decisions seem logical: for example, Origo's low number of homepage images could be a decision to ease the congestion on the homepage because the paper publishes much more articles on it than the others. Some seem a little strange: for example, MNO uses a lot of homepage images but in the articles it uses the least visual elements by far, meaning that the paper took the effort to find an image for most articles, it just did not include them in the articles themselves. In general, we can say that there are no common image policies among the papers.

\subsection{Functions of Visual Elements}

There was only one paper where the traditional illustrative use of images did not prevail: 444.hu (39\%). At the other end of the list there are Válasz.hu and 168 Ora, having only illustrative images (for more data see Figure 2).

Figure 2: Distribution of image functions among articles that have at least one visual element

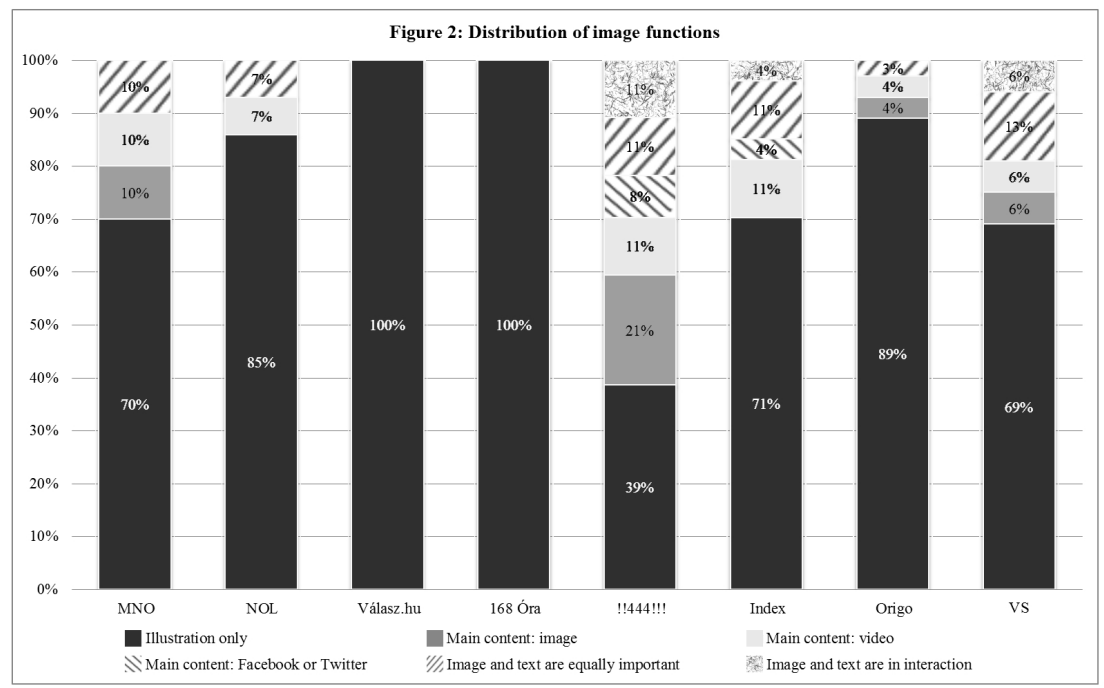

(source: diagram created by the author) 
Among those articles of the "traditional" media that apply at least one image, 87\% uses them only in an illustrative role. The number is $73 \%$ for the "new" media. The difference between the two groups is minor but consistent through all image roles (articles written about an image: $2 \%$ and $7 \%$, respectively; articles about videos: $6 \%$ and $7 \%$; articles about a Facebook or Twitter insert: $0 \%$ and $1 \%$ ).

There are some articles where images and text are equally important: "the text loses effect without the picture, and the picture also loses effect without the text" (Veszelszki 2012: 104).

Among the articles that use at least one image, $6 \%$ in the "traditional" media and $10 \%$ in the "new" media, behave this way. In some articles the visual elements appear in a new role: they are in interaction with the text, forming the message of the article together, achieving a goal that separately none of them could. The following analysis of two of them highlights their methods.

Figure 3: Screenshot detail of the site where the article "These corporations rule the country" appears. The cat picture is a "gif" short video

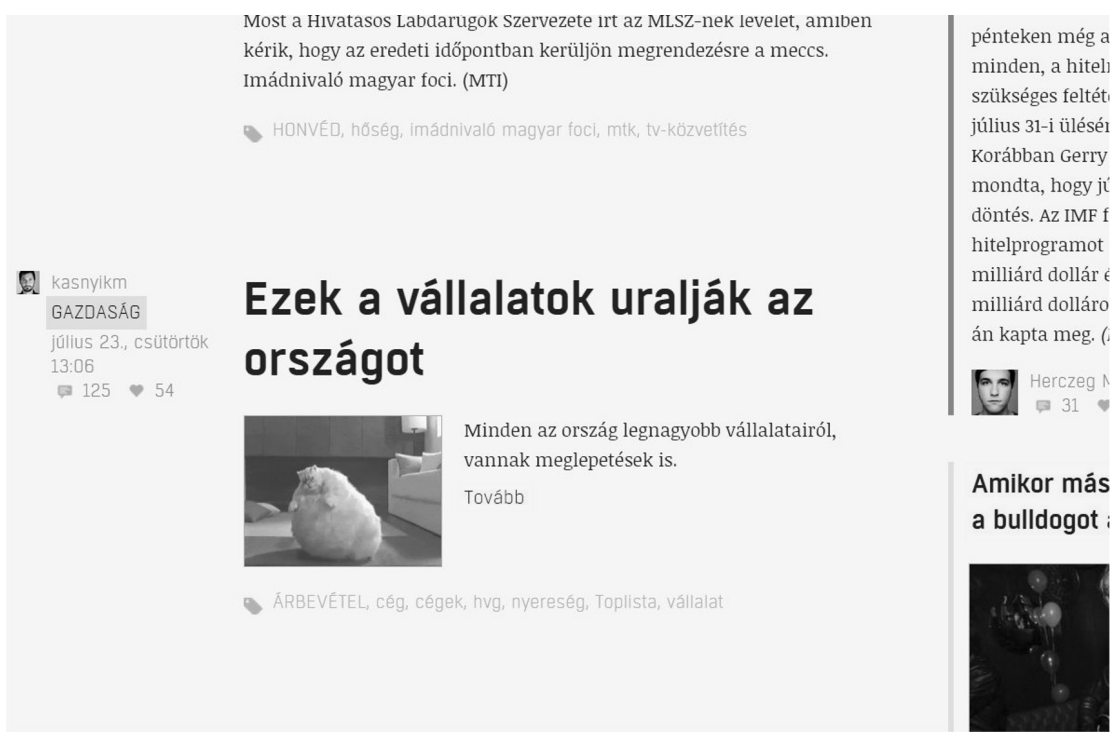

(source: Hungarian newsportal 444.hu, W1; screenshot taken by the author)

The article titled These corporations rule the country (W1) writes about a list of the greatest corporations of Hungary. The text briefly discusses some factual oddities of the list, however it is given a new and much stronger message by the lead (and homepage) "gif" image of a grotesque fat dancing cat (Figure 3). Memes of 
cats are usually presented for a humorous goal, therefore the image raises a lightminded feeling; moreover, the English term "fat cat," referring to the corporations, is recognizable for many Hungarian readers, too. The cognitive approach of the text and the intuitive approach of the image together present the message that the ranking of the corporations is not to be taken too seriously. This message is not present in either the text or the image separately.

Figure 4: Screenshot detail of the article "Zsolt Németh might have sent the woman back to the kitchen with a corny joke"
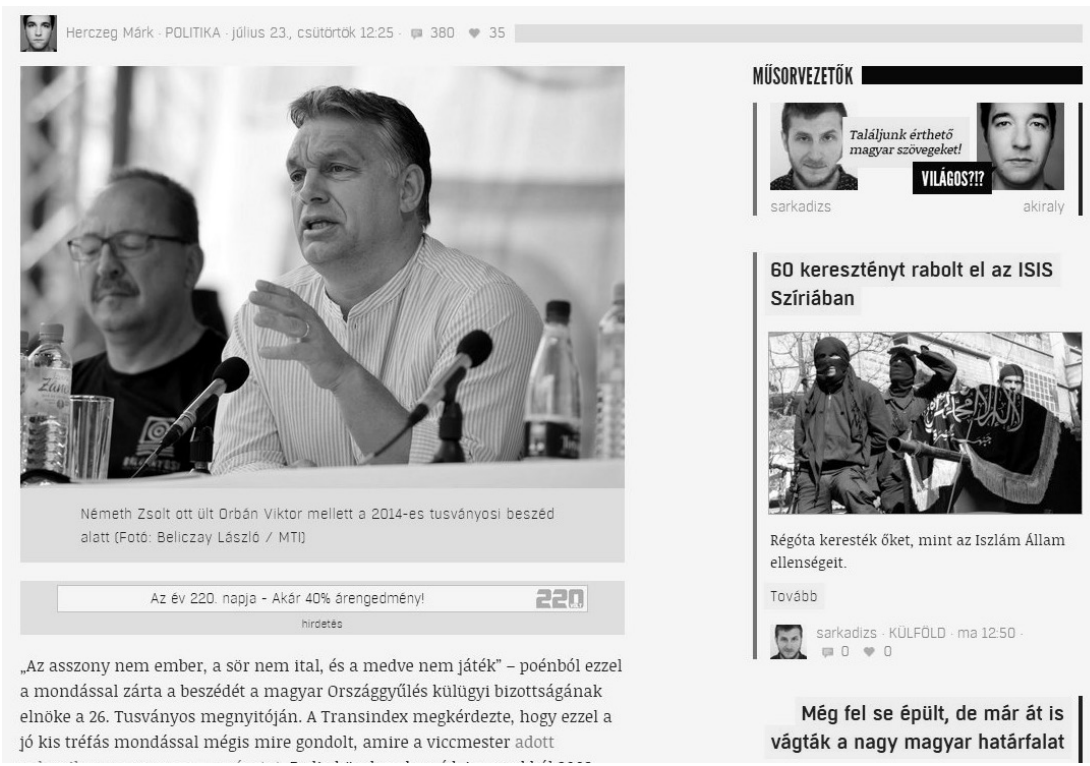

Régóta keresték ôket, mint az Iszlám Allam ellenségeit Tovább

T2. sarkadizs - KÛLFOLL ma 1250 $0 \rightarrow 0$

Még fel se épült, de már át is vágták a nagy magyar határfalat

(source: Hungarian newsportal 444.hu, W2; screenshot taken by the author)

The article titled Zsolt Németh might have sent the woman back to the kitchen with a corny joke (W2) writes about a supposedly embarrassing utterance of Zsolt Németh, a Hungarian politician. The text is only one paragraph long; there is, however, a lead photo above the paragraph: one that shows Németh sitting on the right side of the prime minister Viktor Orbán at an event that is known as being significant for the PM (Figure 4). The image, meaning "Németh is really close to the PM," thus shames the prime minister, himself not even present in this particular piece of news. Again, the message of the article is decodable only by the interaction of image and text. 
We risk the opinion that this role of visual elements demands a greater than average decoding ability from the reader, but they have potentially the greatest impact on him, too - creating the impression of thinking along the same lines with the author, discovering hidden meanings, the feeling of a common mischief.

Among the analysed sites, it is VS that uses the benefits of online visuality to the greatest extent. The layout of the site is different from the standard news portal: images are dominant on the homepage and on the article pages (always applied as lead images). It is more important, however, to take a look at the column "Mega".

Figure 5: Screenshots of the article "If you came to Hungary". Up left: a scrollable photo gallery. Up right: a text block. Down left: a chart. Down right: a video insert

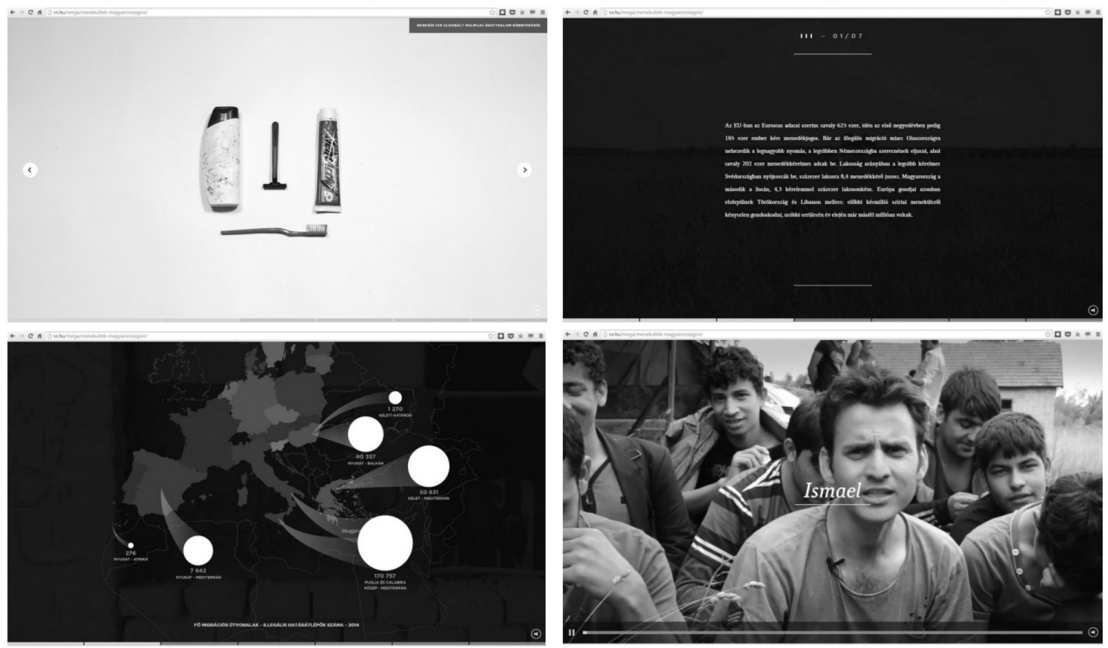

(source: Hungarian newsportal vs.hu, W3; screenshots taken by the author)

The column uses advanced web programming to create interactive, multimedia articles in which images, videos and texts are equally important (Figure 5). Journalists, photo and video professionals, design specialists and programmers work together on them. At the time of our sampling a new "Mega" article appeared on the site: "If you came to Hungary" (W3).

The prevalence of visual elements is clear. One can "scroll" the article and get a new window of content, however the basic layout of the window is static. Most content is based on an image or a video, and they occupy the whole area of the screen: there are no spatially separate blocks; all content is treated the same. Text, when it appears, usually hovers over the visual elements. A timeline shows where the reader is in the article and provides control over it. 
The article uses the interaction of the text and the visual elements heavily. Textual blocks, describing facts, are followed by photos and videos setting the mood and showing personal faces and stories. Charts help with processing the information presented in the text. The timeline, the act of scrolling, the few buttons that point to hidden features, and the interactive photo galleries enable the reader to actively discover the article, as opposed to a passive recipient role.

\subsection{Comparison with Fondevila-Gascón's Study}

Fondevila-Gascón and his group studied the image usage of four news portals of international fame (Fondevila-Gascón et al. 2013). All would belong to the "traditional" group of our study. They counted only photographs, so in this comparison we will use similarly restricted data.

The 2013 study found that the journals published 44.2 images a day on average. The same data in our "traditional" group is 18.25 , in our "new" media group 69.75 , meaning that the four leading Hungarian newspapers in the "traditional" group publish merely $41.29 \%$ of the amount in the foreign papers, while this percentage at our "new" media is $157.80 \%$. The 2013 study writes that photographs far outnumbered videos and other "graphical complements": the same is true for both of our groups.

The illustrative usage of images dominates all four papers of FondevilaGascón's study (even the lowest ratio, that of Corriere della Sierra, shows a fivefold advantage for illustrative images). The same is present at the Hungarian papers, too, with the exception of !!444!!!.

\section{Conclusions}

We studied the frequency and functions of the visual elements at the most visited Hungarian online newspapers. We divided the papers into two groups: "traditional" (those having a primary print version with an online version secondary to this) and "new" (those exclusively online). We did not limit the study to simple pictures because the boundaries between the types of visual elements are indeed blurred.

Our first thesis was that there are significantly more visual elements in the articles of the "new" media. The thesis gained confirmation. "Traditional" media use 0.60 visual elements in an article, "new" media use 2.32, almost four times as much. Curiously, no "traditional" paper reached one image per article and no "new" paper published less than that. Compared with the results of Fondevila-Gascón et al. our leading "traditional" papers fall short of their four newspapers at $41.29 \%$ of their image number, however our "new" papers outperform them at $157.80 \%$. 
Our second thesis was that significantly more visual elements have self-standing contentual value in the "new" media and the images appear in roles that does not exist in the "traditional" media at all. The thesis got confirmed, though less strongly. In the "traditional" media group $85 \%$ of those articles that have at least one visual element uses them only in illustrative roles; the same value in the "new" media group is $73 \%$. Given the short timescale of the study (one day per paper) the difference is not that convincing. However, it is clear that Fondevila-Gascón's statement is true for Hungarian media, too: "[...] photos have only relative meaning for the presentation of the content. They might serve as eye-catcher but they are neither important in terms of transporting, nor communicating an own message".

There exists, however, a role for the visual elements in the "new" media that cannot be found in the "traditional" media: the interaction of image and text, the two presenting together a new meaning that cannot be reached by only one of them alone. The pages !!444!!! and VS.hu are notable for their usage of such interactions.

The ratio of images continues to grow in the online media (Veszelszki 2008). A current example: in October 2015 the site that previously used the least visual elements in its articles by far, MNO.hu, switched to a new page and new image policies - we did not yet gather data from the new page but it clearly uses images more often.

The online public grows accustomed to images presented as self-standing contentual elements. This is why digital media needs to combine image and text. The process of the "pictorial turn" will surely lead to even more papers using images as self-standing contentual elements, equal to the text.

\section{References}

Fondevila-Gascón, Joan-Francesc - Seebach, Swen - Cardona-Pérez, Carlos (2013): Photography in Digital Journalism: A Comparative Case-Study Analysis Between Newspapers in Canada, France, Italy and Spain. Research Open Journal of Science and Technology 1/5: 51-62.

Nyíri, Kristóf (2000): A gondolkodás képelmélete [Picture Theory of Thinking]. Nyelv, megértés, interpretáció - A nyelv mint a kortárs filozófiai áramlatok közös problémája. Conference 5-6.10.2000.http://hunfi.hu/nyiri/ELTE_2000_conf. htm.

Steensen, Steen (2011): Online Journalism and the Promises of New Technology. Journalism Studies 12/3: 311-327.

Veszelszki, Ágnes (2008): Vizuális megoldások a kreatív szövegalkotási gyakorlatokban [Visual Solutions of Creative Writing Exercises]. Anyanyelv-pedagógia 2008/1. http://www.anyanyelv-pedagogia.hu/cikkek.php?id=33. 
Veszelszki, Ágnes (2012): Connections of Image and Text in Digital and Handwritten Documents. In: Benedek, András - Nyíri, Kristóf (eds.): The Iconic Turn in Education. Visual Learning Vol. 2. Frankfurt: Peter Lang. 97-110.

Veszelszki, Ágnes (2014): Information Visualization: Infographics from a Linguistic Point of View. In: Benedek, András - Nyíri, Kristóf (ed.): The Power of the Image. Emotion, Expression, Explanation. Visual Learning Vol. 4. Frankfurt: Peter Lang. 99-109.

W1 = http://444.hu/2015/07/23/30-legnagyobb-ceg.

$\mathrm{W} 2$ = http://444.hu/2015/07/23/nemeth-zsolt-visszakuldhette-a-trefarepat-azasszonnyal-a-konyhaba.

$\mathrm{W} 3=\mathrm{http}: / / \mathrm{vs} \cdot \mathrm{hu} / \mathrm{mega} /$ menekultek-magyarorszagon . 



\section{Trischa Goodnow \\ The Selfie Moment: The Rhetorical Implications of Digital Self Portraiture for Culture}

\section{Selfie and Rhetoric}

When a shard from a bowl is unearthed from an ancient civilization, archeologists and anthropologists learn much about the people who produced it. They discern aspects of life in that time from the way the bowl was made, used, and even decorated. We might call these accidental traces as the original purpose was not to speak about their life but to live it. Alternately, rhetorical critics study purposeful traces, those artifacts that people construct to tell the world, both present and future, who they are. Traditionally, rhetorical critics examined public speeches to infer elements of the immediate and cultural situation in which speeches were produced. More recently, however, critics have begun to examine all types of artifacts in a culture to examine their rhetorical import. In this essay, I examine the digital self-portrait, also known as the selfie, to mine the rhetorical implications of this phenomenon for culture. As Hall (2014: loc 132) suggests, self-portraits "have often been in the vanguard of cultural developments, influencing their own society's sense of identity and selfhood". Consequently, it is appropriate to place the selfie in the vanguard of contemporary culture.

The estimates of the numbers of selfies taken on any given day is approximately 93 million (Kennermer 2014). With this staggering number it is clear that something is going on. Academic studies often focus on the motives of the individual selfie taker. For example, some studies examine the narcissistic nature of selfies (Weiser 2015). Additional studies focus on the differences between the way men and women take selfies (Albury 2015), the functions of selfies as visual conversation (Burns 2015), and even what the conversation about selfies says (Sorokowski et al. 2015). In virtually all of these studies, the selfie is considered as a discreet act that speaks to and of the author. I propose here to examine the phenomenon writ large as an artifact of culture rather than the individual.

Selfies, taken as a whole, can be mined to determine the rhetorical implications they pose. I argue here that selfies reflect cultural perceptions about narrative, time, and values. To undertake this study, I begin with a general discussion of selfies. Then, I will explore each of these areas of cultural perception along with 
theoretical foundations for each aspect, before, finally drawing implications from this analysis. For this study, I examined selfies in general, as well as, individual selfies from which to draw conclusions.

\section{The Selfie Phenomenon}

The first known selfie is also one of the first known photographs. In 1839, Robert Cornelius sat motionless for three to 15 minutes to capture his own visage on film (W2). The cell phone reinvigorated the notion of the self-portrait for the average person as digital technology made taking pictures for no particular reason both easy and inexpensive. With film photography, the average person took photos for a purpose because of the expense and the time it took to have the film developed. However, with digital photography, readily available with most smart phones, the "developing" is instantaneous and cost is negligible beyond the device itself. Further, most selfies are uploaded to social media so there is no expense in printing. As a result, there is no barrier to the impulse to take random, seemingly meaningless photographs. Hence, the evident probability of selfies on social media. I argue here, however, that the selfie is not meaningless. The selfie reveals the current culture's perceptions of narrative, time, and values. The next sections explore these aspects.

\section{Narrative and Time}

A narrative is the telling of a connected sequence of events that have a beginning, middle and end. Fisher (1984) suggests that humans make decisions based on the stories we hear. He opposes this to the rational world paradigm where humans make decisions based on rational argument. In order to make decisions based on narrative, the story must be internally consistent as well as externally consistent. In other words, the story must hold together as a story and make sense with what is known to be true in the real world. I argue elsewhere (Goodnow 2005) that news photographs affirm, challenge or reaffirm known and emerging social narratives. Consequently, the photograph has the power to provide reasons from which to make decisions.

In his 1989 book Art as History Maurice Berger (1992) argues that news photographs are traumatic because they are moments caught in time with no beginning and no end. The viewer is helpless as to know the events that led up to the photo and cannot stop the photo from unfolding. Consequently, the viewer is held to that moment when the image was taken. Though Berger talks about the news 
photograph, the same theory can apply to other photographs as well. Any photo is a moment caught in time without a beginning and without an end.

Narrative is interconnected with the notion of time as narratives happen with the passage of time. While narrative is about the arc of events during a specified time, time itself is an elusive concept. We denote time in seconds, minutes, hours, days, years, decades, epochs, etc. How we perceive time impacts how we approach certain tasks, people, and events. A half an hour in the dentist chair seems to last an eternity while a half an hour laughing with your best friends goes by in what seems like a minute. Photographs are snapshots of time.

Historically, photographs recorded events, either personal or public. They might record a rocket launch, a political candidate at a rally, a wedding, a birthday party or a vacation. They recorded points in a narrative. The selfie eschews the notion of narrative. The selfie is often an image without context. Though some types of selfies do show some background, many selfies feature just the face of the picture taker. In fact, "Selfie City," a website devoted to collecting selfies from major cities, just features images that contain the face of the picture taker. In these instances, selfies are points in time with no context. Granted, a caption may explain more of the story behind the selfie. However, if a story contains a sequence of events, likely the caption will only illuminate one point in a potential story. As a result, selfies are not part of a larger narrative.

The argument can be made that by looking at a series of selfies a story unfolds. While this may be true, most selfies are not meant to be viewed as part of an ongoing narrative. Rather, selfies are discreet images meant to stand on their own. What does this mean for and about culture? A recent generation was known as the "me" generation. Narcissism runs rampant throughout the world, particularly in U.S. culture. The notion that a picture of just your face would be appealing to friends and any potential viewers on social media reveals a great deal about the culture's need and interest in understanding the greater narratives from which good decisions can be drawn. This lack of interest in the whole story is a symptom of what Rushkoff (2013) calls present shock.

Present shock occurs when we are present-oriented without regard to our history or our future. The dangers of present shock manifest itself in a lack of continuity and the need for something to take place immediately. Essentially, present shock is an endless cycle of needing excitement in the present without the patience for a longer term payout. The selfie expresses just this. It says, "Here I am in the present... No wait, now I'm in the present... no wait, NOW I'm in the present!" The selfie is relentlessly a record of the present, without regard to the past or future. 


\section{Values}

Aristotle in The Rhetoric defines the three public speaking occasions: deliberative (legislation that is future oriented), forensic (judicial that is past oriented), and epideictic (ceremonial that is present oriented) (Herrick 2009: 84). Aristotle contends that epideictic address seeks to reaffirm the values prevalent in society (Herrick 2009: 86). Most contemporary forms of address can be identified as one of these types of speeches, even those forms of rhetoric that are non-verbal. Selfies would fall into the epideictic category as they seek to celebrate something, even if that is just the self. What is relevant here is the values that selfies espouse. I identify three values that correspond to the three types of selfies commonly found.

In order to discern these types, I assigned the 40 students in my Visual Rhetoric class to examine a minimum of 20 selfies, either their own or those found on social media sites, and categorize them. Through a process of elimination, we developed three categories that encompassed all of the sample selfies. These categories are adventure, popularity, and attractiveness. Each of these categories relate a corresponding value that can be found prominently in society. In addition, these categories are decreasingly contextualized, relating to the narrative and time aspects of the selfie phenomenon. I discuss each of these categories here.

\subsection{Adventure}

The adventure category usually relates one of two experiences, either daring adventures or location adventures. Daring adventures are those selfies where the person is doing something physically challenging. These images include situations such as skydiving, bungie-jumping, rock-climbing, or finishing a marathon. The idea behind these types of adventure selfies is to illustrate that the picture taker is also a risk-taker.

The second type of adventure is the location adventure selfie. These images show the taker in the context of an exotic place. Such images may show things like the subject at the beach, the Roman Colosseum, the Louvre, the Lincoln Memorial or other such recognizable places. These selfies uphold the primary value of exploration. Based on the Frontier Myth common in Western culture, exploration, of conquering uncharted lands (experiences), is a value that is cherished.

Adventure selfies illustrate that the taker is participating in the value of exploration. These images are highly contextualized. Hence, they relate more of a narrative that can be assumed. When a selfie is posted in the adventure category, the viewer wonders about the story. So, if someone is seen outside the Louvre, the viewer can assume there is a story about the trip that resulted in the image. Though the 
selfie will most often be accompanied by a one sentence caption, such as, "At the Louvre," the narrative itself is incomplete. Consequently, while the adventure selfie contains more context, it still plays into the lack of full narrative.

\subsection{Popularity}

The popularity selfie often depicts the picture-taker with one or more friends. Because of the nature of the devices used to take the selfie, the picture-taker is most often in the center of the image. Even if the person is standing on the edge of the group, the tendency is to center the taker. Consequently, the picture-taker is always center stage. However, what is important is that the picture-taker is viewed as having friends. Not only that, but the images usually picture the subjects as having a good time.

These images espouse the values of camaraderie and support. Since we live in a narcissistic time, being popular enhances the value of the self. Popularity selfies reinforce the notion that the picture-taker is popular. However, these images lack context in most situations. As a result, the narrative of the image is lacking. The selfie-taker is the only important element in the image. The moment of the image is most important as what came before or what comes after is irrelevant. The popularity category functions to illustrate the state of the picture-taker in the moment.

\subsection{Attractiveness}

This category of selfie is the most popular type and consists of two subcategories, the workout selfie and the facial selfie. The workout selfie is interesting in the breakdown between men and women. Images of women in this category usually depicts the taker in workout gear and often depicts only the body with the face cut off. Men, on the other hand, rarely cut off their heads in the photos. Pictures of abs and biceps are prevalent. The other interesting observation available in this subcategory is the method of taking this type. Often the subject takes the picture in a mirror's reflection. Hence, the viewer observes the subject examining themselves. This clearly indicates that the subject is the center of attention and seemingly deservedly so.

On occasion, these images will be accompanied by a "before" shot. Consequently, there is an evident narrative; "this is what I looked like before and now I've lost weight and look great". There is a sequence present. More often than not, however, there is just the image in workout gear, showing off the subject's physique. In this case, the image is of the moment, revealing where the subject is now.

The facial selfie only reveals the face, with little to no background. This is perhaps the most revealing selfie for culture. As mentioned before, the website, Selfie 
City, only collected this type of image and managed to cull over 3200 facial selfies from five continents (W1). Without context the facial selfie can only be about the self. In fact, one could argue that the purpose of the facial selfie is less to share an image than to garner "likes" and comments. In this way, the subject's self-esteem is reinforced because of the potential popularity of the image. A common type of facial selfie is the make-up free selfie which certainly requires a response. Hence the value of pride is paramount in the attractiveness selfie. This type of selfie also reinforces the "now" focus as the subject needs confirmation now.

\section{Implications}

An examination of the selfie phenomenon reveals that the popularity of this type of image communicates the "presentist" nature of contemporary culture. With the focus on now, cultural narratives become less important. When that happens, planning for the future also has less importance since all that matters is now. The problem with this perspective is that it denies the connectedness between events, things, and people (Rushkoff 2013:240). The inability to make connections to the past and plan for the future results in a fractured existence. It's like the person with no short term memory; they have to keep asking why they are where they are.

Further, with the emphasis on self, other actors in the on-going story become unimportant or even irrelevant. The focus on self inhibits the civility in culture. Some tourist destinations have banned selfie sticks because they were causing problems with other tourists, including injuries. Tourists taking pictures of themselves also limits the interactions with others. Before the advent of the selfie, one would ask a fellow visitor to take a picture and perhaps strike up a conversation. Thus, the totality of the experience was enhanced. Now, we need not ever talk with a stranger because we are self-sufficient. The less we interact with others, the less empathetic we are to others. I do not mean to claim that selfies make us selfish. Rather, I believe they are symptomatic of a larger cultural phenomenon.

Finally, looking at the values that the types of selfies represent, a further depiction of the self in culture is evident. Values represent exploration, pride, and presence. While the first value of exploration echoes persistent cultural values, pride and presence are self-centered and counter-intuitive to democratic values. Consequently, the individual's importance breaks down the value of community, presaging a decline in civility. All of these implications are not necessarily harbingers of doom. Rather, they are an assessment of where culture stands today. Understanding these implications can enable citizens of culture to make more informed choices for the future. 


\section{Conclusion}

By looking at the various types of selfies, we can come to a greater understanding of what selfies say about our culture and our future. These purposeful traces reveal the way that we consider time and narrative. Selfies provide evidence of our presentist leanings. We are concerned with the here and now. This has implications for how we plan and prepare for the future. This presentist culture is further evidenced by the values selfies espouse. With focus on the selfie-taker, connections to other people, events and time are minimized. While it is easy to discount the importance of selfies, it is evident that the selfie is a valuable indicator of the status of culture.

\section{References}

Albury, Kath (2015): Selfies, Sexts, and Sneaky Hats: Young People's Understandings of Gendered Practices of Self-Representation. International Journal of Communication 9: 1734-1745.

Berger, Maurice (1992): How Art Becomes History: Essays on Art, Society, and Culture in Post-New Deal America. New York, NY: Icon Editions.

Burns, Anne (2015): Self(ie)-Discipline: Social Regulation as Enacted Through the Discussion of Photographic Practice. International Journal of Communication 9: 1716-1733.

Fisher, Walter R. (1984): Narration as a Human Communication Paradigm: The Case of Public Moral Argument. Communication Monographs 51/1: 1-22.

Goodnow, Trischa (2003): Evaluating the Story: News Photographs and Social Narratives. Visual Communication Quarterly 10/3: 4-9.

Hall, James (2016): The Self-Portrait: A Cultural History. London: Thames \& Hudson.

Herrick, James A. (2009): The History and Theory of Rhetoric: An Introduction. Boston: Pearson and AB.

Kennemer, Quentyn (2014): Android activation numbers. Phandroid. http:// phandroid.com/2014/06/25/android-has-1-billion-active-users-in-the-past30-days-and-other-interesting-numbers-from-io/.

Rushkoff, Douglas (2013): Present Shock: When Everything Happens Now. New York, NY: Current.

Sorokowski, P. - Sorokowska, A. - Oleszkiewicz, A. - Frackowiak, T. - Huk, A. Pisanski, K. (2015): Selfie Posting Behaviors are Associated with Narcissism among Men. Personality and Individual Differences 83: 123-147. 
Weiser, E. B. (2015): \#Me: Narcissism and its Facets as Predictors of Selfie-Posting Frequency. Personality and Individual Differences 86: 477-481.

$\mathrm{W} 1$ = selfiecity. http://selfiecity.net/.

W2 = The Public Domain Review. http://publicdomainreview.org/collections/ robert-cornelius-self-portrait-the-first-ever-selfie-1839/. 


\section{James E. Katz and Elizabeth Thomas Crocker \\ Selfies as interpersonal communication}

We define selfies as images or videos that one takes of oneself, primarily alone, but sometimes among a group of others. Manovich's 2015 study of selfies found that only about $4 \%$ of the images posted on Instagram in a single week were selfies. While that is a relatively small percentage of the overall vast number images captured, it nonetheless translates into about three-quarters of a billion pictures that currently reside on Instagram.

Initially considered the domain of teens, the selfie phenomenon now runs the gamut from religious leaders to politicians and practically everyone in between. Franklin Graham (son and heir of the iconic US evangelist, Billy Graham) takes numerous selfies, while President Obama has wielded a selfie stick in Alaska. Politicians across the spectrum now find selfies as routine as shaking hands or kissing babies. Indeed, a colorful story splashed across the front page of Boston's leading newspaper, dubbing the state's governor "His Excellency Governor Selfie" for his predilection to snap a shot at every opportunity, even when he encounters a cute dog (Miller 2015).

Yet harsh criticism has also been leveled at the selfie and those who take them. For instance, Robert Lucky has called them "personal propaganda" observing that photos had previously been considered "treasured keepsakes" and were now used primarily for self promotion (Lucky 2015), and this description might be characterized as polite relative to other terms that have been applied to them. Among manifold negative responses to selfies have been comments directed at Mr. Obama for participating in a selfie at the funeral of Nelson Mandela. Nor are celebrities immune to criticism; popular US TV personality Al Roker had to apologize for his insensitivity after taking a smiling selfie with hurricane wreckage in the background (Wagner 2015). Beyond the personal politics and moral indignation that selfies have provoked, is the fact that their production can be quite dangerous. With disturbing frequency, people go to such extremes to take a compelling selfie that they put themselves in harm's way, with fatal consequences (Diehl 2015).

Yet criticism also extends to the world of scholarship where not only selfie takers are critiqued for various shortcomings, but so too are those who study selfies (Tifentale 2014). We would like to add our criticism of some selfie studies, because they often do not give sufficient regard to the communicational aspects of selfie production, consumption, and coproduction. More specifically, we see selfies as 
often filling an important conversational role. Of course this is not true for all selfies, but it is, as we endeavor to show below, a sufficiently important aspect to merit systematic inquiry.

In this sense, our analysis seeks to highlight the turn towards visual communication, which, while we admit this is a contested viewpoint, has not received sufficient attention from philosophical or communication research perspectives. That is to say, many analyses of this new practice may be accused of failing to see them as a rich form of reciprocal communication, even as a broad front has been opened about the inability of young people to communicate (Turkle 2015). According to this school of thought, the absence of meaningful conversation may be laid at the doorstep of our communication technology. We take issue with this "soft technological deterministic" position, holding that people use the communication technology available to get done what they want, the way they want. Of course, there is more to this point than can be captured here in a few words, but our point is not to criticize Turkle, but rather to highlight the fact that people use communication technologies that serve their purposes rather than address some externally defined (often elite-driven) set of standards.

We see that selfies do much to effectively communicate among friendship circles and beyond certain sentiments and ideas, and especially emotions, much better than a carefully written essay or letter, or public address. Moreover, there may be high degrees of intriguing ambiguity and multi-layered meanings to selfies that make them a combination of game and puzzle, adding further to their attractiveness. We suggest that selfies are symbols, and as symbolic representations of self they are signs that evoke or provoke variegated meanings, and thereby are communicating ideas that competent viewers can discern (Hefner 1990).

It is worth pointing out that for hundreds of thousands of years evolutionary forces have attuned human beings to become adept at reading each other's faces to understand and exploit the thinking behind the mask of one's visage. By the same token, with effort and experience many facial expressions can be suppressed, giving rise in English to the expression "poker face," blocking the "mind reading" efforts of the one gazing upon the individual's expression. But here we are concerned about the ability to communicate using facial expressions, often with intentionality and effort, just the reverse of the point made in the preceding sentence, which is set forth to provide a juxtaposition.

Hence, the question of selfies as a form of human interaction and communication can now move to the center of our argument. In this regard, we wish to present data from a US survey to help shed light on the process from a communicational perspective. Specifically, although there have been a small number 
of studies of selfies as communication processes, little systematic evidence exists concerning the generalizability of observations concerning the use of selfies "in the eye of the beholder" (but exceptions include Katz-Thomas Crocker 2015). Hence our research seeks to understand the communicational aspects of selfies by surveying an introductory communication class at a large northeastern American university in the fall of 2015. Although of course not representative of the general youth population, 471 freshmen students successfully completed the instrument ( $81 \%$ female, $19 \%$ male). Nearly all were 18 or 19 years old.

In terms of selfie production, all had heard of, and nearly all had taken a selfie (only seven students, or $1.5 \%$, said they had not). As to the intensity of selfie production, over half ( $56 \%$ ) said they had taken a selfie with the past 24 hours. Fourteen percent had shared one selfie in that time period, nine percent had shared two, and seven percent had shared three. About $10 \%$ of the sample said they had shared 10 or more selfies in the past 24 hours. This result suggests high levels of selfie production among this age cohort. Looking over a longer time span, one week, 29 students (about 4\%) reported sending more than 100 selfies, which of course is not a precise count, but rather a general indication of magnitude.

Are selfies designed for friendship circles rather than the general public or unknown others? To get at this question, we asked students to agree or disagree (on a five-point Likert scale) with the statement "selfies should only be shared with friends". The sample was fairly evenly split on this question, with about one third agreeing with that sentiment, one third being neutral, and one third expressing disagreement. However, when the question was formulated differently, "it's okay to share selfies publicly," $69 \%$ agreed or strongly agreed, $22 \%$ were neutral, and $9 \%$ disagreed or strongly disagreed. Hence while selfies in general may be suitable for either public and private consumption, or both, there is a significant proportion of the sample that feels selfies are objects for personal or friendship-circle consumption only. (The public versus private dimensions of selfie production and consumption may be an important topic for future research.)

Selfies are by definition an intentional production, and the question of staging vs. spontaneity is of interest here. In terms of the question "I often carefully stage my selfies," half of the respondents answered affirmatively (agreed/strongly agreed) while a quarter were neutral and another quarter disagreed or strongly disagreed. Our answer to this question would emphasize the intentionality behind selfie production, a point that further implicates their role as a form of communication to others. (As in so many areas, though, staging could also be integral to the personal documentation activity, for both one's own sake and that of posterity. However, even going beyond posterity, it could be readily argued 
that self-documentation is still a communicative act, created now for the future self to consume.)

An interesting finding was the relationship between the questions, "I often carefully stage my selfies" and "selfies are meant to be informal". Although one would expect that those who think that a selfie should be informal would also be those who do not carefully stage their selfies, this was not the case. A statistically significant proportion who strongly agreed that selfies should be informal, were also more likely to strongly agree with the statement that they carefully stage their selfies.

Another aspect of the intentionality of selfie production and sharing is the notion that the act of selfie production is designed, perhaps less for personal gratification, than it is to manipulate the impression that others have of the selfie producer. We found some evidence in support of this proposition when we asked the respondents about their motive for selfie production. In response to the question "I share selfies to impress people," about one third agreed with this statement (6\% strongly agreed, $26 \%$ agreed). Twenty-six percent of the respondents were neutral, while twenty-nine and thirteen percent respectively disagreed and strongly disagreed. While this is not a resounding endorsement of the principle, there is nonetheless evidence that for about a third of the sample this was the case.

It is worth pausing here to note that the topic of motivation is hard to get at through direct survey questions. Self-reports of motive tend to be notoriously hard to validate, in part because the actor in question may not be aware of their true motives, and in many cases the idea of a "true" motive can be hard to pin down. The notion of social desirability also comes into play, since some individuals may not be willing to admit to behavior for less than socially sanctioned rationales (Fisher-Katz 2000); in this particular case, an intent to impress. However, given that nearly two-thirds of our respondents said it was important to look good in a selfie (62.2\%) suggests that undergraduates who post selfies are likely to be concerned with cultivating a positive impression. The extended self is not merely that possessions, text, and images happen to reflect identities, but that they are by their very nature instrumental in communicating those identities.

The two-way communication aspect of selfies is also worth considering. Indeed, it appears that there can be something approximating an interaction effect between selfie producers/centers. We believe this was the case, so we asked the question: "I send selfies back in response to the selfies I get". Of our respondents, $13 \%$ said they strongly agreed with this sentiment, over half (53\%) agreed, while $18 \%$ were neutral, $16 \%$ disagreed, and $7 \%$ strongly disagreed. 
One of the aspects we were unable to probe in any detail via this survey, but hope to do so in future surveys, is the "demand" characteristics of photo exchanges. For example, to what extent do those who send selfies back into in response to the selfies they get do so because they feel obliged to do so? What extent do they do so because they feel they wish to engage in conversation-like interaction, or perhaps simply because of the stimulus or competitive dimension in light of another person's selfies? In terms of our data, there was something of a penumbra concerning this that we were able to probe (although we were not able to do so directly). We did so by the question "I am very interested in how my friends react to my selfies". Here we found close to half of the respondents affirming this attitude (10\% strongly agreed and 36\% agreed), $31 \%$ were neutral and one quarter were not supportive of that attitude (17\% disagreed and $7 \%$ strongly disagreed).

Obviously, our investigation has only scratched the surface here. Specifying medium and audience size might help further illuminate this aspect, since there may be different expectations in responses to selfies, depending on the platform they were shared on and how many individuals could reasonably be expected to view it. Such an inquiry would also provide further information about intentionality, since we presume that the motivation to send a selfie sent to a single individual would be different than a selfie put on a public account available for thousands to view.

Summing up, this is not a definitive survey, and as a research vehicle has a plethora of methodological shortcomings; hence any generalizations must be exceedingly tentative. Yet it may be that some data are better than none. In that light, from our evidence we would argue that selfies are a meaningful form of interpersonal communication, and that they provoke an array of responses that have been previously found in both face-to-face interchanges and conversation. Survey responses suggest that competitiveness, friendship circles and grooming, and the creation of in-group rewards and out-group barriers, are all processes that are played out within the context of selfie production and consumption. As such, mobile technologies, such as the smart phone, are new frontiers of human communication that allow new forms of visual interaction to emerge. These forms allow for richness, playfulness, and competitiveness, as well as jealousy and frustration (and danger). Hence there is no reason not to encompass this form of expression into the panoply of communication tools which have played important roles in the cavalcade of human interaction and popular culture. These other forms have included floral bouquets as communication tools arrayed so as to convey complex sentiments. Likewise, stamps on envelopes have been used as a form of meta-communication to enrich, or in some cases hide, messages. Therefore, selfies, 
far from a unique or new form of communication, are a continuation of existing visual communication strategies, adapting, as ever, to newer technological tools.

Turning briefly to the philosophical dimension, which can only be noted in passing, the proliferation of selfies represents further confirmation of what might be called a "visual turn" in philosophy. As such, it adds to the opening of the way for those who believe that humans think, gain insight through, and even develop arguments, via images. In this sense, our findings provide ammunition against the position of those who, like Nelson Goodman (1976), argue against the possibility of visual argumentation.

The selfie (and accompanying selfie stick) as a mass obsession may be a transient form of communication production, much as was the singing telegram. But we would not bet on it; there is no reason to expect the face itself, and its use as a form of communication, enrichment and expression, to fade from the core set of interests of humans. The power of the facial image, containing as it does so much information and meaning, will doubtless remain an important feature of the way we interpret the world visually, emotionally, and psychologically. Truly, we live in a world of images. Kristóf Nyíri aptly recognized this during his comments at the 2015 VLL6 conference in Budapest when he said, "Children and teens live in images”. Indeed, it's rare to find a human who does not.

\section{References}

Diehl, Caleb (2015): Report: Selfies More Dangerous than Sharks. USA Today College, September 24. http://college.usatoday.com/2015/09/24/report-selfiesmore-dangerous-than-sharks/.

Fisher, Robert J. - Katz, James E. (2000): Social Desirability Bias of the Validity of Self-reported Values. Psychology and Marketing 17/2: 105-120.

Goodman, Nelson (1976): Languages of Art: An Approach to a Theory of Symbols. Second edition. Indianapolis: Hackett Publishing Company.

Hefner, R. W. (1990): Hindu Javanese: Tengger Tradition and Islam. Princeton: Princeton U. Press.

Katz, James E. - Thomas Crocker, Elizabeth (2015): Selfies: Accelerating the visual turn of self-representation in interpersonal communication. Center for Mobile Communication Studies, Boston University. December 15. Boston, MA.

Lucky, Robert (2015): The Ubiquitous Camera. IEEE Spectrum 52/3: 30.

Miller, Joshua (2015): Charlie Baker's Passion for Selfies Pays Off in Many Ways. Boston Globe. December 18. https://www.bostonglobe.com/metro/2015/12/18/ his-excellency-governor-selfie-massachusetts/kfMNAqzs774DMNAyeRpP7H/ story.html. 
Tifentale, Alise - Manovich, Lev (2014): Selfiecity: Exploring Photography and SelfFashioning in Social Media. http://manovich.net/index.php/projects/selfiecityexploring.

Tifentale, Alise (2014): The Selfie: Making Sense of the "Masturbation of Self-Image" and the "Virtual Mini-Me". http://d25rsf93iwlmgu.cloudfront.net/downloads/ Tifentale_Alise_Selfiecity.pdf.

Turkle, Sherry (2015): Reclaiming Conversation: The Power of Talk in a Digital Age. New York: Penguin Books.

Wagner, Meg (2015): Al Roker Apologizes for Smiling Selfie during South Carolina flooding. New York Daily News. October 6. http://www.nydailynews.com/ entertainment/tv/al-roker-apologizes-smiling-selfie-s-flood-article-1.2386783. 



\section{Ágnes Veszelszki \\ \#time, \#truth, \#tradition. An image-text relationship on Instagram: photo and hashtag}

This chapter aims to examine the relationship between image (photo) and text (hashtag), on the photo sharing social network Instagram, through the examples \#time, \#truth, \#tradition.

\section{What Is a Hashtag?}

A hashtag is a type of label or metadata tag primarily used on social networking websites and microblogging services. It makes it easier for users to find content of the same topic. Hashtags are created by inserting the hash character $(\#)^{1}$ in front of a word or unspaced phrase.

The tagging system was initially popularized by Twitter $^{2}$, and later taken over by Instagram, Facebook and other social networking websites as well. Now hashtags trend beyond social networking sites and digital communication into other media like television, print and they even appear in spoken conversations. The expression itself has not only become a verbalized form in orality but has also triggered changes in nonverbal communication: the hashtag sign can be shown by using the index and middle fingers from both hands laid over each other, rather than saying "hashtag" (Parker 2011; Kamer 2013). Because of its widespread use, the word hashtag was added to the Oxford English Dictionary in 2014.

Metadata (in a relationship with images) has the "ability to append linguistic signs to an image (or other data object), to facilitate its classification, archiving, retrieval and indicate provenance (authorship, ownership, conditions of use)" (Rubinstein-Sluis 2013). Searching on a hashtagged word on a social networking website will display all content so labelled on that website. With this sorting and searching function, however, hashtags not only connect different content or thematic blocs, but also connects users having similar fields of interests ("hashtag

1 In the English language, the \# symbol is the number sign or the hash as Northern Americans call it (not to be confused with the sharp sign \# in music, the abbreviation No. or the pound sign in North American English).

2 Its first appearance on the microblogging site Twitter is commonly associated with Chris Messina (W1), who used this sign in a message in 2007 the following way: "how do you feel about using \# (pound) for groups. As in \#barcamp [msg]?” [23 Aug 2007]. 
serves as [...] a symbol of membership of a community," Yang et al. 2012). It is often used as an instrument by social movements (for example, with the hashtag \#bringbackourgirls Nigerian students directed attention to the fact that 270 girls were kidnapped from their school in 2014). Hashtags are important for social sciences too, as they make it possible to search and analyse opinions from different individuals about an event (Rambukkana 2015). Marketing professionals have also recognised the potential in hashtags (Ting et al. 2015: 16): they can use these labels to measure the effectiveness of promotion in social media.

In addition to its above-mentioned basic functions, hashtags are also used to abbreviate messages and to add some kind of a stylistic touch to what is being said. "Hashtags are deictic, indexical - yet what they point to is themselves, their own dual role in ongoing discourse" (Rambukkana 2015). The metacommentary written after the hash can be used to indicate the user's attitude toward the hashtagged content (an apparently serious text can be made funny or ironic by adding the right label to it; cf. Parker 2011). In its broader sense, the hashtag may be taken as the marker of epistemological modality in relation to the text. ${ }^{3}$

Hashtags go unregistered and uncontrolled, so users can create as many tags as they want and use them the way they want to. Still, there are collections of advice on how to make hashtag campaigns. According to Cohen (2015), a good hashtag (that is suitable for marketing purposes) is unique, distinctive, easy to remember but not too general, short but meaningful, not too abstract and includes no slang elements. It is often advised that the initials of multiple word hashtags should be capitalised. Users should also make sure that there is only one way to spell out their hashtag ("if a hashtag can be misunderstood, it will be misunderstood," e.g. \#SusanAlbumParty vs. \#SusAnalBumParty; Slegg 2014) and check whether it has been used earlier for other purposes (Hill 2012).

Certain tags most likely go hand in hand with others. Co-occurring, multiple hashtags are called in this paper hashtag chains (on the relationship of hashtag chains and phrasems cf. Veszelszki 2016). Analysing various contents shared on Instagram (Cohen 2015), the highest interaction is triggered by 11 or more hashtags, so on this platform the more hashtag someone uses, the more efficient he or she will be in building community. Hashtag chains typically relate to the most popular topics of amateur photography (travel, touristic sights; food and drink; fashion; selfie 'self-picture'and work), and their structure prototypically follows

3 For example: "I can't decide which series to watch this evening. \#firstworldproblems". The expression "first world problem" is a self-ironic reflection on the fact that for the user the mentioned issue is the greatest problem in life. 
the user name, text, hashtags order: It's a classic mille feuille but with a twist... the flavors of bananas! \#recipeoftheday \#syntaghthshmeras \#millefeuille \#napoleon \#dessert \#sweets \#deliciousrecipes \#recipes \#food \#foodlover \#foodblogger \#foodtricks \#instafood \#instagood \#instadaily \#instalover \#instamood \#foodpics \#bananas. Or: Cica szelfi \#selfi \#selfie \#szelfi \#cat \#macska. As the second example shows, hashtags are often made of spelling variants or synonyms of the same word. Using multiple hashtags in the middle of the text makes comprehension quite difficult (e.g. Very \#cute \#lovely \#kitten \#cat \#kitty! I so \#love it!).

Based on empirical research, hashtags are classified into three main groups (Csire 2015; with my own observations and examples):

1. Like-hunter tags are added to images to boost the number of views (e.g.: \#followme, \#likeforlike; \#instadaily, \#instalove; \#photooftheday). They do not form an integral part of the image, their only aim is to obtain new likes and followers and that way they lead to a certain microcelebrity which "is a mind-set and a collection of self-presentation practices endemic in social media, in which users strategically formulate a profile, reach out to followers, and reveal personal information to increase attention and thus improve their online status" (Marwick 2015: 138, according to Senft 2013).

2. Thematising tags usually relate to the topic of the photo, how it was made (blackand-white, no-filter [\#nofilter]), its atmosphere, or sometimes the persons on the picture (\#girls, \#friends, etc.), objects (\#food, \#cake) or events (\#wedding, \#conference), so this way they contribute to the searchability of similar contents.

3. Contextualising tags complete posts with the user's emotions, mood or the circumstance of taking the photo, such as: \#cominghometothis, \#annapostedit, \#grüsseausdertaiga. Such hashtags are much more characterised by uniqueness: they do not want to enhance searchability but to add extra verbal information to the visual content. For this reason, they are one-time, non-recurrent texts.

As one of the main functions of hashtags is to facilitate searching, their presence is relatively constant on the internet. This stability ${ }^{4}$, however, can only be true

4 Examples of this fixed form include: \#mik (acronym of Hungarian Instagram Community), \#yolo (you only live once), \#swag, \#sundaymorning; \#bestoftheday, \#picoftheday, \#worstnightmare, \#grexit. The same need for stability may motivate the usage of joker suffixes, such as -porn and -gram (deriving from the word Instagram): coffee porn, foodporn, wordporn, lobster porn; latergram, travelgram, foodstagram; as well as prefixes, such as insta- (also deriving from Instagram): instafood, instatravel, instagood, instamood, instadaily, instasize, instahun, instanight (on further linguistic characteristics of hashtags: Thode Hougaard 2014). 
to like-hunter and thematising hashtags, because contextualising hashtags are unique and casual.

\section{Corpus and Method}

The present study aims to describe the hashtag as a new, image-bound, minimalistic type of text. For the empirical analysis, five hypotheses (presented at the results) were formulated which combine the potentials of qualitative and quantitative analyses.

The examination was carried out on the Instagram photo sharing site. Highfield and Leaver outlined emerging methods to study uses and activity on the image-sharing app and social media platform Instagram. They found that "the importance of tagging on Instagram [...] has conceptual and practical links to the hashtags employed on Twitter (and other social media and 'Web 2.0' platforms), with tags serving as markers for the main subjects, ideas, events, locations, or emotions featured in tweets and images alike" (Highfield-Leaver 2015). "So far, textual content has dominated social media research, particularly for large-scale analyses; this is in part due to the ease of collecting and processing text in comparison to images. [...] Preliminary research into Instagram has offered large-scale analyses of images from specific locations" (Highfield-Leaver 2015, mentioning Hochman-Manovich 2013). With the hashtag function the images of Instagram also include "fragments of metadata" (Wendt 2014: 37).

As a start, I selected three keywords that matched the theme of the VL-conference (\#time, \#truth, \#tradition) and used them as hashtags to search related content. The results were sorted using two methods: first, by choosing photos with the highest number of likes (indicating popularity) and second, by selecting the most recent Instagram photos on the day of examination (25 October 2015). For each keyword 100 photos were saved together with labels. This corpus was later completed with a sample containing another 100 items selected from the latest photos, serving as control corpus, to balance (at least to a certain degree) the bias caused by the keywords. In line with Instagram's privacy policy, only publicly posted images were examined. This 400 -item corpus was analysed according to the aspects specified in the hypotheses. The analysis was based on a sample (what I refer to - according to Rocheleau-Millette [2015] - as 'small data'), so its results may not necessarily correspond to the results produced by automatic analyses of big data. Using a different sampling method can produce different results. After presenting the data, I used a mixed methodology, taking advantage of both 
qualitative and quantitative data collection and analysis methods. This method is accepted as valid by Highfield and Leaver, who deal with Instagram research methodology. They found that "Studying data through qualitative methods is critical to understanding how social media are used in non-standard ways, identifying practices that might easily be missed through automated analyses. [...] For visual platforms such as Instagram, this is even more critical, for the textual and graphic components of a post each offer key information, and analysis needs to take into account both aspects" (Highfield-Leaver 2015).

My aim was not only to describe the image-text relationships (the semantic and semiotic connection points - or with other words: the immediate context of these keywords) on Instagram, but also to complete the time-truth-tradition theme of the conference with a new semiotic aspect, namely with what visual and verbal signs connect to these keywords - on one of the most popular photo sharing sites of our time.

\section{Results}

Searching on the hashtag \#time on the date of examination resulted in 24 million posts. Not surprisingly, many of the pictures depicted a clock or watch, so this sub-corpus contained a much higher share of advertisements than the search results of the other keywords. The hashtag \#truth was used in more than 29 million posts, dominated by religious content (Buddhist texts, Bible and Quran quotes), wisecracks, aphorisms, sophisms and inspirational messages. As a characteristic feature, these texts were not attached to a picture but a picture was organised around them. The keyword \#tradition resulted in 2.2 million Instagram pictures, primarily depicting traditional, often folk costume, seasonal preparations and the architecture or culture of exotic countries.

After removing repetitions, altogether 2784 different hashtags were added to the corpus out of the total 4966 . On the list by frequency of occurrence, the three keywords are followed by the rather general \#love, \#life, \#happy \#instagood, \#family, \#beautiful, \#followme, \#photooftheday and \#smile tags. The gesture of showing something is not only represented by the pictures but is also reflected in the hashtags. The significance of publicly sharing something is primarily emphasized by possessive structures (e.g.: \#myart, \#mybag, \#mybirthday, \#myboy, \#mylife, \#mysore; \#ourdisneyadventure) or by the Hungarian word muti... ['show me'] (\#mutimiteszel ['show me what you eat']). 
As regards the hypotheses, I found the following:

\subsection{Hypothesis 1: Instagram users will generally tag their photos with eleven hashtags, where a hashtag chain is expected to contain synonyms and spelling variants of the same forms}

The 400 pictures contained altogether 4966 hashtags, that is an average of 12.41 hashtags per picture. This figure is a little bit higher than the expected eleven but it supports Cohen's (2015) views who recommended at least 11 hashtags per picture to trigger the most user interactions.

Hashtag chains usually contain multiple words having the same semantic field (e.g.: \#time, \#hours, \#sundayfunday, \#timeless, \#timepass, \#timepieces; \#teatime). Various morphological forms of the same word may appear next to each other: derived words (e.g.: \#health, \#healthy; \#cook, \#cooking); plural and singular forms (\#fitgirl, \#fitnessgirl, \#fitnessgirls); clipping (\#sis, \#sisters; \#chillin, \#chilling). The elements of a collocation may also appear together (e.g.: \#happy \#time; \#life \#time). Sometimes the same word appears in different languages in a hashtag chain (e.g.: \#time \#zeit \#idö \#tiempo). Mistyped forms do not count as intentional word forms (e.g.: \#autmn, \#autum instead of autumn).

\subsection{Hypothesis 2: The major part of hashtags will be in English, but at least half of the examined photos will contain hashtags in two languages (particularly in the case of users for whom English is a foreign language)}

The language of the hashtags was English in almost all of the cases (there were some rare instances in the corpus of Russian, Chinese, Korean, Italian, Arabic, German and Hungarian tags but almost always next to English counterparts). Naturally, the fact that the three keywords were in English strengthened this trend. The greater presence of German tags was partly due to the fact that the English tradition and the German Tradition are formal equivalents. In most of the cases, however, hashtags were given in English even if the text accompanying the picture is in another language (е.g.: Возможно, вы не знаете, но я желаю всем доброй ночи. Каждую ночь!!! \#jasmin \#jasminshor \#smile \#love \#night \#sweet \#dream \#my \#time).

As the sampling was done by a Hungarian linguist, so after English, the second most frequently used language was Hungarian, followed by Spanish, German and Russian. Languages with less than ten occurrences, single-occurrence and therefore unclassifiable forms (\#bezel), nouns (\#Berlin), numbers (\#1956), interjections 
(\#braaaap) and vague, uncommon abbreviations (\#bzh) were all classified into the Other category. Nearly $90 \%$ of all hashtags were in English (if only different tags are considered, and repetitions are deleted, this rate is $82 \%$ ), so non-English tags accounted for only $10 \%$ (571 items). This partly supports my hypothesis, as English hashtags indeed dominate the international corpus, but not every second picture is accompanied by a non-English hashtag.

\subsection{Hypothesis 3: The most characteristic pattern of photo subtitles will be a connection of text and independent hashtags}

The most typical picture-text pattern is the following: the picture is followed by non-linked text which can be taken as a subtitle and then - as further textual content - the hashtags (Table 1). Subtitles can be a single word, a sentence, a poem, a quote, and sometimes, though relatively rarely, even a very long text. If the post is shared on Instagram, subtitles sometimes appear as hashtags. This may take the specific form that instead of a series of independent hashtags all syntactic units or all words of a phrase or sentence are marked with a \# sign. Sometimes more important elements and keywords are emphasized as hashtags within the subtitle text (and this may be further combined with @ signs marking persons).

Table 1: Photo subtitling patterns on Instagram

\begin{tabular}{|l|l|}
\hline Pattern & Examples \\
\hline no text, only image & - \\
\hline only hashtags & $\begin{array}{l}\text { \#awesome \#time \#sunday \#bff \#love \#music } \\
\text { \#followback \#Delhi \#sdamarket }\end{array}$ \\
\hline only non-linked text & $\begin{array}{l}\text { [No occurrence in the corpus, as only hashtagged } \\
\text { pictures were collected. Still, there may be one example: } \\
\text { Christmas] }\end{array}$ \\
\hline $\begin{array}{l}\text { non-linked text + independent } \\
\text { hashtags (the most typical form) }\end{array}$ & $\begin{array}{l}\text { Found this old photo from over 25 years ago. Scary } \\
\text { how quickly time passes! \#time \#passingtime \#teenager } \\
\text { \#teenageyears }\end{array}$ \\
\hline $\begin{array}{l}\text { hashtags within a text (keywords } \\
\text { are emphasised by hashtagging) }\end{array}$ & $\begin{array}{l}\text { Our latest \#mashreads book selection is } \\
\text { \#FatesandFuries by Lauren Groff, a love story told from } \\
\text { two very disparate \#perspectives. Based off of the themes } \\
\text { of the \#book, for this weeks MashReads social challenge, } \\
\text { we want to see examples of juxtapositions you find } \\
\text { in the wild such as light and dark or two contrasting } \\
\text { textures. Be sure to tag your photos with \#mashreads to } \\
\text { enter. \#NYC \#PhotoChallenge (Image: @tylertronson) }\end{array}$ \\
\hline
\end{tabular}




\begin{tabular}{|c|c|}
\hline Pattern & Examples \\
\hline $\begin{array}{l}\text { coherent text with hashtags }+ \\
\text { list of extra hashtags }\end{array}$ & $\begin{array}{l}\text { \#cloudporn with \#lighthouse at old \#port of \#Chania } \\
\text { \#Crete \#Creta \#Greece \#travelgram \#instatravel }\end{array}$ \\
\hline $\begin{array}{l}\text { hashtagged words in } \\
\text { expressions, collocations }\end{array}$ & \#sweet \#dream \#my \#time \#crazy \#time \\
\hline $\begin{array}{l}\text { each word in a text is } \\
\text { hashtagged }\end{array}$ & $\begin{array}{l}\text { \#life \#is \#like \#a \#car \#if \#you \#keep \#going \#in \#reverse } \\
\text { \#you \#will \#not \#get \#to \#your \#destination \#but \#if } \\
\text { \#you \#speed \#up \#and \#do \#not \#take \#the \#time \#to } \\
\text { \#enjoy \#your \#surroundings \#you \#might \#get \#lost }\end{array}$ \\
\hline
\end{tabular}

\subsection{Hypothesis 4: The vast majority (90\%) of the hashtags will fall into the thematising or like-hunter categories, while unique hashtags will represent only a small minority (10\%). A large number of hashtags is expected to refer to the manner the photo was created}

Analysing the corpus, the originally planned three categories (thematising, likehunter, unique hashtags) had to be completed with another three: hashtags indicating group identity, hashtags describing how the picture was created, and hashtags that did not fit into any category and were meaningless for outsiders without a context, though not necessarily containing unique words (e.g.: \#N16, \#is, \#and, \#get).

Thematising context-marker hashtags dominate the sample (83\%). Similarly to posted pictures, these were characterised by seasonality: keywords like autumn, fall, halloween, pumpkin appeared in such high numbers as the sample was taken in late October.

A user's popularity is measured with the number of its followers and thus the number of user interactions it can achieve. In the case of the Instagram profile of companies, products and brands, the large number of followers enhances the efficiency of advertising and helps reaching the highest possible number of potential customers. For this reason, there were many ( 55 different types, 230 with repetitions) hashtags which encouraged following in several forms (e.g.: \#followme, \#follow, \#follow4follow, \#followback, \#followmeplease). Similarly, hashtags encouraging users to like or share the post (\#like, \#likesplease, \#likeitplease, \#likeme, \#likemyphoto; \#pleaseshare) also aim to popularise the posted information reaching as many users as possible, and are often based on mutuality: like is offered for a like or a follower (\#like4like, \#likesforlikes, \#likeforfollow). Hashtags reflecting on the 
phenomenon of hashtagging can be taken as meta-hashtags. ${ }^{5}$ Hashtags referring to joining to a community also serve the spreading of the content (e.g.: \#poetrycommunity, \#PoetsofInstagram; \#instaitalia).

Usually, unique hashtags are not only made of set phrases or collocations (\#goodfood, \#goodgirl, \#goodlife, \#goodvibes) but they are also created by writing a longer syntactic unit, even a full sentence, as one word. The sample comprised 154 unique hashtags (e.g.: \#gottadowhatyougottado, \#StillAKidAtHeart, \#tellmewhatyoudask, \#whereisthebagelemoji). Although they are not totally unique, imperatives and good advices constitute a separate group (e.g.: \#thinkaboutit, \#riseup, \#neverstopexploring, \#livethemoment).

Meta-information about creating the pictures was expected to be much more dominant in the corpus: only 50 types (with 102 occurrences) were found in this category (e.g.: \#vscocam, \#photoshoot, \#nofilter, \#blackandwhite, \#canon; cf. Schrey 2015).

\subsection{Hypothesis 5: The examined pictures are expected to be mostly about people, followed by objects and animals in order. As a sub-hypothesis, selfies are expected to represent $20 \%$ of the pictures depicting people (cf. Wendt 2014)}

The biggest thematic group contained indeed photos of people (138 out of 400). Of this, 43 evidently or admittedly (according to the hashtags) qualifies as selfie. This rate, however, surpassed my expectations: $31 \%$ of the pictures taken of people are self-portraits. Surprisingly though, only 11 of the 43 selfies reflected explicitly on the act of taking a selfie with the hashtag \#selfie.

The second largest group of pictures depicted objects (furniture, books, etc). Probably, the keyword \#truth resulted in the high number of posts displaying texts (memes, quotes) as images. Further categories deal with food and beverage (often hashtagged as \#foodie by analogy with selfie), nature, built environment and animals. Surprisingly, the traditional composition of a person posing with a famous touristic site in the background was quite rare in the sample (note that this would have been one of the most dominant composition if the keyword \#travel or \#travelgram had been used).

5 An example: \#lookatthecutekittenontherightalsoextralonghashtagsrule. 


\section{Conclusion}

I used three keywords matching the theme of the VLL conference to describe the relationship between pictures and hashtags, these new-type minimalistic texts which are similar to subtitles but have many different functions compared to them. Quantitative and qualitative analysis of small data was carried out to test the validity of five hypotheses.

The first hypothesis, which expected to find many spelling variants and synonyms among the hashtag chains consisting of an average of eleven hashtags, was mainly confirmed: the pictures in the corpus were accompanied by an average of 12 hashtags, which however, indeed included synonymous words and morphological variants. The second hypothesis, which expected an overwhelming dominance of English hashtags, was clearly justified with a $90 \%$ rate. The third hypothesis relied on previous observations when expecting that Instagram subtitles mostly follow the pattern of "unlinked text + independent hashtags". The fourth hypothesis was based on the results of former hashtag analyses. According to my results the three categories (thematising, like-hunter, unique hashtags) should be completed with at least three further categories (hashtags marking group identity, hashtags indicating how the picture was created and unclassifiable hashtags). The highest number of items belonged to the category of contextualising hashtags which verbally represent the content of the photo, while technical meta-information relating to the taking of the photo was not so characteristic than it seemed to be prior to the analysis. The analysis of the fifth hypothesis applied a semiotic approach, focusing on the connection between the content of the photos and the accompanying hashtags. More than one third of the pictures depicted people, and of this, one third qualified as selfie though seldom indicating this fact with the \#selfie hashtag.

As it has been emphasized earlier, my results on frequency of occurrence are valid only to this corpus and were meant to complete the theme of the conference. However, hashtag types, subtitle patterns and the very strong co-occurrence of words having the same semantic field in a hashtag chain are results that can be generalised. Further examinations may deal with the co-occurrence of certain elements in hashtag chains from a semantic aspect and the grammatical analysis of neologisms and word formation methods in Instagram-related texts. 


\section{References}

Cohen, David (2015): SurePayroll: Infographic: Hashing Out Hashtags. 23. 04. 2015. http://www.adweek.com/socialtimes/infographic-surepayroll-hashtags/619169.

Csire, Tímea (2015): \#selfie. A hashtagek használata az Instagramon. E-nyelv Magazin 2015/2. http://e-nyelvmagazin.hu/2015/05/29/selfie-a-hashtagekhasznalata-az-instagramon/.

Highfield, Tim - Leaver, Tama (2015): A Methodology for Mapping Instagram Hashtags. First Monday 20/1. http://firstmonday.org/ojs/index.php/fm/article/ view/5563/4195.

Hill, K. (2012): \#McDStories: When A Hashtag Becomes A Bashtag. Forbes. 24. 01. 2012.http://www.forbes.com/sites/kashmirhill/2012/01/24/mcdstories-whena-hashtag-becomes-a-bashtag/ [not available].

Hochman, Nadav - Manovich, Lev (2013): Zooming into an Instagram city: Reading the Local Through Social Media. First Monday 18/7.http://firstmonday.org/ article/view/4711/3698.

Kamer,Nimrod (2013): Brace Yourselves for the Proliferation of the 'Finger Hashtag'. Wired. 06.03.2013.http://www.wired.co.uk/news/archive/2013-03/06/hashtags

Kim, Erin (2012): Twitter Unveils 'Cashtags' to Track Stock Symbols. CNNMoneyTech. 31. 07. 2012. http://money.cnn.com/2012/07/31/technology/twittercashtag/.

Marwick, Alice E. (2015): Instafame: Luxury Selfies in the Attention Economy. Public Culture 27/1: 137-160.

Parker, Ashley (2011): Twitter's Secret Handshake. New York Times. 10. 06. 2011. http://www.nytimes.com/2011/06/12/fashion/hashtags-a-new-way-for-tweetscultural-studies.html.

Rambukkana, Nathan (ed., 2015): Hashtag Publics. The Power and Politics of Discursive Networks. Frankfurt et al.: Peter Lang.

Rocheleau, Sylvain - Millette, Mélanie (2015): Meta-Hashtag and Tag Cooccurrence: From Organization to Politics in the French Canadian Twittersphere. In: Rambukkana, Nathan (ed.): Hashtag Publics. The Power and Politics of Discursive Networks. Frankfurt et al.: Peter Lang.

Rubinstein, Daniel - Sluis, Katrina (2013): Notes on the Margins of Metadata. Photographies June 2013: 151. http://www.tandfonline.com/doi/abs/10.1080/ 17540763.2013.788848\#preview.

Schrey, Dominik (2015): Retrofotografie: Die Wiederverzauberung der digitalen Welt. MEDIENwissenschaft 01/2015: 9-26. 
Senft, Theresa (2013): Microcelebrity and the Branded Self. In: Hartley, John Burgess, Jean - Bruns, Axel (eds.): A Companion to New Media Dynamics. Malden, MA: Wiley. 346-354.

Slegg, Jennifer (2014): What Marketers Can Learn From These Hashtags Fails. The SEM Post. 01. 08. 2014. http://www.thesempost.com/marketers-can-learnhashtags-fails/.

Thode Hougaard, Tina (2014): \#hashtags \#metakommunikerende \#nøgleord. In: Schoonderbeek Hansen, Inger - Thode Hougaard, Tina (eds.): 15. Møde om Udforskningen af Dansk Sprog. Århus. 149-170.

Ting, Hiram - Winnie Wong Poh Ming - Run, Ernest Cyril de - Lau Yin Choo, Sally (2015): Beliefs about the Use of Instagram: An Exploratory Study. International Journal of Business and Innovation 2/2: 15-31.

Veszelszki, Ágnes (2016): A hashtag mint új frazeologizmus? [Are hashtags new phrasemes?]. In: Bárdosi, Vilmos (ed.): Frazeológia - az emberi világkép tükrözöje [Phraseology]. Budapest: Tinta. 147-158.

Wendt, Brooke 2014: The Allure of the Selfie: Instagram and the New Self-Portrait. Network Notebook \#08. Amsterdam.

Yang, Lei - Sun, Tao - Zhang, Ming - Mei, Qiaozhu (2012): We Know What @ You \#Tag: Does the Dual Role Affect Hashtag Adoption? University of Michigan. http://www-personal.umich.edu/ qmei/pub/www2012-yang.pdf.

$\mathrm{W} 1$ = \#OriginStory. Carnegie Mellon University. 2014. http://www.cmu.edu/home page/ computing/2014/summer/originstory.shtml. 
VISUALITY IN TEACHING AND LEARNING 

Matthew Crippen

\section{Dewey on Arts, Sciences and Greek Philosophy}

\section{Introduction}

In this chapter, I ponder John Dewey's efforts to understand science in terms of both the practical and fine arts; and how his writings on art and science suggest that Plato and Aristotle correctly identified conditions under which things become visible to cognition, even while not satisfactorily answering how these conditions can be met. Since Dewey understood aesthetic experience as a dramatic process, I also discuss how visual experience is imbued with narrative and therefore temporal structure, and the importance of this to understanding and learning.

\section{Intelligible Appearance, Modern Science and Art}

Dewey wrote that " $[t]$ he doings and sufferings that form experience are, in degree to which experience is intelligent or charged with meanings, a union of the precarious, novel, irregular with the settled, assured and uniform - a union," he added, "which also defines the artistic and esthetic" (1925: 358). "Doings" here meant actions carried out; "sufferings," the effects undergone in consequence. Thus a blind woman pushing her cane into the world meets non-haphazard resistance and thereby undergoes meaningful consequences of her actions, and perceptual experience of the world emerges. By emphasizing the union between the novel and assured, Dewey further stressed that experience is pallid and thin when there is little free play; but simultaneously that meaningful connections are lacking when actions are unvarying and mechanical, so that things lose significance and withdraw from notice.

For Dewey, the conditions under which we have meaningful experience are also conditions under which "we become capable of perceiving things instead of merely feeling and having them" (1925: 182). The distinction might be compared to the difference between seeing a candle flame as a candle flame and merely being aware of a fluttering smear. In the first instance, we do not merely register qualia; we discern what the thing is; and in traditional philosophical parlance discerning the "what is" means discerning "essence". It will be recalled that eidos - usually translated as form and occasionally as essence - is a Greek word that "basically means 'something that is seen"' (Novak 2004: 77). It is a word, moreover, that Plato poetically and brilliantly used to signify that which allows the "being" or "what is" 
of a thing to appear to the knowing mind. Brilliantly does not mean unproblematically, however; but while Plato's concept of eidos entails a theory of knowledge Dewey criticized, he was not unsympathetic to classical Greek outlooks. In fact, Dewey favored concepts of experience articulated by Plato and Aristotle, albeit giving experience more value than his predecessors. He retained the classical opposition to nominalism, though did so in non-classical ways - a point addressed later. He also seems to have accepted the classical view that things can only appear intelligibly if the following criteria are met: There must be structure, unity and endurance.

Dewey's discussions of experience - particularly aesthetic experience - illustrate this last point. They do so by showing experience and therewith intelligible appearance - which Plato's concept of eidos equates to form - emerge when doings and undergoings are linked in worldly action, integrating in much the same way incidents in a story cohere into a single, narrative structure that endures over time. Thus a focal point in a painting pulls other elements into a more coherent unity; and when we reach the climax of a play, earlier portions unite and gain significance in comparable ways. By virtue of this, constituents in things experienced aesthetically do not appear as isolated, fleeting bits, here now, gone an instant later. They gain stability within a temporally extended and integrated narrative-like structure.

Dewey gave the following example. Imagine a painting "in which masses point upward". A "first impression" may be "that of movement from below to above". If the painting has horizontal rhythms, our eyes are also drawn "across the picture," even while "the intensity remains in patterns that rise". Suppose further that a heavy mass dominates a lower corner, and "that instead of fitting into the vertical patterns," this mass "transfers attention to [...] horizontally disposed" features in the composition. When our eyes meet it, "there is a halt, an arrest, a punctuating pause". However, this does not "operate as a disturbing interruption" or "break in experience," but rather "as a re-direction of interest and attention" and therewith an "expanding [of] the significance of the object" (Dewey 1934: 174). If the experience is truly aesthetic, moreover, it will be one that pulls the capacities of our body into unity. Here, wrote Dewey, a "tendency to turn the eyes and head is absorbed into a multitude of other impulses"; and while "the eye is primarily active, [...] the color quality is affected by qualities of other senses overtly active in earlier experience" (1935: 175), so that we can "perceive, by means of the eyes as causal aids, the liquidity of water, the coldness of ice, the solidity of rocks" (1934: 123). Thus the painting appears unified because of the way it coordinates our sensitivities and doings, so that they "become members of a single act" (1935: 256; for review, also see Crippen 2014 and 2016). 
The unity of the painting also emerges because the pattern of activity it brings about has dramatic pauses, culminations and more. Aesthetic experience is accordingly temporally extended and narrative-like, and interestingly, it satisfies the earlier mentioned classical criteria for intelligible appearance. However, while sharing the classical view that structure, unity and endurance are pre-conditions of things appearing to us, Dewey did not equate unity to universals binding the many into one, nor endurance to immutability. Instead, change, irregularity and instability help bring unity, structure and endurance. Hence a movie endures as a unity largely because of the way it changes and builds, whereas mechanical and unchanging intervals tend to lose significance, coherence and withdraw from notice. Paintings are similar.

By emphasizing change as a precondition of things appearing intelligibly, Dewey shifted away from the traditional Western philosophical view that the intelligible and therewith the knowable are beyond change. Some might be inclined to ask "So what?" on the grounds Modern era science has done the same. Yet this conclusion is somewhat misplaced. After all, Isaac Newton advanced laws meant to hold across time and place - laws, therefore, that are immutable and universal. Furthermore, though Newton partly derived his laws from observation, they do not exactly describe motions we could perceive through the senses. Instead, they capture how planets would theoretically move if they were point-like objects, which is to say, under ideal conditions never observed. Newton thus described physical reality in terms of immutable and universal patterns only realizable under ideal conditions in which all materiality is subtracted away - conditions, therefore, never actualized. Other physicists have done similarly, with Galileo deriving kinematic laws by first observing rolling marbles, and then imagining their motion on non-existent frictionless surfaces, which recalls Aristotle's observation that inquiries cease to deal with material nature and consequently to be natural science to the extent they become mathematical. ${ }^{1}$

At the same time, the Modern emphasis on experimental science has given credence to the view that we come to know reality by actively manipulating it. Dewey argued, in particular, that this involves an adjustment to the classical tendency to think tekhne a lesser form of knowledge than theōria, that is, theoretical or contemplative knowledge. In the texts of Plato and Aristotle, tekhne encompasses everything from statecraft to the medical arts to the art of war, calculating, ship piloting, playing musical instruments, painting, making shoes and managing money.

1 For elaboration, see Book I, lesson 9 in Thomas Aquinas's Commentary on Aristotle's Metaphysics. 
It entails knowledge about certain kinds of objects, but these objects of knowledge are not objectives at which it ultimately aims (see Aristotle Eud: 1216b16-18; Phys: 193b10-20). Awls, leather and even shoes are objects of knowledge for the shoemaker, but the objective of the shoemaker's art is not to know what these things fundamentally are, but rather to know how to work available materials into shoes.

According to Dewey, the rise of Modern science entailed "a generalized [...] adoption of the point of view of the useful arts" (1925: 133) and therewith a reordering of classical Greek values. An initial point to remember is that "science" from Latin scientia for "knowledge" - traditionally refers to any organized field of knowledge. Traditionally, moreover, it has designated fields of inquiry held in high esteem. Hence when Christianity became dominant, Christian theology became a science. Then, when systematic observation and experimental study of material nature became a preferred approach, it was designated as science. So if modern science adopts the point of view of the useful arts, it follows that reverence for tekhnē has grown - and today many do esteem technology (i.e., useful arts). Dewey suggested, however, that we express esteem more in deeds than words, for we often classify disciplines as "scientific" with the intention of distinguishing them from arts. Dewey obviously thought this distinction overdrawn, and offered a number of reasons for thinking so.

First, scientific observation is carried out with the aid of instruments or tools by means of which we work upon things; and when workings are skillful, imaginative and intelligent, directed towards an end and efficacious at producing some result, they fall within the scope of what we call "art". Dewey explained that scientists study an object by bringing "some energy to bear upon [it] to see how it reacts" (1920: 113) or by "deliberately alter[ing] the conditions under which we observe [it]" (1929: 85), as when using a telescope to redirect light. Aristotle characterized art as a kind of applied knowing that works in the "sphere of coming to be" (An. Post.: 100a9), and contemporary scientists, through application of art, introduce "changes which will elicit some previously unperceived qualities" (Dewey 1929: 87).

Second, scientists do not typically build or learn theories with the final objective of securing them as objects of knowledge. Rather, their objective is securing means through which observable phenomena can be rendered intelligible. Thus whereas knowledge of Platonic forms - assuming, for a moment, that forms have being - is knowledge of reality, knowledge of scientific theories is possession of instruments that work to make reality knowable or at least intelligible (Dewey 1929: 205-206). So while it is perhaps going too far to equate scientific theories, say, to the shoemaker's knowledge of leather, the two share an important commonality: both are used for 
working and making. The shoemaker's knowledge is applied to the making of shoes; scientific theories as sense-making instruments; and neither are complete until they work upon and re-form materials, thereby making them appear in new ways.

Scientific theories, moreover, structure how scientists directly and indirectly work upon objects of investigation and thereby "shake loose" heretofore "unperceived qualities" (Dewey 1929: 87). In addition to and by virtue of structuring hands-on work, theories also structure how scientists make objects - both conceptual and physical - relate. Therewith they structure how given fields of inquiry knit together into coherent worldviews or narratives. The Copernican theory that the Sun is at rest literally changes how we must picture relationships between celestial objects if we are to picture them coherently at all. The point is that scientific theories - however they may arise - perform work; they perform what Dewey called "the work of art" (1934: 214). In the case of fine arts, this "work takes place when a human being cooperates with [an artistic object ...] so that the outcome is an experience that is enjoyed because of its liberating and ordered properties" (1934: 214). And with scientific theories, the work takes place when actions, incidents and objects coordinate into instrumental, which is to say, integral and hence meaningful relationships, so that orderly arrangements cohere intelligibly into appearance.

Dewey believed his understanding of knowledge as art was anti-skeptical in the sense that it "does not commit us to the notion that classes are [...] purely mental" or "merely nominal" (1920: 154). It does not because "knowing" means making "a certain difference in reality" (Dewey 1908: 47) and conceptual classes are realized in "objective action" (Dewey 1920: 154). The general distinction, for example, between hard and softwood is realized in how carpenters generally work and build with lumber. Very literally, therefore, the distinction is based in human constructions. Yet we do not designate houses and other constructed entities as figments of imagination, so Dewey warned against rejecting conceptual distinctions as such simply because they reflect worldly arrangements we help build (1925: 181-191). Like artists, we confer "upon things traits [...] which did not previously belong to them." Complaints that this makes knowledge a "perversion" reflects "a confusion of tenses. Knowledge is not a distortion [...] which confers upon its subject-matter traits which do not belong to it, but is an act which confers upon non-cognitive material traits which did not belong to it" (Dewey 1925: 381).

\section{Implications on Teaching}

So how might all this translate into classroom practices? To begin with, the forgoing account reaffirms that things are not visible to the knowing mind if there is no unity, endurance and structure. In contrast to older views, however, it also suggests 
things only take such form if there is change, yet artful and not just random variation. In line with more recent approaches, therefore, it affirms that knowledge involves mucking around. By means of this, we change the world and produce outcomes that change us. Thereby we learn. The imaginative experimentations of impressionist painters, for example, open us to seeing light in new ways, and something analogous occurs in experimental science.

Interpreting this mucking about into what counts as knowledge means, in effect, arranging it into dramatic form. This point is illustrated in the earlier example of the painting. But likewise, when students engage in learning by doing, whether they are putting car engines together or doing scientific experiments, comparable effects are achieved. Making sense of an experiment means telling a story, and putting an engine together or even learning how it is put together can be experienced as a story. This view, which is typified in Dewey's claim that science and knowledge are art, resonates with the prevailing view that we learn more from doing than mere listening or reading (Sousa 2006: 95).

Regarding images and visual learning, Dewey's account offers a viewpoint that has received relatively little attention: namely, that pictures, when they engage us in a relatively full manner, do not merely operate on a purely cognitive or mental level, but engage a variety perceptual faculties, along with motor capacities. I therefore conclude with a plea: that when pondering visual aspects of learning, we consider how images can motivate a total body process. That is, we ought to consider how the visual is never merely visual, how it not only mobilizes other perceptual faculties but movements too; and how, by developing visual tools along such lines, we might become better teachers.

\section{References}

Aristotle: Eudemian Ethics. Translated by H. Rackham (1971). Cambridge: Harvard University Press.

Aristotle: Physics. Translated by R. P. Hardie and R. K. Gaye. In: McKeon, Richard (ed.) (1941): The Basic Works of Aristotle. New York: Random House. 213-394.

Aristotle: Posterior Analytics. Translated by G. R. G. Mure. In: McKeon, Richard (ed.) (1941): The Basic Works of Aristotle. New York: Random House. 108-186.

Crippen, Matthew (2014): Body Phenomenology, Somaesthetics and Nietzschean Themes in Medieval Art. Pragmatism Today 5: 40-45.

Crippen, Matthew (2016): Dewey, Enactivism and Greek Thought. In: Madzia, Roman - Jung, Matthias (eds.): Pragmatism and Embodied Cognitive Science: From Bodily Interaction to Symbolic Articulation. Berlin: De Gruyter. 233-249. 
Dewey, John (1908): The Practical Character of Reality. In: Dewey, John (1931): Philosophy and Civilization. New York: Minton, Balch \& Company. 35-56.

Dewey, John (1920): Reconstruction in Philosophy. New York: Henry Holt and Company.

Dewey, John (1922): Human Nature and Conduct: An Introduction to Social Psychology. New York: Henry Holt \& Co.

Dewey, John (1925): Experience and Nature. Chicago: Open Court Publishing Company.

Dewey, John (1929): The Quest for Certainty. New York: Minton, Balch \& Company. Dewey, John (1934): Art as Experience. New York: Minton, Balch \& Company.

Novak, Joseph (2004): A Sense of Eidos. Eidos 28: 77-81.

Sousa, Ronald (2006): How the Brain Learns. Third edition. London: Sage Publishing. 



\section{András Benedek \\ SysBook as a Visual Learning Frame}

Thinking with pictures is an essential strand in the intellectual history of technological development.

(Ferguson 1977: 827)

\section{Introduction}

This chapter points out that measurable learning activities show time-dependent features that correlate with the use of visual communication forms used in study programs. This chapter also presents the basic principles of systems and control for everyone, hopefully in an understandable way and also with deeper explanations and a mathematical description. According to the author's hypothesis, visual learning carries the possibility of such parables that will be able to improve the efficiency of human learning, currently characterised by a constant lack of time and information pressure. SysBook, as opposed to a traditional education based on verbal communication (Vamos-Bars-Benedek 2015: 7), is software that links visual content related to a given subject to traditional written information, very much the way comics work. At the same time, it also addresses the given subject in the language of mathematics and recommends references for those who seek further information. In this way, students learning from a particular document while processing its content become actively involved, and the curriculum may be continuously updated and extended. All this is realised in a modern, accessible, online framework.

\section{Theoretical Background}

The process that resulted in historic changes in education may be viewed from several aspects. One of these may be approaching the process from the direction of changes in content and the applied tools of demonstration. In this single field only, a large and diverse group of didactics experts and theorists developed numerous theories on how to teach more and increase the efficiency of teaching. Ferguson's paper The Mind's Eye: Nonverbal Thought in Technology (Ferguson 1977: 827-836) almost forty years ago pointed out how poorly our current education paradigm is able to exploit the potential of visual learning. The art interpretations of learning make us abandon older teaching traditions when designing new curricula in a 
digital environment, providing learners with a flexible, continuously developing curriculum. Higher education has always been a unique laboratory for educationrelated innovations, concentrating significant research and development potentials with excellent subjects for experiments aiming at modernising education, i.e. students. In the past 25 years, several theorists pointed out that increasing curricular requirements cannot be efficiently managed by formal education and the traditional tools of education should be modernised. The rapid penetration of ICT tools since the second millennium in particular presents a challenge regarding the practice and methods of education (just consider mobile communications, hybrid solutions in smartphones, multiple functions or apps). Hence, we selected the new possibilities of visual learning as a subject of our research, responding to the main trends of these changes. In addition to theoretical research, our work also included innovative didactic development aiming at creating a new system of teaching of increased complexity, regarding both the activation of students and the development of curricula. Keywords in the process include increasing the number and quality of visual elements, exploiting the potentials of the new technology and thus increasing the activity of students.

An important preliminary aspect of our research was the realisation that both learning and the teaching process have become increasingly open systems. This openness is partly the result of a change of paradigm, and partly the application of ICT tools themselves, that have rendered learning a form of communication no longer dependent on either space or time constraints. Learning in this latter sense is about information that is no longer characterised by closed text blocks, but images and other elements presented in particular selection algorithms. This process was recognised by philosophers as early as the turn of the 20th century, and interpreted as a return to the origins of visual communication. In this sense, the natural way of communication between human beings relies on the application of images, icons or comics where film clips represent an interesting manifestation of unique, relatively short narrations (they quickly penetrated the world of teenagers in the past decade in the form of television advertisements and YouTube clips).

At the turn of the millennium, because of mobile technologies, we are moving fast from the appearance of human-machine interactive communication to the formation of spatial independence of human communicational possibilities. These two landmarks imply new pedagogic challenges figuratively also symbolize thresholds, one of which we have already crossed, and we hesitate to cross the other, from which we are faced with an ever complex transformation of the world of education. Our traditional approach to classroom teaching and learning has fundamentally changed in the last decade with the possibility that visual 
aids - overhead projectors or video projectors - have became virtualized, made in 'real-time' by broadband data transmission without physical presence.

A series of new frameworks have appeared in learning (digital environment) and the relevant new approaches are being formed currently. In his essay Open Work (Opera aperta, 1962) Eco, a half century ago, discussed the aesthetic properties of "open work" as essentially ambiguous, offering a range of potential meanings, where the author offers 'the interpreter, the performer, the addressee a work to be completed' (Eco 1989: 8-9) and it all became real. Today's modern e-learning curricula (OER - Open Education Resources) try to find the answer to the question how the curriculum can be "opened" and the knowledge transferred to students in an open structure. Nyíri took a particularly inspiring role in finding such answers (Nyíri 2003, 2012, 2014). Joining his work and in the very framework of the VLL workshop and conferences, I decided to examine the questions related to educational construction (Benedek 2014,2015). It is important to emphasise the joint thinking process here, as several major higher education institutions all over the world separate the dimensions of this problem and tackle them individually. Initiatives related to research on education theory were turned into experiments in the past decade with important practical relevancies. Such practical results include the expressed involvement of the representatives of connectivism, promoting initially the openness of higher education (Siemens 2005) and the penetration of MOOC (Massive Open Online Courses) in rank-leading higher education institutions. The development and dissemination of open educational structures have become priority topics (Molnár 2014).

\section{From Theory to the Practice}

In 2013 and 2014, 29 digital textbooks were developed at the Budapest University of Technology and Economics in the framework of a new curriculum development project (Benedek-Molnár 2014: 3646-3650). Their authors, distinguished experts of their respective fields, were requested to participate in a training session where they were expressly asked to include visual objects in the content, corresponding to the principles of modern OER (Open Education Resources) development. Analysing 10 randomly selected examples of the textbooks with different professional content, but essentially made for the training of vocational teachers, we could conclude that the textbooks, 90 pages long on average and optimised for a screen, included altogether 602 images (figures, photos, tables). It means that even in the newest textbooks that support online learning, there is one image for every 1.5 pages on average only. From these, tables and figures 
(drawings) represented $42 \%$ and $36 \%$, respectively, and only $22 \%$ (one-fifth of the visual content) were photos.

Improving the efficiency of an education system predominantly relying on verbal content may represent a significant challenge due to the lack of the necessary time and information and the slowness of correction mechanisms in the case of traditional curricula, as it was proved by several methodology experiments as cooperative methods, project-based work, and connectivism (Siemens 2005) in learning. Even "modern" curricula that had been developed by the end of the 20th century had a linear structure and the prevailing dominance of verbal content ( $80 \%$ on average) was changing only slowly, giving way to visual content which in turn were mostly composed of static pictures.

In the first semester of the study year 2015/2016, we directly surveyed our postgraduate students who studied for a second-degree about the learning frameworks facilitated by ICT tools. We presumed that cooperative networking activities well matched the life of students as well as their everyday ICT use. We surveyed students specialised at teaching as they were presumed to be interested both in teaching and learning. The survey also included questions related to the use of visual content. Conventional learning and preparing for classes often necessitates the processing or development of visual content, including learning aids and demonstration materials. Although students specialised at teaching received support in the form of online content and e-learning programmes, we also phrased direct questions about the framework system (Moodle) that has been applied for almost a decade.

The survey included altogether 27 questions; most of these could be answered on a 5-point scale. They tackled the attitude of the users of e-learning curricula. The survey was sent to 150 students from which 115 responded. The sample may be described as follows: respondents were both males and females, 56 and 59 persons, respectively; the age of respondents approached normal distribution: $28 \%$ between 31 and 40 years old, $40 \%$ between 41 and 50 years old and $28 \%$ between 51 and 60 years old.

To the question "How efficiently can you learn from the e-learning curriculum regarding didactics and methodology?" students' responses were essentially positive. Those who were fully satisfied with these curricula made up for $20.4 \%$. More than half of the respondents, $54.9 \%$ ranked these curricula as 'good' while $21.2 \%$ considered them being of 'medium quality'. Only $2.7 \%$ indicated dissatisfaction.

As for the active contribution of students to curriculum development, the preference of students regarding visual content was particularly important. To the question "Would you consider it useful if case studies (descriptions of good 
practices) were developed in this framework?" almost two-thirds of the respondents $(61.7 \%)$ fully agreed and no rejections were received. Considering all this, we created a new learning content net with the following features:

Figure 1: The schema of complex learning content net

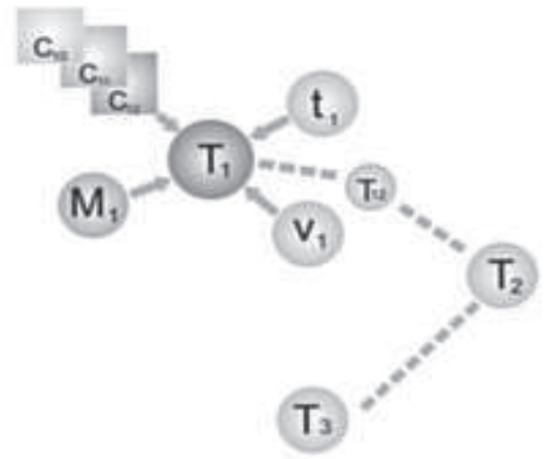

This program had methodological questions in mind, with special regard to mathematics and other disciplines of natural sciences and the related applied sciences such as technical sciences and their applications. The schema of the complex learning content net (Figure 1) shows how the curricula are based on descriptive verbal elements $($ Text $-\mathrm{t}$ ) that are supported by visual elements (Visual $-\mathrm{V}$ ) and mathematical formulas (Math - M). Traditional curricula (published in the format of textbooks) usually include the combination of these, structured in a rigid linear sequence, such as 'explanation, figures, formulation, explanation' and so on. Often random examples are only given as case studies (Case - C) to illustrate practical applications. The visual representation illustrates the most important features of the structure as knowledge elements are organised into a system, which is independent of scale. For curriculum design developed in open access, cloud services offer a development infrastructure surpassing all previous solutions. Showing other connections between these elements in order to develop a dynamic network was typically hindered by disciplinary and temporal restrictions knowledge on systems.

This new curriculum was supported by e-learning, i.e. a digital textbook was available for students in the MOODLE (Modular Object-Oriented Learning Environment) framework system as a form of permanent support. Also we used the SysBook platform (W1), mentioned previously, which combines general knowledge with applications, thus creating a framework where textual information, 
static comics elements, animated GIFs (Graphics Interchange Format) and, in several cases, elements of mathematical representation (formulas, functions) together form a 'knowledge space' that can be extended as needed.

\section{Forward to the New Content Development}

Our survey indicated that creative tasks and the possibility of the complex use of visual elements match the ideas of students about e-learning content. This new curriculum, where verbal and visual elements are presented in a one-to-one ratio, and where knowledge elements are organized into a network, would be scale-independent and structured as a graph. It would also be supported by a mathematical representation to enhance both its theoretical and practical aspects, and users would be allowed to extend it by means of case studies and practical examples.

The e-learning textbook was created in the fall semester in 2015 by the curriculum developers (subject: Systems in Vocational Education) with the SysBook platform assisting those who were interested. We asked the students to make "case studies" as micro-content, with the compulsory inclusion of visual elements. These case studies had to be optimised for a screen (laptop, smartphone, etc.) according to the rules applying to micro-content, include visual content that describe the operation of the system and, if possible, also include a mathematical formula for the same purpose.

Figure 2: Illustration from SysBook - Probability frequency

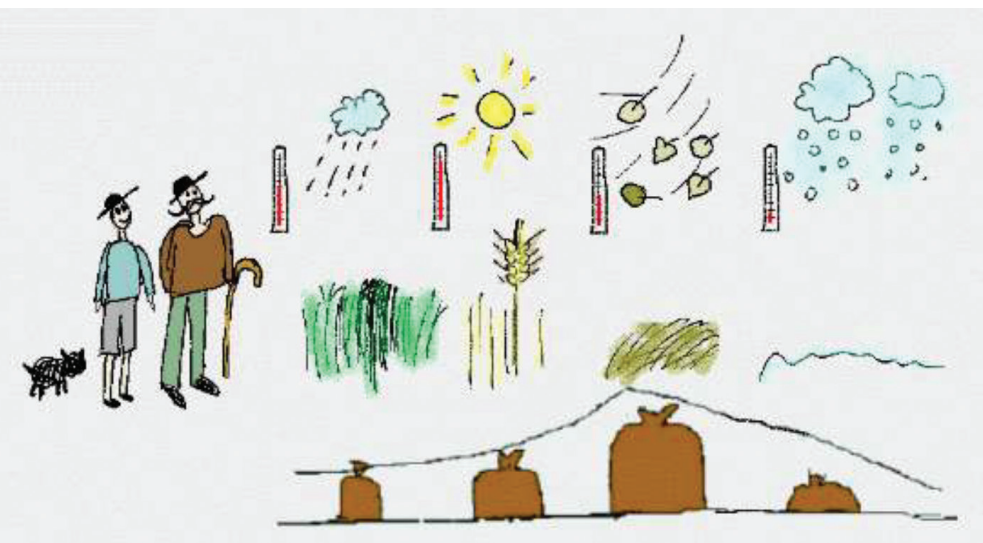

(source: W2) 
The SysBook gives the students a peculiar structure. Each one of the almost 140 sections is customised for digital screens and each one is constructed to represent six levels of interpretation (Comics - Description - Maths - Example - Theoretical - Education). The content is presented in quantified units which the reader can read linearly but because of the levels of interpretation mentioned above, each unit offers a range of possibilities to get familiar with a particular topic and examine it from various aspects. As a result of its structural features, SysBook takes the middle ground between modern hypertexts and traditional books.

Most students proved to be extremely creative when completing this task. For illustration, we selected the picture explaining free fall, a perfect example of how well such a relatively complex phenomenon can be illustrated, explained and understood this way.

Figure 3: Free fall

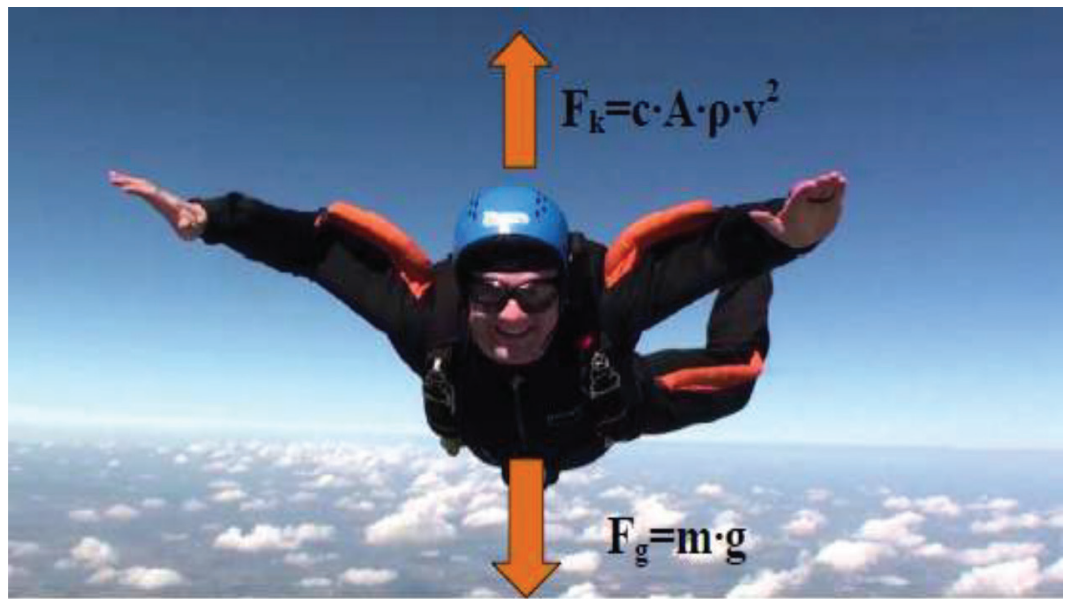

(source: part of a student's work; author: Tibor Tóth, Budapest University of Technology and Economics, 2015)

Such case studies that use strong visual elements and apply these for the purposes of orientation can be prepared by the students when given as a task. Explanations and the editing work may be considered themselves as educational constructions and thus, the preparation of the case studies is viewed as a unique way of collaborative learning.

It is also obvious, however, that the network environment defined by the applied technologies and virtual reality that breaks down the spatial and temporal limits of social interactions both symbolically and physically have an increasingly 
important role in shaping the social environment of learning. We may consider it a major trend. For those committed to modernising education, the possibility of learning systems divided in time and space may be a good basis for innovation, while the same fills the advocates of conventional education with terror. Although the virtual learning environment offers several options to modernise teaching methods, major projects in this field are less typical in Hungary than social initiatives illustrating the key idea of the change. In this initial phase of our research, we can phrase a few hypotheses that should be verified empirically in the years to come, by means of research that should involve other disciplines (psychology, informatics, physiology) in addition to pedagogy. Focusing on key aspects, the conscious strengthening of the role of visual learning may yield the following results:

A chance for collaborative development where the construction of microcontent by students and teachers facilitates a strong and efficient horizontal communication to replace the conventional vertical communication, and thinking outside the box of formal education which is limited both in space and time.

\section{Conclusions}

Open online content can be considered as the key results of innovation. The new ICT environment and the applied technical tools guarantee the essential openness of these contents. This unique feature clearly distinguishes the content from the strictly controlled and closed system of conventional curricula; however, obtaining experiential knowledge in the process of collaborative creation significantly reduces the risk of using unverified elements when the common knowledge base is extended.

- Continuous synchronisation. While it is apparently a technical aspect only, it has a great significance in relation to the features described above. Creation, even at the level of elements, may be evaluated (validated and approved) in well-defined phases. Although the medium is developed in the specific social dimensions of the learning environment, it is important to know which one of the many phases the process has reached at any given moment. This is facilitated by continuous synchronisation, a feature that is also linked to the next one.

- Automatic updating, an important process to follow various changes in the knowledge elements and the differences between sources. Updating in the current phase of research is much simpler in the framework provided by modern 
IT infrastructure than in the restricted and formal system of public education, in the practice of higher education in particular.

- Content sharing and data security are also features considered important in our experimental teaching environment. Of course, we also had to take into account the possibility that students would submit ideas for image content that represent a serious technical challenge to the traditional educational infrastructure. However, the latest ICT developments offered solutions to this problem, also directing our attention to a unique feature:

- Unlimited memory - cloud services. Their advantages were first experienced by researchers in high-tech subjects who needed superior infrastructure for their work but cloud services, like so many other technical innovations, have already started to penetrate the daily operation of education. The most important result here is that the restrictions forced by traditional technologies (allowed number of characters, pages, etc. in the curricula) can be now eliminated, hence images will cease to be a "necessary evil". Cloud services make it possible to include more visual content, resulting in an increasingly complex representation of knowledge. It does not only diversify demonstration possibilities but also changes learning communication, putting more emphasis on visual elements:

- A new creative learning environment is being/may be created. Whether the present continuous tense indeed applies or we are only talking about some obscure possibility will be decided by the results of the coming years.

\section{References}

Benedek, András (2015): More Visual Content into Vocational Education. Opus et Educatio 2: 39-47.

Benedek, András (2014): Visual Education: Old and New Dilemmas. In: Benedek, András - Nyíri, Kristóf (eds.): The Power of the Image. Emotion, Expression, Explanation. Visual Learning. Frankfurt/M.: Peter Lang Internationaler Verlag der Wissenschaften. 199-212.

Benedek, András (2015): Visuality as a Tool for Expanding Learning. In: Teixeira, António Moreira - Szűcs, András - Mazár, Ildikó (eds.): Expanded Learning Scenarios. Barcelona: European Distance and E-Learning Network. 3-8.

Benedek, András - Molnár, György (2015): New Approaches to the E-content and E-textbook in Higher Education. In: Chova, Gómez - Martínez, López - Torres, Candel (eds.): INTED2015 Proceedings, 9th International Technology, Education and Development Conference. Madrid, International Academy of Technology, Education and Development (IATED). 3646-3650. 
Eco, Umberto (1962): Opera aperta. Forma e indeterminazione nelle poetiche contemporanee. Milano: Bompiani.

Eco, Umberto (1989): The Open Work. Cambridge: Harvard University Press.

Ferguson, Eugene S. (1977): The Mind's Eye: Nonverbal Thought in Technology. Science 197: No. 4306, 827-836.

Ferguson, Eugene S. (1994): Engineering and The Mind's Eye. Cambridge: MIT Press.

Molnár, György (2014): Modern ICT Based Teaching and Learning Support Systems and Solutions in Higher Education Practice. In: Turčáni, M. - Drlík, M. - Kapusta, J. - Švec, P. (eds.): 10th International Scientific Conference on Distance Learning in Applied Informatics. Nitra: Wolters Kluwer, Law \& Business. 421-430.

Nyíri, Kristóf (2003): From Texts to Pictures: The New Unity of Science. In: Nyíri, Kristóf (ed.): Mobile Learning: Essays on Philosophy, Psychology and Education. Vienna: Passagen Verlag. 45-67.

Nyíri, Kristóf (2012): Visualization and the Horizons of Scientific Explanation. In: Benedek, András - Nyíri, Kristóf (eds.): The Iconic Turn in Education. Series Visual Learning, vol. 2. Frankfurt/M.: Peter Lang. 127-150.

Nyíri, Kristóf (2014): Meaning and Motoricity: Essays on Image and Time. Frankfurt/M.: Peter Lang.

Siemens, George (2005): Connectivism: A Learning Theory for the Digital Age. International Journal of Instructional Technology and Distance Learning. http:// www.elearnspace.org/Articles/connectivism.htm.

Vámos, Tibor - Bars, Ruth - Benedek, András (2015): Basic Disciplines of System and Control for Everyone. In: Guran, Ardeshir - Bars, Ruth - Gwinner, Joachim Krmela, Jan (eds.): 12th International Symposium on Stability, Vibration and Control of Machines and Structures. Prague.

$\mathrm{W} 1$ = http://sysbook.sztaki.hu/index.php?\&lang=en.

W2 = http://sysbook.sztaki.hu/sysbook6.php?page=19\&left=intro\&right=intro. 


\section{János Horváth Cz. \\ Micro-content Generation Framework as a Learning Innovation}

\section{Introduction}

Young people today have established a new content consumption culture by the active, everyday use of content sharing sites. The time dedicated to particular content items has decreased, while the number of texts, images or other media items viewed in a given unit of time has increased. Technology poses no limit to "information gluttony": state of-the-art Web 2.0 technologies facilitate connection to a continuous news feed. The basic economic principles also work here, however, as the value of ample resources is low. To compensate for the inflation of information value, an experiment was initiated to examine the potential of microcontent to add value to education. Micro-content generated for the purposes of higher education are well structured, have limited volume and can be managed as units, while the validity of the information contained therein is guaranteed by the involvement of named authors, feedback by the community and proofreading provided by teachers. In this paper we discuss the latest phase of a work process started earlier to renew micro-content. Using software that operates in a Web 2.0 environment, participants can create and publish their own micro-content collections. Each micro-content receives a unique identifier and authors' data are preserved, facilitating the free copying of collections and their components into other micro-content collections. I offer the conclusion that in using this method, student communities may create their own knowledge assets on their own merits, which in turn lead to better learning results.

\section{The Early History of Micro-Content}

Micro-content (Lindner-Hug 2006; Lindner 2007), as their name suggests, are created to convey information in the most compact form possible (Nyíri 2010). Text-based micro-content are characterised by a concise, straightforward style and a complete lack of "verbal fluff". One of their important features is the low cognitive load associated with obtaining and understanding a given unit of information, compared to other media such as news, novels, radio interviews, etc.

Micro-content cannot be strictly defined according to their size only, as size may depend on time, location and application, or the relevant agreement within 
a group of users. The tool used to transfer the content also influences the size and quality of content. Conventional postcards, for example, could only convey messages limited in size, representing an early form of micro-content.

The short message service, still popular today, limits messages to 160 characters. We might think that this limit was due to technological limitations at the time when the GSM telephone system was being standardised in the 1980s, but actually, if the related press information is to be trusted (W1; W2), it was based on the decision of a single person. Twitter was supposed to be the short message supplier of the Internet, initially allowing 140 characters for a user message. However, Twitter policy has radically changed since then (W3), and unlimited messages can be now accompanied by pictures, too. Hence, this representative of micro-content has ceased to exist.

A message may not only be defined as micro-content using the number of its written characters. Snapchat allows a maximum of 10 seconds for viewing an image or video sent by a user, and you cannot replay it. In this case, users should phrase straightforward messages that can be perceived and understood in the given time frame.

Magyar Virtuális Enciklopédia (Hungarian Virtual Encyclopedia; W4) was developed relying on the micro-content approach, supervised by Kristóf Nyíri. Its fifteen hundred entries, of an average length of 1400 characters each, were written by acknowledged experts and they are heavily interlinked. Entries are concise, yet they are efficient in informing the reader about scientific achievements in several fields (e.g. law, environment, EU, learning, health, etc.)

At the Visual Learning Lab (VLL) of Budapest University of Technology and Economics, Kristóf Nyíri and András Benedek supervise the work of research teams that focus their efforts on the modern-time exploitation of visual communication with special regard to everyday teaching processes in higher education. Research also includes micro-content.

Another good example of practical micro-content applications is SysBook, developed by Tibor Vámos and his team. At the moment, SysBook can display 140 content units optimised specifically for small screens. Though these content units essentially form a sequence, there are six interpretation levels associated with each unit (image, text, mathematical demonstration, demonstrations from everyday life, theory, and education). These interpretation levels may be displayed together, facilitating comparison.

I wish to discuss here two earlier experiments of mine related to the use of micro-content in education. The first one is an early, yet fully operational microcontent editing system that was used by the students involved in the experiment 
to generate compacted visual and textual content in fields they were interested in. These were saved on a computer by means of a browser software (maximum width of images: 300 pixels; maximum number of characters for texts: 1024). Students were expected to generate blocks of content that can be interpreted individually while also forming a coherent description of a given topic. The figure below illustrates a few solutions from the several hundred we received:

Figure 1: An early micro-content editing system
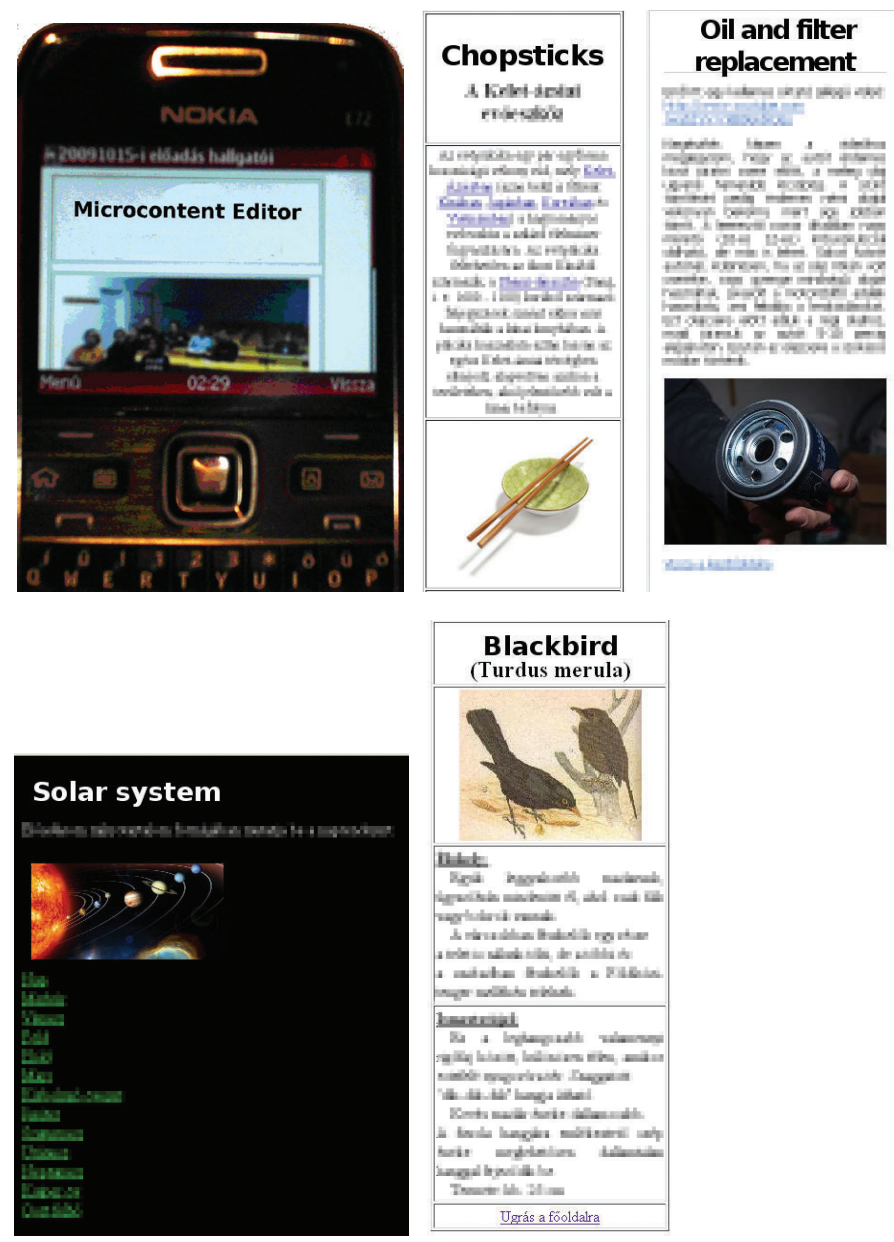

(source: students's projects, Budapest University of Technology and Economics; authors: János Horváth Cz., Ákos Czurkó, no author indicated [W5], Balázs Brosch, Boglárka Szili) 
In our next experiment, we developed a system to display student activity as micro-content, based on colour codes, in the framework of Moodle (a course management system used by the Department of Technical Education):

Figure 2: A micro-content experiment, based on colour codes

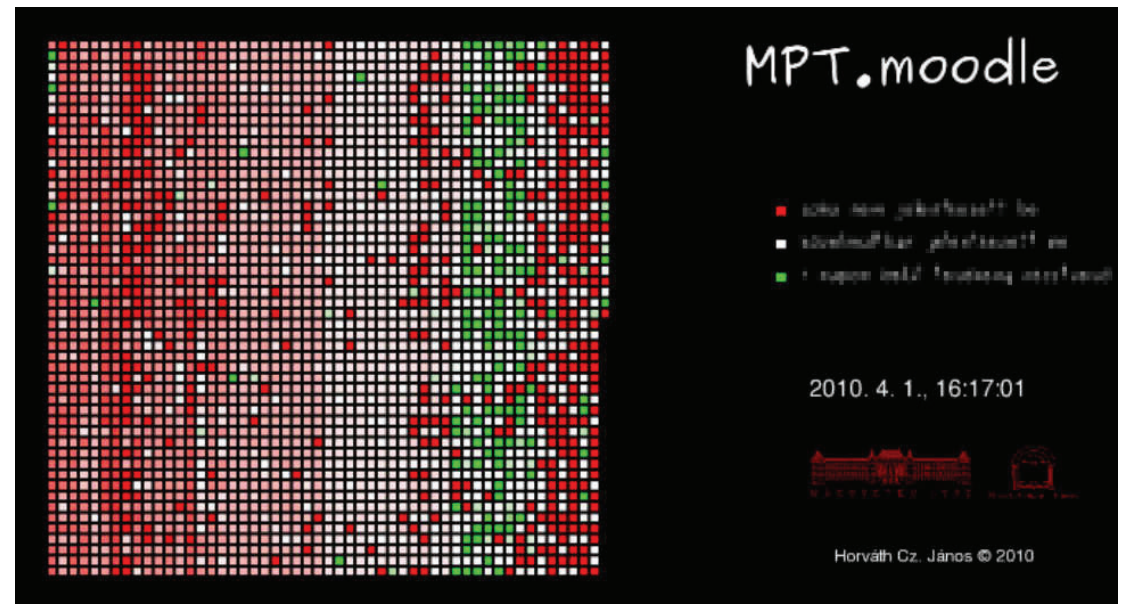

(source: Moodle, Budapest University of Technology and Economics; screenshot taken by the author)

In Figure 2, each square represents a student in the Moodle system. The colour of a square corresponds to the time interval between the "present" as represented by the date of the survey and the last time the student was active in Moodle. Green squares mark currently active users while the colour red means the last time a given user logged in was rather long ago. The hues between these two extremities represent intermediate intervals. In this experiment, we looked for a way to display a relatively large number of states on a limited screen. As the figure illustrates, colour codes represented an ideal solution.

\section{Typical Contemporary Ways of Content Use}

Since these experiments, technical conditions have changed a lot and fast. While users' screen size, computing performance and the speed of data transfer used to be important limiting factors that rendered the compaction of information unavoidable, these limitations are no longer relevant. Currently used mobile devices, while being much smaller than PCs used to be just a few years ago, have much better performance parameters than those. Improved performance has led to changes in user behaviour. 
According to the relevant references (Töröcsik 2013; Carr 2010; Howe-Strauss 2000; Ollé et al. 2013), the group born between 1995 and 2005 (known as Generation Z) is different from older generations in several aspects. One of their distinguishing characteristics is their taking the Internet as a readily available resource. Accordingly, Generation $\mathrm{Z}$ considers connection to the network essential and promptness has become a more or less basic requirement. Generation $\mathrm{Z}$ people prefer being preoccupied with many things; however, they are not able to devote much time to a particular topic. This behaviour, also known as multitasking, presumes the division of attention; however, its efficiency is dubious. These people search for information all the time and become frustrated if this demand of theirs cannot be satiated. Although they continuously hunt for new bits of information, organising these into some mental framework may often represent quite a challenge for them.

In his book, Nicholas Carr (2010) details the way various devices providing access to information can change the mental processes of users, sometimes in a really short time, including changes caused by Internet use. This uniqueness of Generation $\mathrm{Z}$ gives rise to the question whether there is a device that can be used both by them and the older generations.

\section{Micro-content Organised into a System}

In the previous sections we discussed the unique ways Generation $\mathrm{Z}$ approaches the processing of information. At our department, we educate the experts of the future who will have to work with this generation of students as relatively old teachers. Our students, specialised in the teaching of a particular course, experience difficulties when trying to understand young people, so it is a challenge to organise lessons that can grab their attention and facilitate efficient teaching.

We realised that information management based on micro-content is a good way to practice "tuning in to Generation Z". To support this "tuning," we developed the Web 2.0 version of the micro-content editing system, under the name MEdit. MEdit facilitates the generation, limitless storage, thematic organising and sharing of compact content. Our goal was to facilitate easy and prompt use, both when generating and receiving content, reducing the burden related to the application of this information, known as cognitive load. 
Figure 3: Examples of image and text based micro-content in the MEdit system

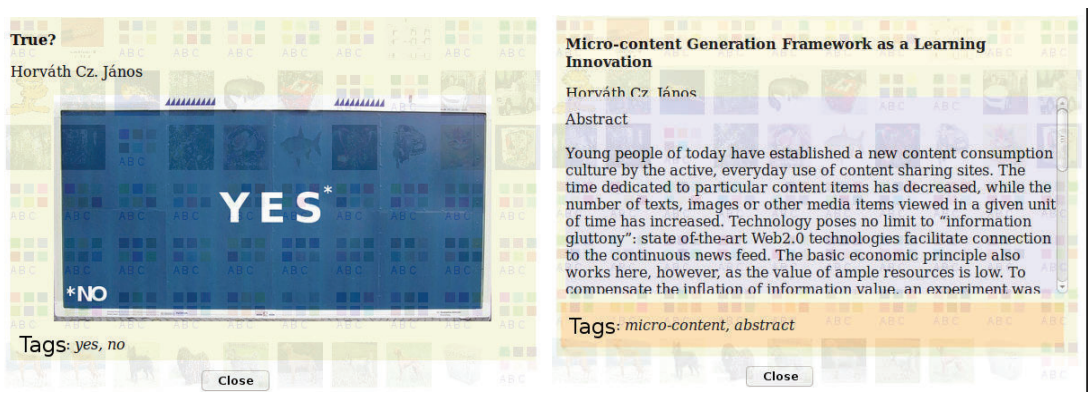

(source: MEdit; screenshots taken by the author)

Figure 3 shows examples of image and text based micro-content units. We should note here that micro-content units always have their own names, information about the author is always maintained and content may also be labelled.

Figure 4: Mass preview of micro-content

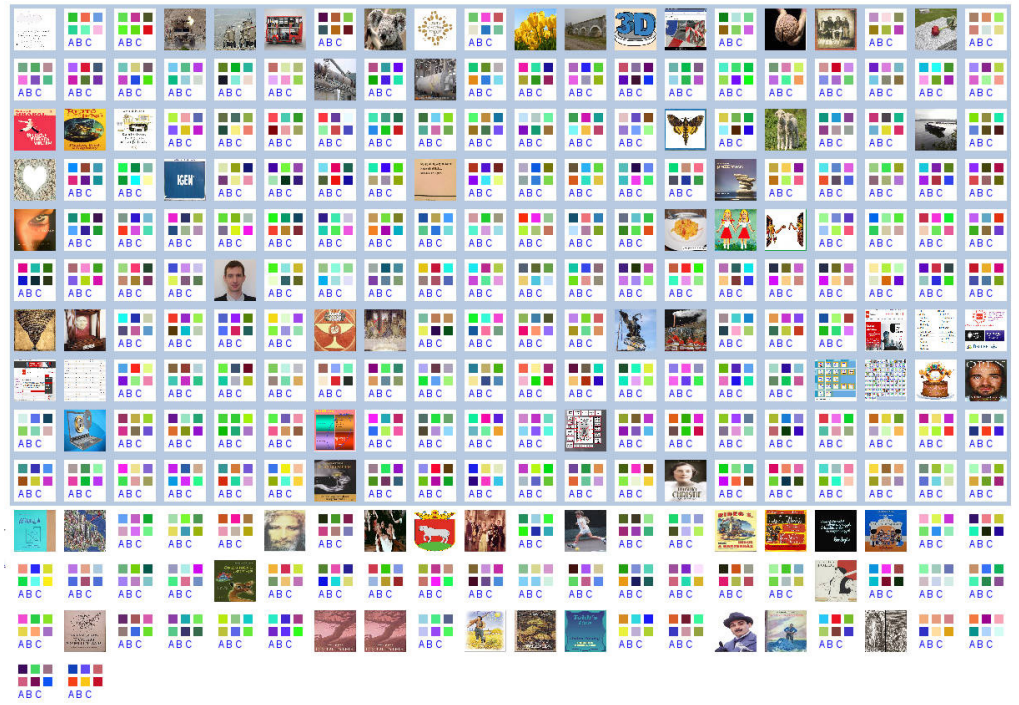

(source: MEdit; screenshot taken by the author)

Figure 4 provides a preview of micro-content uploaded into the MEdit system. When clicking on any given compact unit, its actual content can be viewed. Compact units containing images have a stamp-like preview. In the case of text based 
units, however, the preview gives a colour combination generated by a method developed by ourselves, thus facilitating distinction.

Figure 5: Creating a thematic collection of micro-content

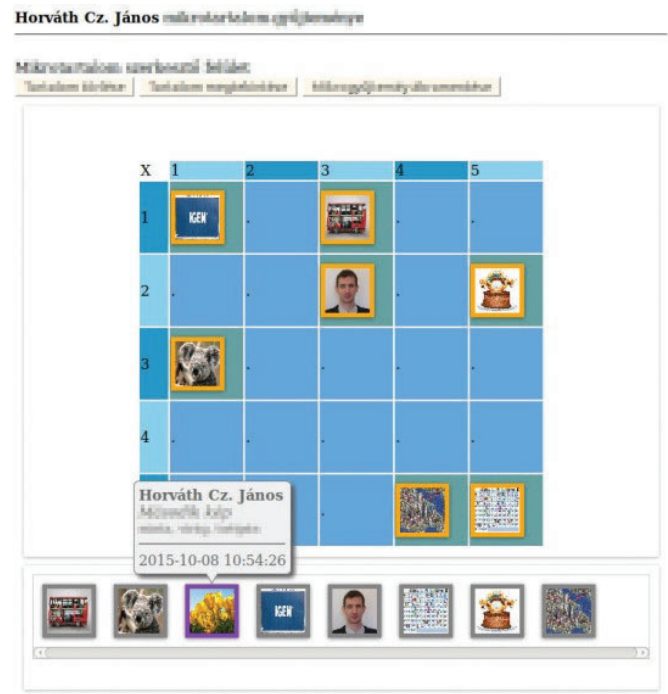

(source: MEdit; screenshot taken by the author)

Micro-content units may be organised into thematic collections as illustrated by Figure 5. In this case, users may organise their own compact units in a table, using its cells. Compact units may be moved between cells or deleted.

Students participating in the trial runs needed some time to get used to the interface and to learn to appreciate the system. Once the first, well edited microcontent units had been uploaded, the majority followed the good example and started to develop their own compact units and then organise these into thematic collections. Most students processed their latest reading experiences, organising the content of rather long books into five to 10 micro-content units, thus enabling others to decide whether a particular book is worth reading or not. Some students prepared collections in their own professional fields, processing content related to topics such as boilers for domestic heating systems or raw materials for manufacturing wood products. Topics related to recreation and hobbies were also represented (e.g. Hungarian dog breeds, fish species for fishing, descriptions of one's home town, etc.). All in all, a very diverse and valuable set of data was generated in the trial period. 


\section{Future Work}

The MEdit system is developed continuously, with new abilities added to it every now and then. An important improvement promoting daily use is supporting the use of units using content other than image or text (audio, video or binary records). Providing opportunities for users to evaluate content is an adaptation of the practice of social evaluation and, as users are free to comment on content, we expect a boost in communication between them.

Once a critical number of users has been reached, the volume of uploaded content is expected to soar. We consider the use of data mining tools an exciting option to form an increasingly accurate picture on the information recorded in the MEdit system and its changes.

The micro-content based processing of certain subjects of courses organised by our department is a novel didactic experiment. Is it possible to compact high volume curricula written according to conventional principles into micro-content units? How can the author cooperate with students in this process? How efficiently can we use micro-content for the courses held for diverse age groups (Generations $\mathrm{X}, \mathrm{Y}, \mathrm{Z})$ ? Further research is needed to answer these questions.

In this paper, essentially micro-content used in an online environment are discussed. However, these principles are viable in other forms as well.

Figure 6: Micro-content in a printed format (posters created by the author)
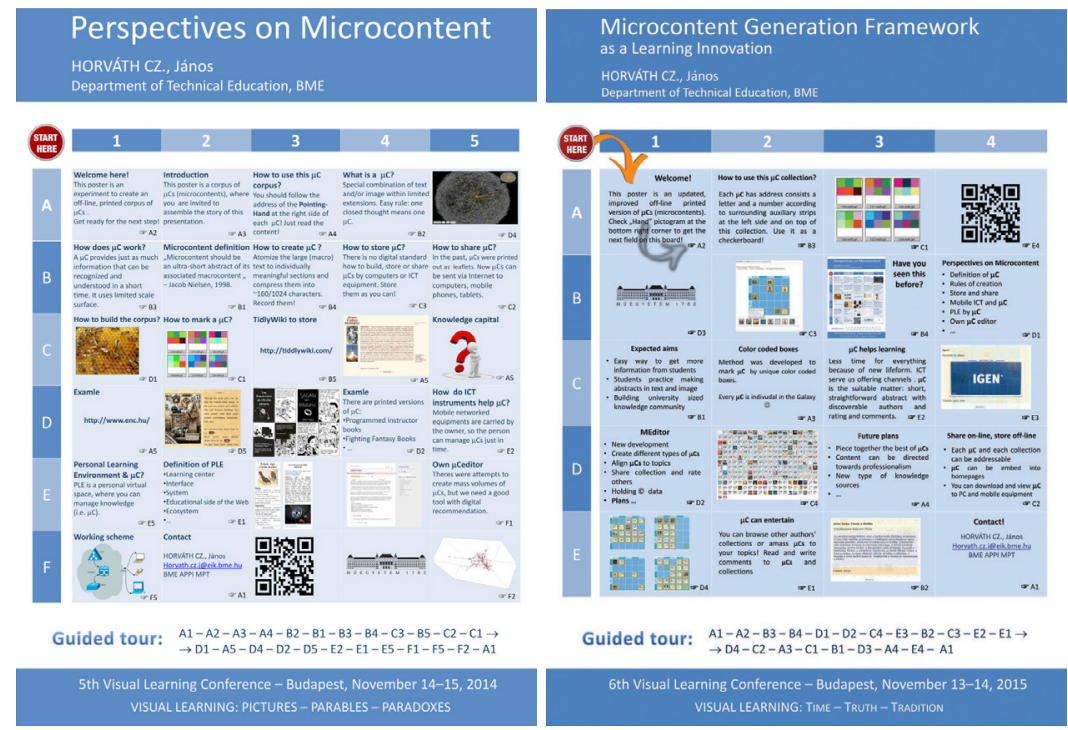

Guided tour: $A 1-A_{2}-B 3-B 4-D 1-D 2-C A-E B-B 2-C 3-E 2-E 1 \rightarrow$

6th Visual Learning Conference - Budapest, November 13-14, 2015 VISUAL LEARNING: TIME - TRUTH - TRADIION 
The last figure shows two printed posters where micro-content are arranged on a coordinated plane, their location being determined by the information on the horizontal and vertical axes. Content in the cells are coherent texts and selfexplanatory images that can be fully interpreted in themselves; however, they can also be processed following a "recommended order" that conveys the exact original message of the author.

This paper wishes to provide an overview about the rapidly developing world of micro-content, focusing on practical applications in education.

\section{References}

Carr, Nicholas G. (2010): The Shallows: What the Internet Is Doing to Our Brains. W. W. Norton \& Company.

Howe, N. - Strauss, W. (2000): Millennials Rising: The Next Great Generation. Knopf Doubleday Publishing Group.

Lindner, Martin - Hug, Theo (2006): Human-centered Design for 'Casual' Information and Learning in Micromedia Environments. Austrian Computer Society (OCG) - Work Group HCI\&UE - 2nd Symposium.

Lindner, Martin (2007): What Is Microlearning? Proceedings of the 3rd International Microlearning 2007 Conference.

Nyíri, Kristóf (2010): Mobilvilág. A kapcsolat és közösség új élményei [Mobile world. New experiences of connection and community]. Budapest: Magyar Telekom.

Ollé, János - Papp-Danka, Adrienn - Lévai, Dóra - Tóth-Mózer, Szilvia - Virányi, Anita (2013): Oktatásinformatikai módszerek. Tanitás és tanulás az információs társadalomban [Methods of teaching informatics. Teaching and learning in information society]. Budapest: ELTE Eötvös Kiadó.

Törőcsik, Mária (2013): Tudománykommunikáció a Z generációnak. A fiatalok fogyasztása, tartalomfogyasztása [Science communication for Generation Z. Content consumption of youth]. http://www.zgeneracio.hu/.

W1 = http://beolog.blog.beol.hu/2009/05/06/miert-pont-160-karakter-egy-sms/ W2 = http://latimesblogs.latimes.com/technology/2009/05/invented-text-mes saging.html.

$\mathrm{W} 3$ = https://blog.twitter.com/2015/removing-the-140-character-limit-fromdirect-messages.

$\mathrm{W} 4=\mathrm{http}: / / \mathrm{www} \cdot \mathrm{enc} \cdot \mathrm{hu} /$.

W5 = http://web.t-online.hu/wxsd47uuhxg4/autoszereles/. 



\section{Notes on Contributors}

ACZÉL, Petra, is a Professor at Corvinus University of Budapest and head of the Institute of Behavioural Science and Communication Theory, as well as member of the Social Communication Doctoral School. She studied at Eötvös Loránd University, Budapest, earned her PhD degree in Linguistics with a thesis titled Winning with Word: Classical and Modern Argumentation Theory in 2003, and gave her habilitation lecture in 2011. Her research interests are focused on the theory and practice of rhetoric. She is author and co-author of four books and numerous essays on verbal and visual argumentation, persuasive communication and (new) media communication. Her recent publications include contributions to the debate on "new rhetoric" and new media rhetoric, among them her paper "Enchanting Bewilderment: Concerns for Visual Rhetoric" (in András Benedek and Kristóf Nyíri eds. 2011: Images in Language: Metaphors and Metamorphoses. Series VISUAL LeArning, vol. 1, Frankfurt/M.: Peter Lang), "Mediarhetoric: Complex Visual Literacy" (in András Benedek and Kristóf Nyíri eds. 2012: The Iconic Turn in Education. Series Visual Learning, vol. 2, Frankfurt/M.: Peter Lang); "Visionary Rhetoric: Teaching Imagistic Communication" (in András Benedek and Kristóf Nyíri eds. 2013: How to Do Things with Pictures: Skill, Practice, Performance. Series Visual Learning, vol. 3, Frankfurt/M.: Peter Lang); “Expressivity and Emotion in Visionary Rhetoric" (in András Benedek and Kristóf Nyíri eds. 2014: The Power of the Image: Emotion, Expression, Explanation. Series Visual LEARNING, vol. 4, Frankfurt/M.: Peter Lang), and "Ingenious Rhetoric: The Visual Secret of Rhetoricality” (in András Benedek and Kristóf Nyíri eds. 2015: Beyond Words: Pictures, Parable, Paradoxes. Series Visual Learning, vol. 5, Frankfurt/M.: Peter Lang). She is chairing and holding memberships in Hungarian and international communication associations and boards.E-mail: petra.aczel@uni-corvinus.hu.

BARNEY, Tiмотнy, born 1980, is Assistant Professor of Rhetoric \& Communication Studies at the University of Richmond. He is a specialist in visual rhetoric and has written criticism about political cartography, the Cold War, and post-communist Europe for journals such as Rhetoric \& Public Affairs, Quarterly Journal of Speech, Popular Communication, Communication \& Critical/Cultural Studies, and The Journal of International \& Intercultural Communication. His book Mapping the Cold War: Cartography and the Framing of America's International Power was published by the University of North Carolina Press in 2015. E-mail: tbarney@richmond.edu. 
BENEDEK, ANDRÁs, Professor, Department of Technical Education, Budapest University of Technology and Economics, has published some 150 papers to date in connection with human resource development issues, among them the essays "New Vistas of Learning in the Mobile Age" (in Kristóf Nyíri ed. 2006: Mobile Understanding: The Epistemology of Ubiquitous Communication. Vienna: Passagen Verlag), "Mobile Learning: New Horizons and Unstable Summits" (in Kristóf Nyíri ed. 2009: Engagement and Exposure: Mobile Communication and the Ethics of Social Networking. Vienna: Passagen Verlag), and "Visual Education: Old and New Dilemmas" (in András Benedek and Kristóf Nyíri eds. 2014: The Power of the Image: Emotion, Expression, Explanation. Series Visual LeArning, vol. 4, Frankfurt/M.: Peter Lang). From 1976 to 1979 he studied systems analysis on a scholarship and acquired a Ph.D. at the Academy of Sciences in Moscow. During the 1980s, he was a scientific advisor to the Hungarian Academy of Sciences. He was the Director of Vocational Training (from 1984 to 1989), then Director General (from 1989 to 1990) at the National Pedagogical Institute. As its first Director General in 1990, he established the National Institute for Vocational Education. He was involved in numerous UNESCO and ILO projects and continues to participate in the preparation of various World Bank and Phare projects in the area of human resource development. Further information: www.benedekandras.hu.

CARREÑO, JAVIER, born 1979 (Colombia), is an assistant professor of philosophy at Franciscan University of Steubenville in Gaming, Austria, where he teaches courses in the history of philosophy, aesthetics, and the philosophy of literature. He received his undergraduate degree in philosophy and literature from the University of Dallas, and his M.A. and Ph.D. in philosophy from the Katholieke Universiteit Leuven. His area of research is 19th and 20th Century Continental Philosophy, in particular the thought of Edmund Husserl. He has published articles at the crossroads of Husserlian phenomenology and aesthetics in Husserl Studies, The New Yearbook for Phenomenology and Phenomenological Philosophy, The Yearbook on the History and Interpretation of Phenomenology, Acta Latinoamericana de Fenomenología, and Humanities Across The Borders: More Interdisciplinary Issues. E-mail: jcarreno@franciscan.edu.

CRIPPEN, MATTHEW primarily researches intersections between American philosophy, phenomenology and art, with an eye to contributing to cognitive science. His publications discuss aesthetics andmind, and also media, politics, Wittgenstein, Frankfurt School, Dewey, James, Thoreau, Nietzsche, history of science, religious faith, freewill, Greek philosophy and more. While diverse, his 
work unites around "ecological" approaches that place objects of investigation in world-contexts. Matthew has been pleased to teach an international population of students first at York University in Toronto, and now at the American University in Cairo, where he is an assistant professor. Outside of the academy, he has worked as a musician, mandolin and guitar teacher and gymnastics coach.

ENDRÖDY-NAGY, Orsolya, born 1977, is an Associate Professor of Education at the Department of Psychology and Pedagogy, Eötvös Loránd University of Budapest, Faculty of Primary and Preschool Education. 2005-2008 she was editor-in chief of pedagogic periodicals. She has just obtained her PhD in 2015 in the field of education. During her studies, she won the Hungarian State Scholarship, Hungarian Initiatives Fund, Washington DC and Doctoral Scholarships of ELTE, her research was made at Lyon, INRP and Bologna, Archiginnasio. Her main research fields are history of childhood, iconography and multiculturalism. Some main publications: Children in Europe 1455-1517 (Education, Psychology \& Humanities International Conference, Silver Spring, Washington DC, 2014); "Media in the Middle Ages and sources of the History of Childhood" (in Andrea Kárpáti and Emil Gaul eds. 2011: Art - Space - Education. Proceedings of the 33. INSEA World Congress, Budapest: HATA).E-mail: endrodyorsolya@gmail.com.

GIARDINO, VALERIA is researcher at the Centre National de la Recherche Scientifique (CNRS), affiliated to the Laboratoire d'Histoire des Sciences et de Philosophie - Archives Henri-Poincaré in Nancy (France). Her research interests concern the role of diagrams and images in our system of knowledge, in particular the use of diagrams and figures in the practice of mathematics and the sciences; the cognitive basis of mathematical knowledge, in relation to the studies in cognitive science; more in general, the connection between the representation of information and problem solving. Recently, she has been working also on the role of gestures in problem solving. Some main publications: "An Inquiry into the Practice of Proving in Low-Dimensional Topology". Boston Studies in the Philosophy and History of Science 308: 315-336, 2015 (with Silvia De Toffoli); "Forms and Roles of Diagrams in Knot Theory". Erkenntnis 79/4: 829-842, 2014 (with Silvia De Toffoli); "Diagramming: Connecting Cognitive Systems to Improve Reasoning" (in András Benedek and Kristóf Nyíri eds. 2014: The Power of the Image: Emotion, Expression, Explanation. Series Visual Learning, vol. 4, Frankfurt/M.: Peter Lang). Further information: http://poincare.univ-lorraine.fr/fr/membre-titulaire/ valeria-giardino. E-mail: valeria.giardino@univ-lorraine.fr. 
GOLDEN, DANIEL L. (1974) is a research fellow in the Institute of Philosophy at the Research Centre for the Humanities of the Hungarian Academy of Sciences. His main fields of interest are media philosophy, pragmatism and the philosophy of science. His publications include several papers in English and in Hungarian on different aspects of the digital turn in the history of culture; most recently "Face to Face: Towards a New Sincerity" (in András Benedek and Kristóf Nyíri eds. 2014: The Power of the Image: Emotion, Expression, Explanation. Series VISUAL LEARning, vol. 4, Frankfurt/M.: Peter Lang).

GOODNOW, Trischa, is a Professor of Speech Communication at Oregon State University. She received her Ph.D. from the University of Pittsburgh where she focused on Visual Rhetoric. Her primary research area continues to be visual rhetoric. She has published essays in Visual Communication Quarterly, American Behavioral Scientist and various book chapters. She has also published the books Parliamentary Debate: A Guide to Public Argument, The Daily Show and Rhetoric: Arguments, Issues, and Strategies, and the forthcoming co-edited book The Ten Cent War: Comic Books, Propaganda and World War II with the University Press of Mississippi. She has previously published two essays in the Visual Learning Series.

HAVASMEZÖI, Gergely, born 1983, is a PhD student at Eötvös Loránd University (Budapest) at the PhD Program at the Doctoral School of Linguistics. He works also as an online journalist and editor. His research topic is the online media. His publications include "A Vörös Ujság. Egy kommunista lap a Népköztársaságban és a Tanácsköztársaságban, 1918-1919” [The Vörös Ujság. A communist paper in the Hungarian People's Republic and the Hungarian Soviet Republic 1918-1919.]. Filológia.hu 2009/1. E-mail: havasmezoi@gmail.com.

HORVÁTH, JÁnos Cz., born 1975, is assistant lecturer at the Department of Technical Education of the Budapest University of Technology and Economics. He has MSc degrees as Electrical Engineer (2000), Certified Engineer-teacher (2002), Economic-Engineer (2009). His research interests are focused on the role of knowledge networks and student networks in education; educational technology; the handling of the knowledge assets from the pedagogical point of view. E-mail: horvath.cz.j@eik.bme.hu.

KATZ, James E., Ph.D., is the Feld Family Professor of Emerging Media at Boston University's College of Communication where he directs its Center for Mobile Communication Studies and Division of Emerging Media. His research on the internet, social media and mobile communication has been internationally 
recognized, and he is frequently invited to address high-level industry, governmental and academic groups on his findings. His latest book is Philosophy of Emerging Media: Understanding, Appreciation, Application, edited with Juliet Floyd (Oxford University Press), includes contributions from Kristóf Nyíri and Zsuzsanna Kondor. He is also the co-author of The Social Media President: Barack Obama and the Politics of Citizen Engagement, published in 2013 by Palgrave Macmillan. Prior to his Boston University appointment, he was the Governors Distinguished Professor of Communication at Rutgers University (the title being the highest honor that Rutgers can bestow on one of its faculty) and served two terms as chair of its Department of Communication. Preceding his tenure at Rutgers, Katz was a Distinguished Member of Staff and director of the social science research unit at Bell Communications Research (Bellcore). Earlier, Katz taught at other universities, including the University of Texas, Austin, where he was elected chair of the Austin World Affairs Council. His many other books include Magic in the Air: Mobile Communication and the Transformation of Social Life, Social Consequences of Internet Use: Access, Involvement, Expression (with Ronald E. Rice) and Handbook of Mobile Communication Studies. Author of more than 100 scientific articles and papers, his publications have been translated into seven languages.

KRÄMER, Sybille is Full Professor for Philosophy at the Free University in Berlin. 2000-2006 member of the German 'Scientific Council'; 2005-2008 'Permanent Fellow' at the 'Wissenschaftskolleg' (Centre for advanced study), Berlin; 2007-2013 Member of the European Research Council; 2008-2014 chair of the Research Training Group 'Notational Iconicity. On materiality, visibility and usability of writing'; since 2010 member of the 'Senat' of the Deutsche Forschungsgemeinschaft. Guest professorships in Zurich, Lucerne, Graz Vienna and Tokyo. Fellowships: International Research Institute, (IFK Vienna), Institute for Cultural Techniques and Mediaphilosophy, (IKKM Weimar), Media Cultures for Computersimulation (Mecs Lueneburg).

NYÍRI, KRISTóF, born 1944, is Member of the Hungarian Academy of Sciences. He was Leibniz Professor of the University of Leipzig for the winter term 2006/07. His main fields of research are the history of philosophy in the 19th and 20th centuries, the impact of communication technologies on the organization of ideas and on society, the philosophy of images, and the philosophy of time. Some main publications: Tradition and Individuality (Dordrecht: Kluwer, 1992); "Electronic Networking and the Unity of Knowledge" (in Stephanie Kenna and Seamus Ross eds. 1995: Networking in the Humanities, London: Bowker-Saur); "The Picture Theory of Reason" (in Berit Brogaard and Barry Smith eds. 2001: Rationality 
and Irrationality, Wien: öbv-hpt); Vernetztes Wissen: Philosophie im Zeitalter des Internets (Vienna: Passagen Verlag, 2004); Zeit und Bild: Philosophische Studien zur Wirklichkeit des Werdens (Bielefeld: transcript, 2012); Meaning and Motoricity: Essays on Image and Time (Frankfurt/M.: Peter Lang, 2014). Further information: www.hunfi.hu/nyiri.E-mail: knyiri@t-email.hu.

SZABÓ, Krisztina, $\mathrm{PhD}$, is an assistant lecturer at the Department of Philosophy and History of Science, Budapest University of Technology and Economics where she teaches Argumentation, Negotiation and Persuasion Techniques. She graduated from the same university in 2013 as a Communication and Media Studies Expert specialized in Communication Design and Cultural Industries in the framework of MA in Communication and Media Studies Program. Research fields: Digital Literacy, Reading Process, PISA surveys, Hermeneutics, Literary Theory. E-mail: kriszti.szabo@filozofia.bme.hu.

VESZELSZKI, ÁGNES, PhD, born 1982, is a Senior Assistant in Hungarian linguistics (Corvinus University of Budapest), editor of the online periodical Filológia.hu (Hungarian Academy of Sciences). Research fields: impact of infocommunication technology on the Hungarian language (digilect), modern philology, grammar of spoken language, interdisciplinary connections between marketing and linguistics. Her publications include: "Image and Self-representation" (series VISUAL Learning, vol. 1, 2011); "Connection of Image and Text in Digital and Handwritten Documents" (series Visual Learning, vol. 2, 2012); "Promiscuity of Images: Memes from an English-Hungarian Contrastive Perspective" (series VISUAL LEARNING, vol. 3, 2013); "Information Visualization: Infographics from a Linguistic Point of View" (series Visual Learning, vol. 4, 2014); most recently: "Emoticons vs. Reaction-Gifs. Non-Verbal Communication on the Internet from the Aspects of Visuality, Verbality and Time" (in András Benedek and Kristóf Nyíri eds. 2015: Beyond Words. Pictures, Parables, Paradoxes. Series Visual Learning, vol. 5, Frankfurt/M.: Peter Lang). Homepage: www.veszelszki.hu. E-mail: veszelszki. agnes@gmail.com. 


\section{Index}

A

Aczél, Petra 9, 69, 181

aesthetic experience $12,63,153$, 154,155

algebra $9,45,46$

Aristotle 12, 53, 72, 73, 78, 80, 81, 126, $153,154,155,156,158$

Arnheim, Rudolf 8, 18, 19, 23, 24, 25

artificial images 24

Atlas of Disease 86, 87

authority $33,34,39$

B

Barney, Timothy $10,83,181$

Benedek, András 7, 12, 13, 26, 49, 121, $161,163,169,170,172,181,182$, $183,184,186$

big data 142

bodily experience 45

C

caption 125,127

Carreño, Javier 9, 59, 65, 182

childhood 10, 91, 92, 93, 95, 97, 98, 99,183

chronos 59

cognitive artefact $9,41,42,43,46,48$

Cold War 10, 83, 84, 85, 86, 87, 88, 89, 181 comics 106, 107, 161, 162, 166, 167 common-sense realism $8,17,19,21$, 22,25

contemporary culture $11,123,128$

Crippen, Matthew 12, 153, 154,

158,182

curriculum development 163, 164
D

Darwin, Charles 18, 25

Derrida, Jacques 8, 31, 32, 33,38

De Toffoli, Silvia 47, 48, 49, 183

Devitt, Michael 22, 25, 26

Dewey, John 12, 153, 154, 155, 156, $157,158,159,182$

diagram $9,19,41,43,45,46,47,48$, 49,183

diagramming $8,42,43,44,45,46,48$, 49,183

digital communication 10,139

digital literacy 103, 111, 186

discursive truth $8,29,30,31$

documentary film $8,29,34$, 35,37

E

education $12,45,48,55,91,92,93,94$, $95,98,106,121,161,162,163,164$, $166,167,168,169,170,171,172$, $179,182,183,184$

eidos $153,154,159$

embodiment $8,43,44,45,48,49,50$, 158

Endrödy-Nagy, Orsolya 10, 91, 183

existential truth $8,29,32,33$

experiential knowledge 168

F

Facebook 114, 116, 139

facial expressions 18, 19, 132

Ferguson, Eugene S. 161, 170

fiction, fictional 22, 30, 31, 34, 35, 64, 65 
G

Galileo 20,155

gestures $9,18,19,41,44,45,48,51$, 96, 183

Giardino, Valeria 8, 9, 41, 42, 43, 46, $47,48,49,183$

Golden, Daniel L. 9, 51, 184

Gombrich, Ernst H. 8, 24, 26, 98

Goodnow, Trischa 11, 123, 124, 129,184

Greek philosophy 153, 182

Gulag 10, 83, 85, 86, 87, 89

H

hashtag $10,11,139,140,141,142,143$, $144,145,146,147,148,149,150$

Havasmezői, Gergely 10, 113, 184 higher education. cf. education Horváth, János Cz. 12, 171, 184 human mind $8,9,17,19,43,51$ Husserl, Edmund 9, 59, 60, 61, 62, 63, $64,65,66,182$ hypertext $104,107,110,167$

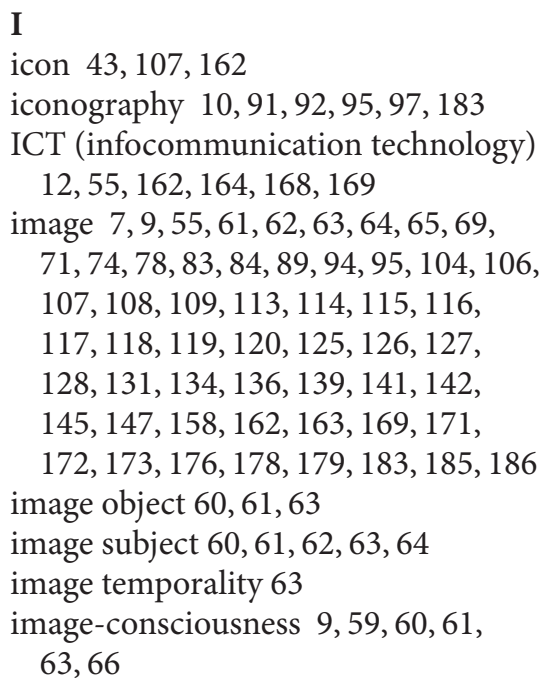

imagery $19,69,74,75,76,77,78,80$ imaginability 22 imagination $18,47,48,65,70,74,75$, $85,108,157$

Instagram $11,131,139,140,142,143$, $144,145,146,148,149,150$

J

Johnson, Mark 45, 49

journalism 87, 113, 120

K

kairos 59, 63, 65

Katz, James E. 11, 131, 133, 134, 136, 184

Kierkegaard, Søren 8, 32, 33, 34, 39

knowledge $8,12,13,25,31,32,33,34$, $35,39,41,44,70,72,73,76,93,106$, $154,155,156,157,158,163,165$, $166,168,169,171,183,184,185$

Krämer, Sybille 8, 29, 32, 35, 39, 41, $42,43,49,185$

Kusch, Martin 20, 21, 26, 39

L

Lakoff, George P. 45, 49

learning by doing 158

learning innovation 12,171

Leibniz, Gottfried Wilhelm 30, 39

M

manipulative imagination 47,48

Manovich, Lev 11, 55, 131, 137, 142, 149

map $10,41,83,84,85,86,87,88$, 89,114

marketing 140, 186

mathematics $9,41,42,44,45,46,47$, $49,50,161,165,183$

mechanical time 9,51

MEdit 175, 176, 178

meme $116,147,186$ 
memory $8,12,18,31,41,42,70,74$, $75,77,80,169$

mental image 17,24

metadata $11,139,142,149$

metaphor $19,45,54,71,75,76,77$, 80,81

micro-content $12,166,168,171,172$, $173,174,175,176,177,178,179$

moderate embodiment 43

Mona Lisa 61, 62, 94

N

narrative $11,12,55,93,123,124,125$,

$126,127,128,129,153,154,155,157$ new media $103,111,113,150,181$

news portals 113,119

nonverbal communication 139

Nyíri, Kristóf 7, 8, 13, 17, 22, 24, 26, $49,51,56,94,98,113,120,121,136$, $163,169,170,171,172,179,181$, $182,183,185,186$

O

online media $10,115,120,184$

online reading $10,103,104,106,107$, $108,109,110$

online text 103, 106, 107, 108, 109,110

operative iconicity $41,42,43$

organic time 51

$\mathbf{P}$

painting $10,24,59,73,91,93,94,95$, $96,97,154,155,158$

paramap $10,84,85$

Peirce, Charles Sanders 43, 50

perception $8,19,21,23,24,31,32,34$, $42,43,44,45,60,61,76,86,87,88$

persuasion $9,69,70,71,72,73,74,75$,

$76,77,78,80,81,181,186$

phantasy $9,59,60,61,62,63,64$, 65,66 phenomenology 59,60, 182

photograph $11,24,35,59,84,113$, $119,120,124,125,127,131,135$, $139,141,142,144,145,146,147$, $148,163,164$

picture $11,18,24,25,55,70,75,77$,

$91,93,94,95,96,97,104,106,107$,

$108,109,116,124,125,127,128$,

$131,140,141,143,144,145,146$,

$147,148,154,161,164,167,172,178$

Plato $12,18,153,154,155,156$

presentist culture 129

private time 9,52

propositional truth 30

public time 9,52

$\mathbf{R}$

reading literacy $103,104,106,110$

realism $8,19,21,22,23,24$

relativism $8,17,19,20,21,24,25,26$

Renaissance 10,74, 91, 92, 95, 97, 99

representation $11,24,35,38,43,44$, $47,48,56,60,64,84,87,89,93,94$,

$97,132,165,166$

resolution 55

rhetoric $7,9,10,11,59,69,70,71,72$, $73,74,75,76,77,78,79,80,81,83$, $89,123,126,181,184$

rhetorical force 70

rhetorical life $10,84,86,87$

right timing 9, 59, 60, 63, 65

S

science $9,12,21,22,44,69,71,153$,

$155,156,158,165$

segmentation 55

selfie $10,11,123,124,125,126,127$,

$128,129,131,132,133,134,135$,

$136,140,147,148$

Selfie City 125,128

self-presentation 141

Sellars, Wilfrid 18, 22, 26, 27 
smart phone 124, 135

Snapchat 12,172

software $12,161,171,173$

Soviet Union $83,84,85,86$

speech $32,34,35,45,70,71,73,75,76$, $77,78,80,123$

spontaneity 11,133

staging $11,38,133$

surprise 73

symbols $46,47,85,132$

SysBook 12, 161, 165, 166, 167, 172

Szabó, Krisztina 10, 103, 106, 107, 108, 111, 186

\section{$\mathrm{T}$}

Taylor, Frederick W. 9, 52, 57

tekhnē 12, 155, 156

temporality $59,60,61,62,63,65$

testimony $8,29,31,32,33,34,35,36$,

$37,38,39$

text $10,11,75,80,83,89,103,104$, $106,107,108,109,110,113,116$, $117,118,119,120,121,134,139$, $140,141,142,143,144,145,146$, $148,162,170,171,172,176,178,179$

textuality 103,108

thauma, thaumazein $9,71,72,73,78$

theōria 12,155

Thomas Crocker, Elizabeth 11, 131, 133,136

time $7,9,11,22,45,51,52,53,54,55$,

$56,59,60,61,62,63,65,106,107,123$,

$124,125,126,129,139,142,143,185$

time economy 52

time management 52, 53, 54, 55, 56

time-consciousness 9, 59, 62, 63

tools for thought $41,42,43$ topology $9,46,47,48,49,183$

tradition $7,11,13,49,71,78,113,119$, $139,142,143,144,161,162,164,167$ truth $7,8,11,20,22,26,29,30,31,32$, $33,34,35,36,39,72,85,139,142$, 143,147

U

United States 85,86

V

Veszelszki, Ágnes 7, 11, 13, 113, 116, $120,121,139,140,150,186$

visionary $9,69,70,71,76,77,78$, 80,181

visual communication $132,136,161$, 162,172

visual content $141,161,164,166,169$ visual conversation 123

Visual Learning Lab 7, 13, 172

visual memories 17

visual rhetoric $7,69,126,181,184$

visual translation 51

visual turn 136

visuality $7,8,9,10,12,15,69,86,103$,

104, 106, 107, 108, 110, 118, 169, 186 visualization $22,54,55,86,121$,

170,186

W

Web 2.0 142, 171, 175

Weber, Max 51, 76, 81

witness $8,29,30,31,32,33,34,35,36$, $37,38,39$

witnessing $8,31,32,33,34,35,36$, 37,39

word/image dichotomy 42,47 